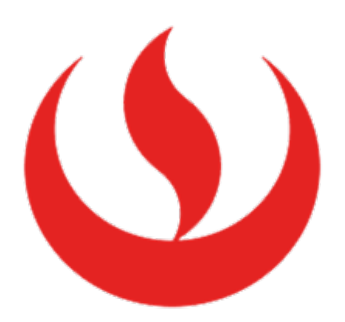

UNIVERSIDAD PERUANA DE CIENCIAS APLICADAS

FACULTAD DE NEGOCIOS

CARRERA DE MARKETING

\title{
SERVICIO DE DELIVERY DE COMIDA CASERA Y SALUDABLE CON EL SABOR DE CASA
}

\author{
"LA TOMATE" \\ TRABAJO DE INVESTIGACIÓN \\ PARA OBTENER EL GRADO DE BACHILLER EN: MARKETING
}

\begin{abstract}
AUTOR(ES)
ANGULO CARDENAS-GARCIA, SAMUEL ARTURO Y LEONARDO

0000-0003-0077-2767

PEÑA MANRIQUE, JAQUELINE SILVANA

0000-0002-8502-8808

RIVERA MUÑANTE, STEWART JOEL

0000-0002-2314-1872

ROJAS TACUCHI, MINELLY ELIZABETH

0000-0002-0468-5874

ASESOR(ES)

SOLIS PELLANNE, PEDRO MARTIN

0000-0003-3272-337X

DANERI ROMERO, MIGUEL ANGEL

0000-0001-8202-4783
\end{abstract}


Agradecemos todo el apoyo, predisposición y tiempo de nuestros profesores, Pedro Solis y Miguel Daneri, quienes fueron de vital importancia y ayuda en el desarrollo de nuestro trabajo de investigación, a la Universidad Peruana de Ciencias Aplicadas UPC por apoyarnos y tener siempre a nuestra disposición todo el material necesarios y sus instalaciones para nuestro desarrollo profesional e intelectual, a nuestros amigos y a nuestras familias por el soporte durante todo este tiempo, a todos ustedes, Gracias. 


\section{RESUMEN EJECUTIVO}

En el presente planteamiento de negocio, presentamos a "LA TOMATE". El servicio que ofrecemos consiste en llevar a nuestros clientes una comida casera y saludable con la receta de mamá, en el horario que el cliente lo solicite.

El cliente elegido segmento son personas con estilo de vida hogareño, que disfrutan de la comida preparada en casa, con la receta familiar y con insumos de calidad. Los mismos que trabajen y demanden de este servicio en la comodidad de su centro de trabajo y en el horario que ellos tienen programado para almorzar.

Para esta primera etapa, nos hemos enfocado en personas que trabajan en el distrito de San Isidro y que tienen una edad promedio entre 25 a 50 años.

Nuestro objetivo es ofrecerles:

- Un Menú de tipo casero y saludable.

- En el horario que ellos soliciten.

- A un precio competitivo.

- Con una presentación diferenciada.

Actualmente, existen restaurantes que ofrecen un menú, pero el problema principal es que al cocinar en cantidad muchas veces pierden características propias de la comida elaborada en casa tales como la sazón, niveles bajos de grasa, utilización de insumos de calidad, etc.

Aprovecharemos la tecnología, utilizando redes sociales, publicidad en centros de trabajo para hacernos conocidos y recibiremos los pedidos por vía telefónica (fijos o celulares), WhatsApp, mensajes de texto, etc.

El servicio de entrega se realizará vía delivery, el cual se efectuará posicionándonos en un lugar estratégico donde nuestros repartidores puedan tener un punto base de recojo de los almuerzos.

Palabras Clave: Sabor de Casa, Delivery, Reparto a domicilio, Comida sana, Alimentación diaria, La Tomate. 


\section{ABSTRACT}

In the present business proposal, we present "LA TOMATE". The service we offer consists of bringing our customers a homemade and healthy meal with the mum's recipe, at the time the client requests it.

The client chosen as a segment, are people with a homely lifestyle, who enjoy home-prepared food, with a family recipe and high quality ingredients.

The ones who work and demand this service in the comfort of their workplace and the schedule they have organised for lunch.

For this first stage, we have focused on people who work in the district of San Isidro and who have an average age between 25 to 50 years.

- Our objective is to offer them:

- A homemade and healthy menu.

- At the time they request.

- At a competitive price.

- With a differentiated presentation.

Nowadays, there are restaurants that offer a menu, but the main problem is that when cooking in quantity, they often lose the characteristics of homemade food such as seasoning, low levels of fat, use of good quality supplies, etc.

We will take advantage of technology, using social networks, advertising in work centers to make ourselves known and we will receive orders by the phone (fixed or mobile), WhatsApp, text message, etc.

The service will be done via delivery, which will be done by positioning ourselves in a strategic place where our distributors can have a base point for picking up lunches.

Keywords: Home Taste, Delivery, Healthy Food, Daily Food, Tomato. 


\section{TABLA DE CONTENIDO}

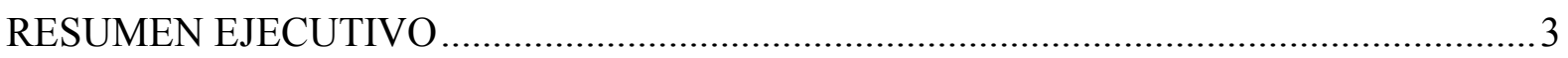

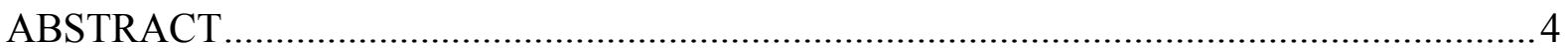

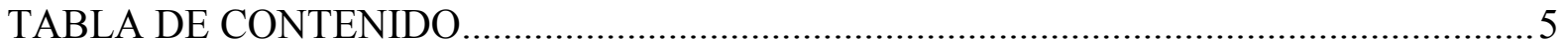

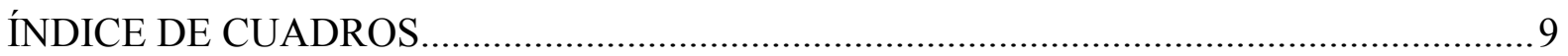

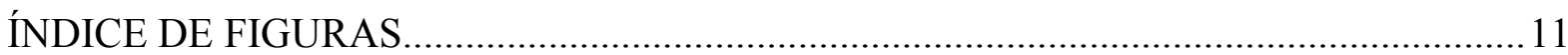

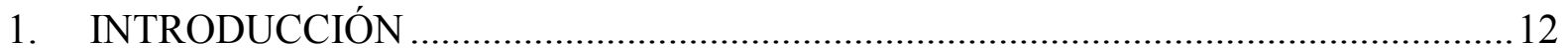

2. ASPECTOS GENERALES DEL NEGOCIO ............................................................. 13

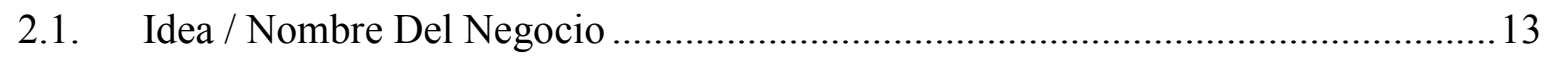

2.2. Descripción del producto/servicio a ofrecer ...................................................... 14

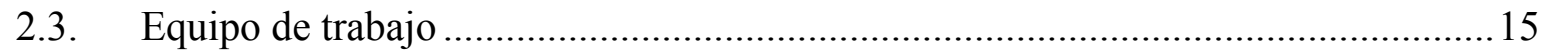

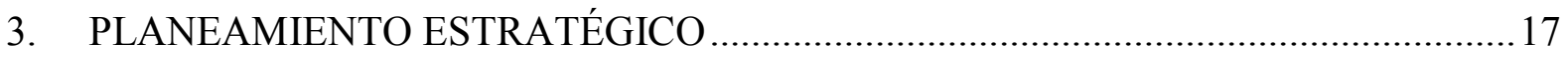

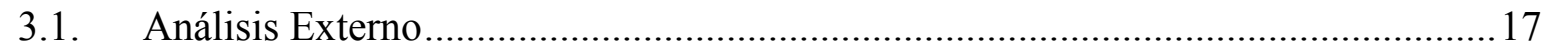

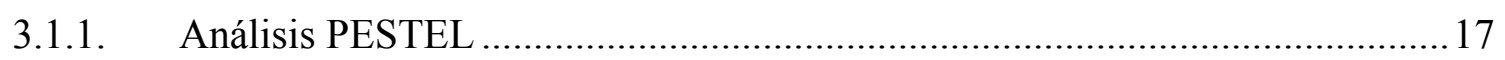

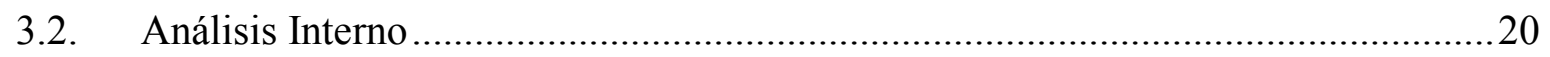

3.2.1. Business Model Canvas: desarrollo de los nueve bloques..............................20

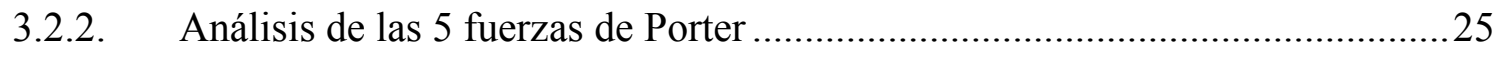

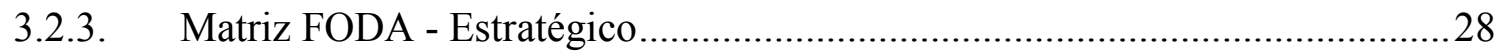

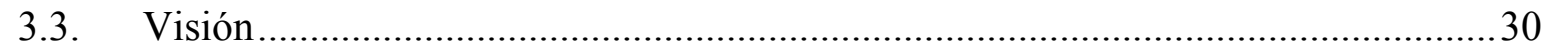

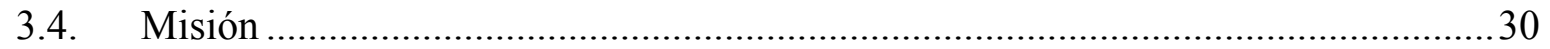

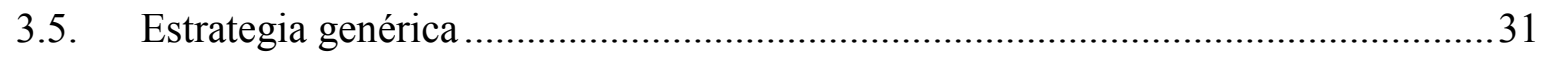

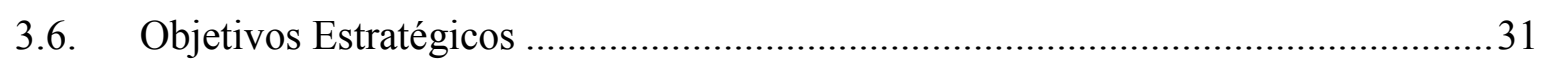

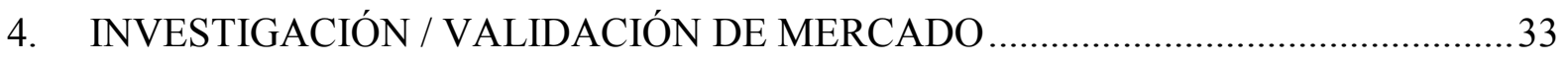

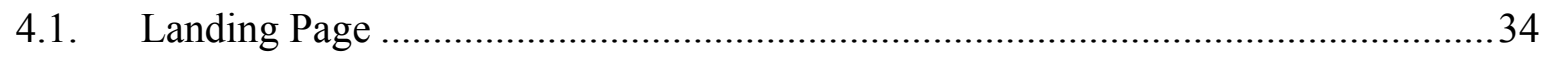

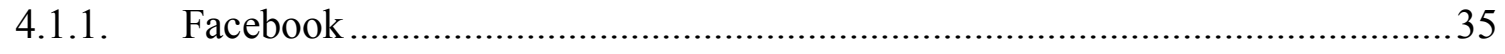

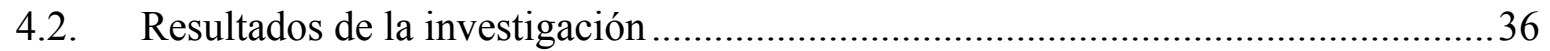

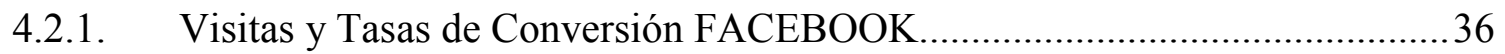

4.2.2. Métricas de la LANDING PAGE ................................................................... 37

4.2.3. Resultado de la decisión y del aprendizaje de las entrevistas ..........................38

4.3. Informe final: elaboración de tendencias, patrones y conclusiones......................... 41

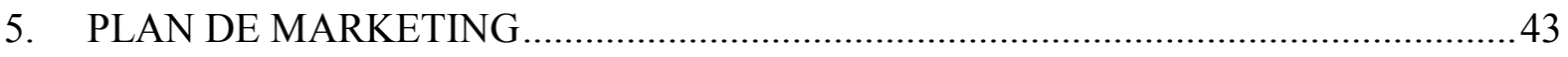


5.1. Planteamiento de Objetivos de Marketing.... .43

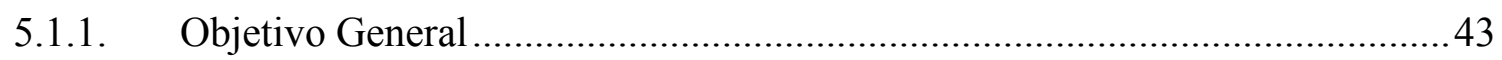

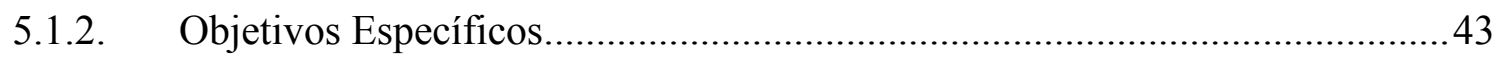

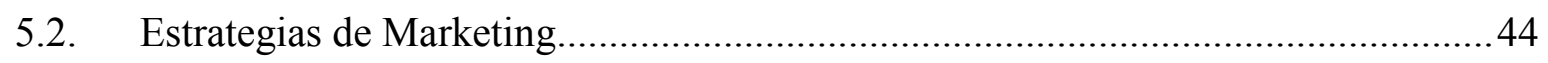

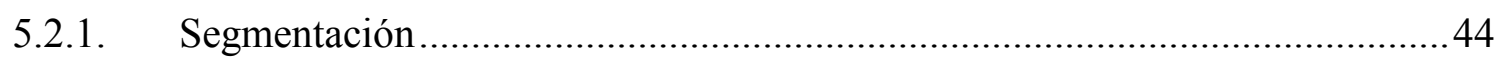

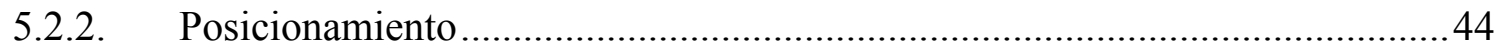

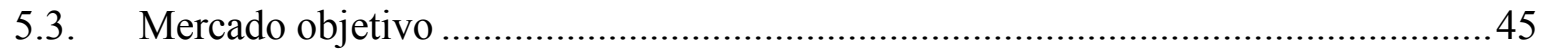

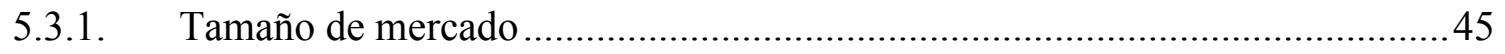

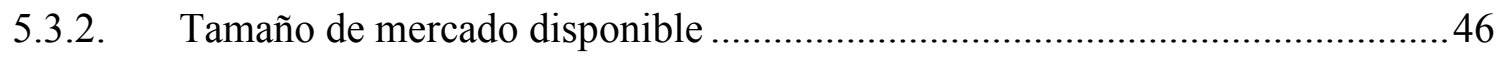

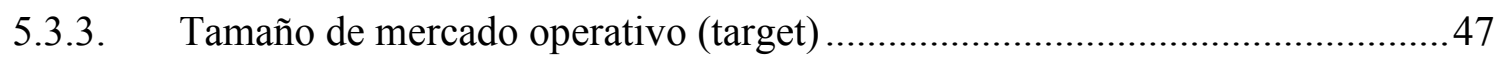

5.3.4. Potencial de crecimiento del mercado ........................................................... 48

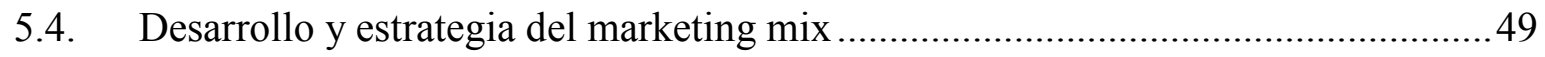

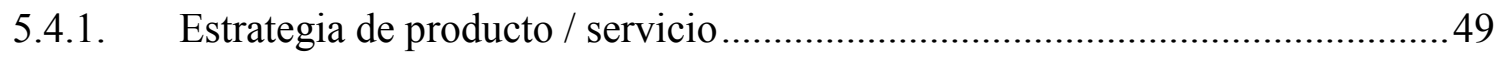

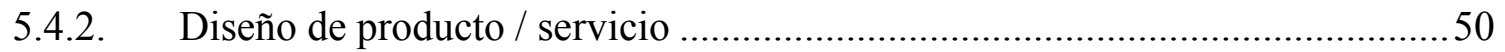

5.4.3. Estrategia de precios (Análisis de costos, precios de mercado)........................50

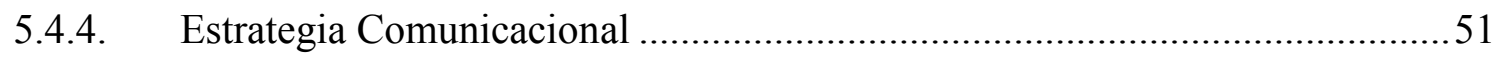

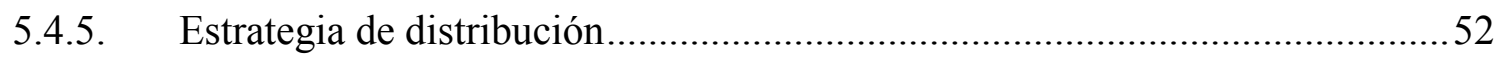

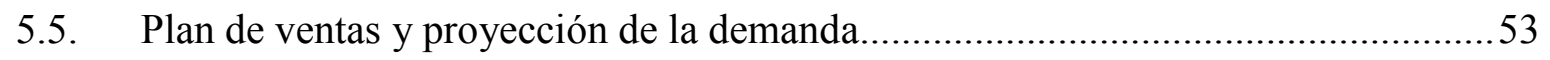

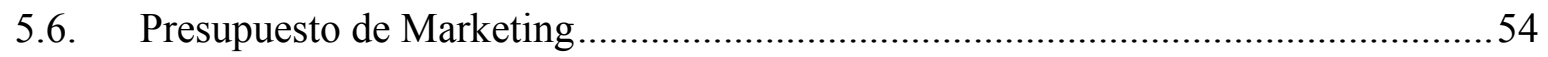

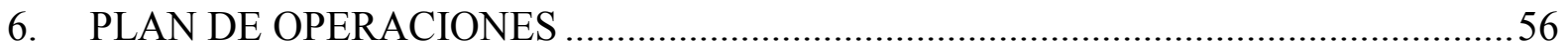

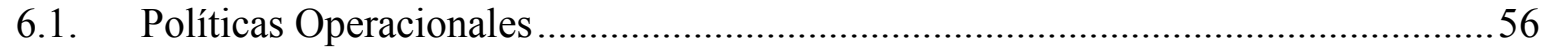

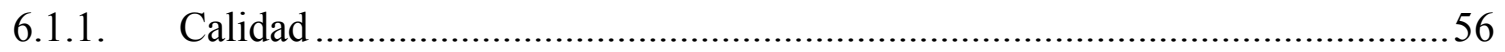

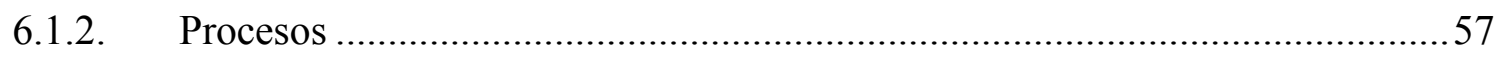

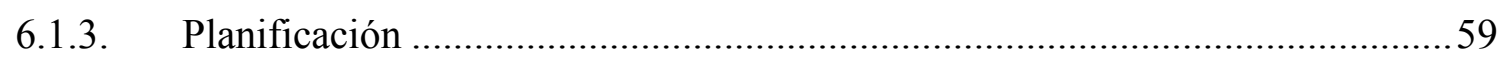

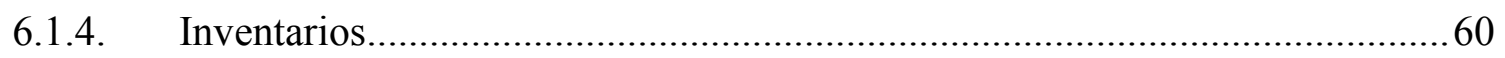

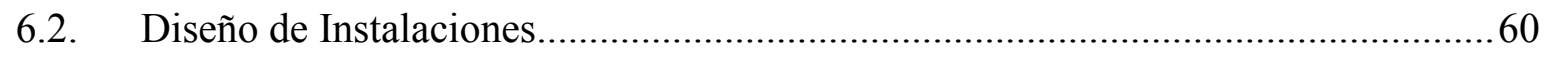

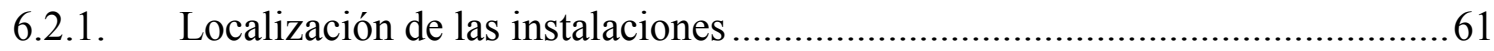

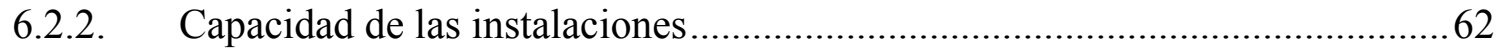

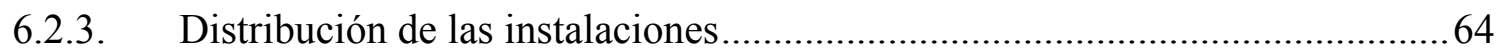

6.3. Especificaciones Técnicas del Producto / Servicio................................................69

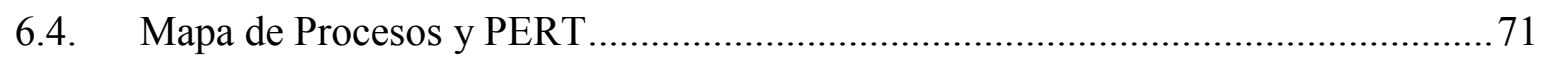

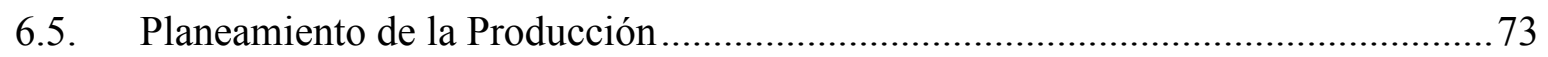

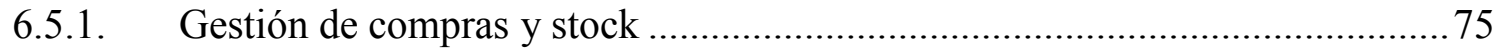

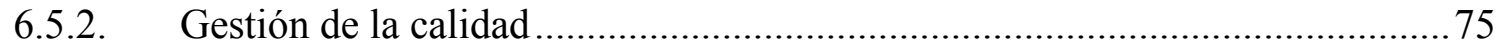




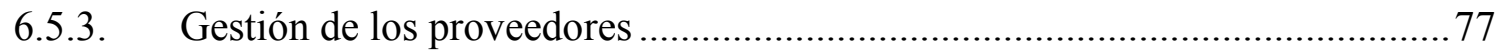

6.6. Inversión en activos fijos vinculados al proceso productivo. ................................. 79

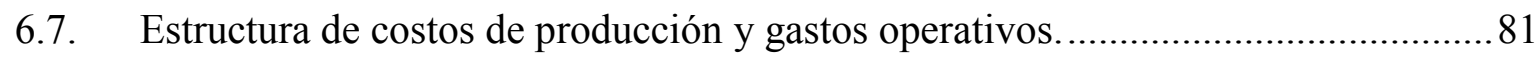

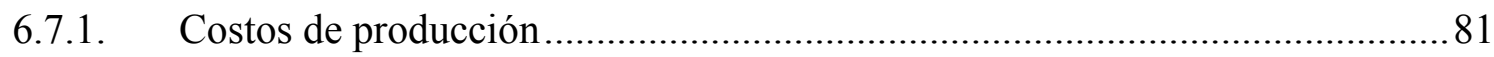

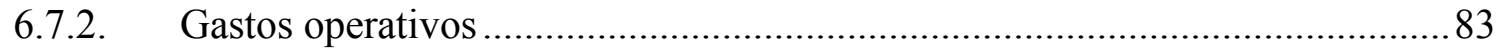

7. ESTRUCTURA ORGANIZACIONAL Y RECURSOS HUMANOS …....................... 84

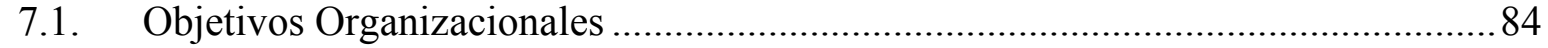

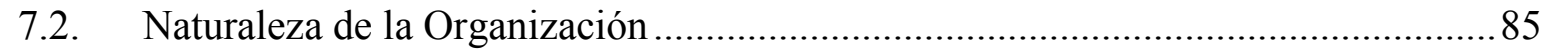

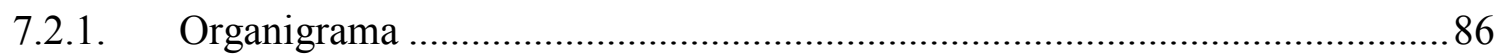

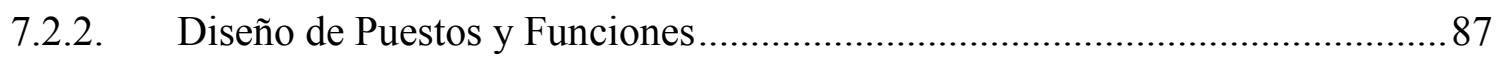

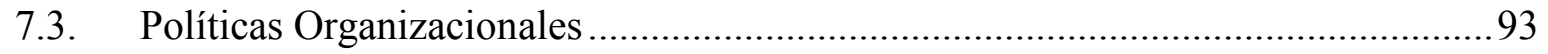

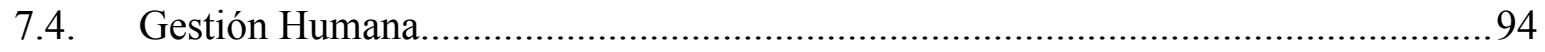

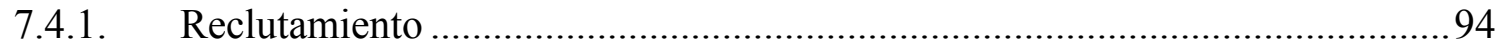

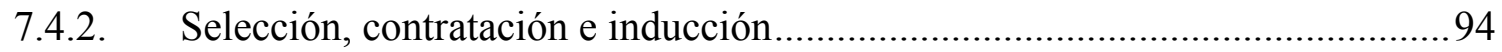

7.4.3. Capacitación, puesto en práctica y evaluación del desempeño.........................98

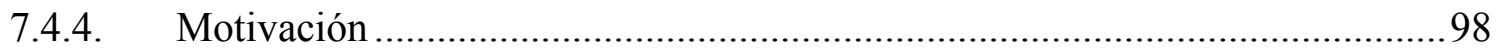

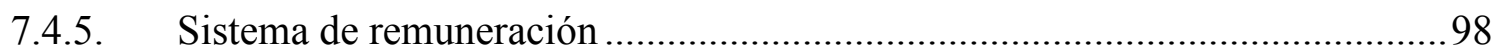

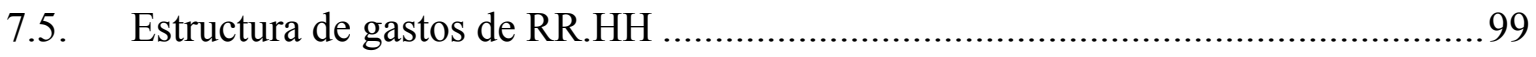

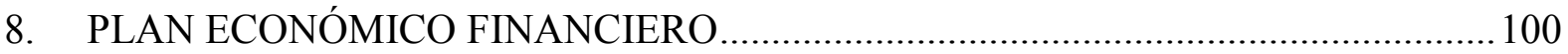

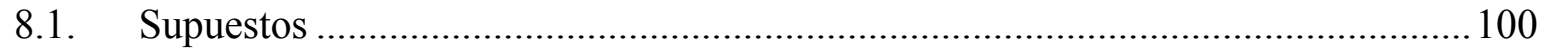

8.2. Inversión en activos (fijos e intangibles) y depreciación...................................... 100

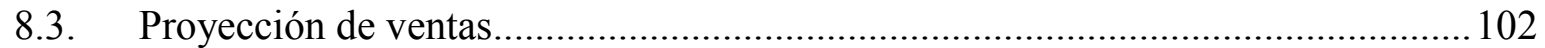

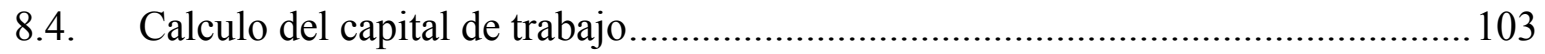

8.5. Estructura de financiamiento: Tradicional y No tradicional.................................. 105

8.6. Estados Financieros (Balance General, Estado de GGPP, Flujo de Caja)............. 105

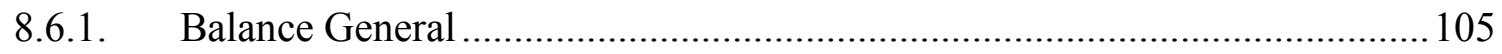

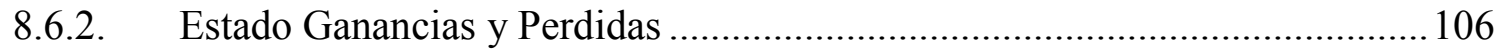

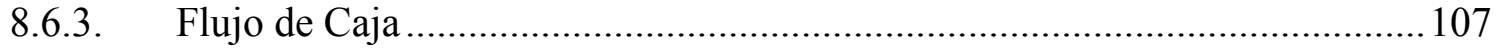

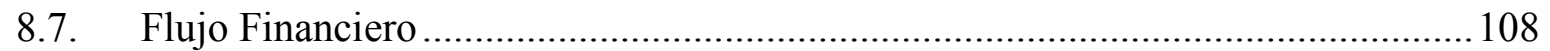

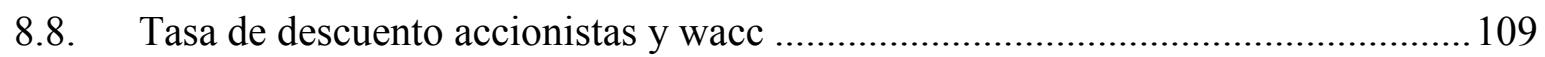

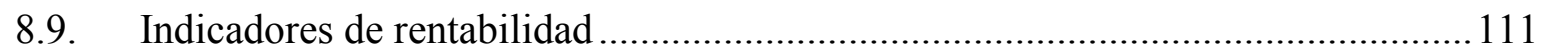

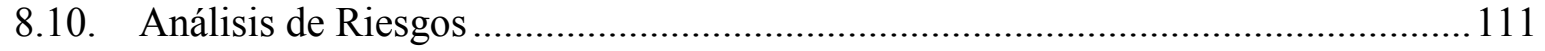

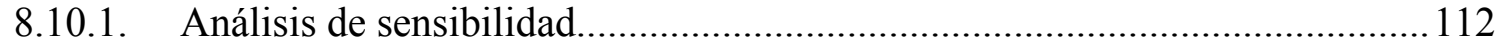

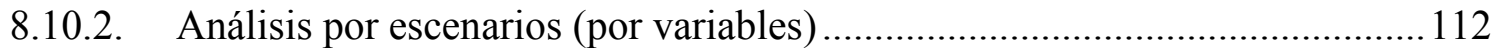




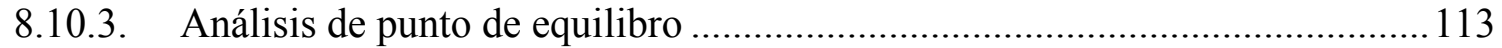

8.10.4. Principales riesgos del proyecto (cualitativos) ............................................. 114

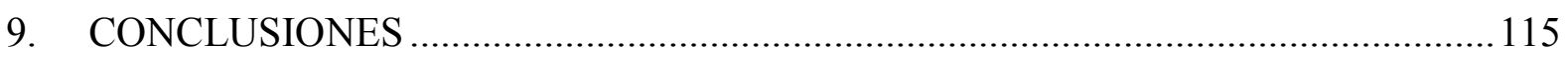

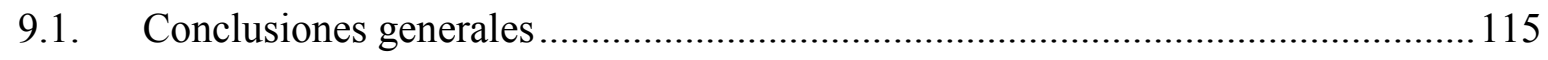

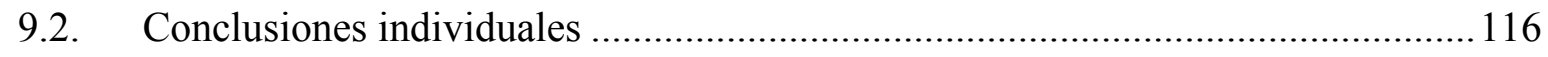

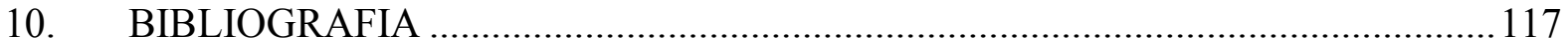




\section{ÍNDICE DE CUADROS}

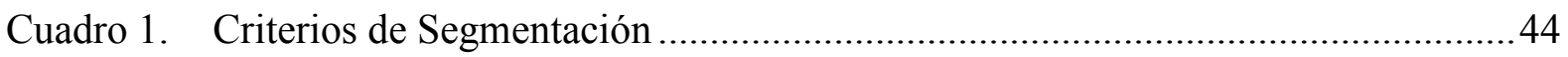

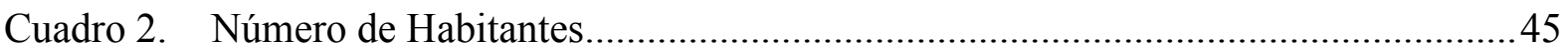

Cuadro 3. San Isidro: Población económicamente activa estimada de 6 años y más ocupada total, local y flotante según número de empresas o establecimientos. Año: 1993-20082012. 47

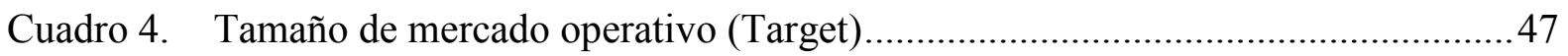

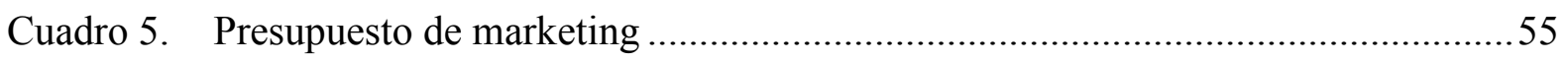

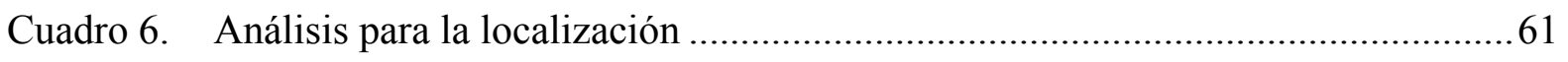

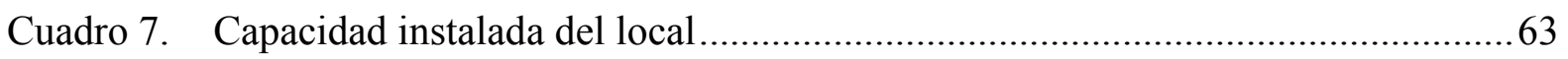

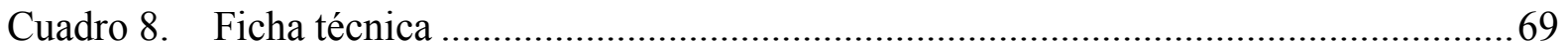

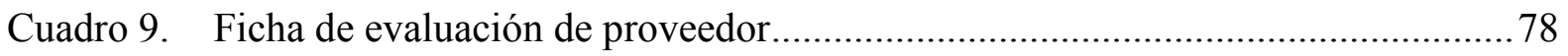

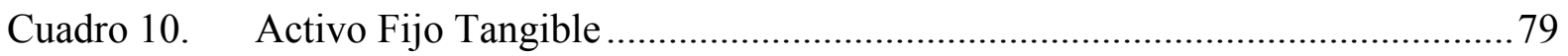

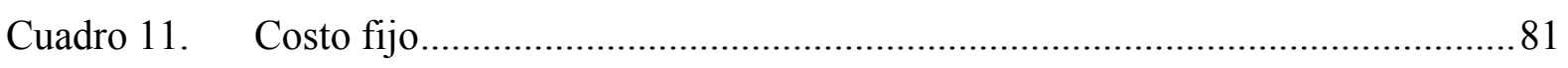

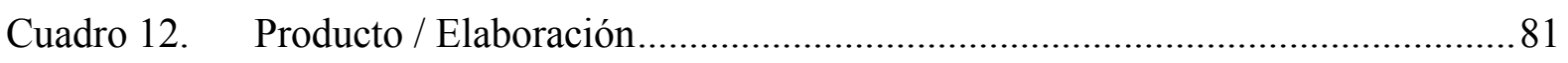

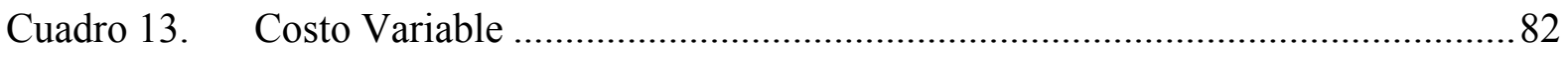

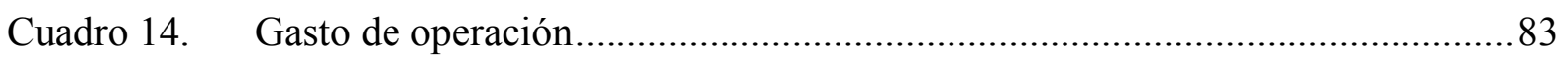

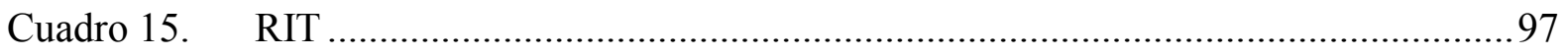

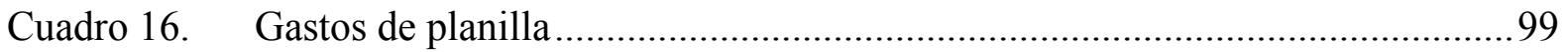

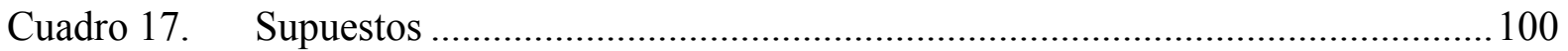

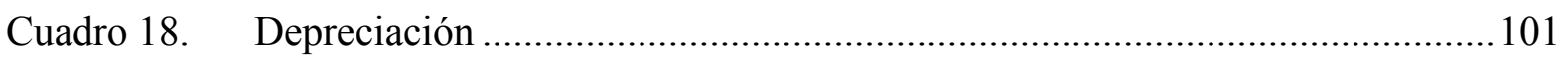

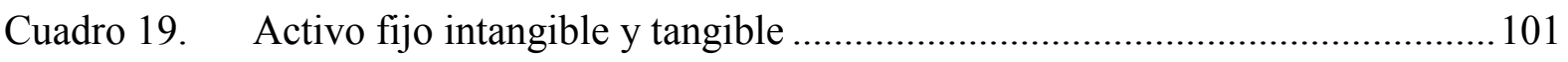

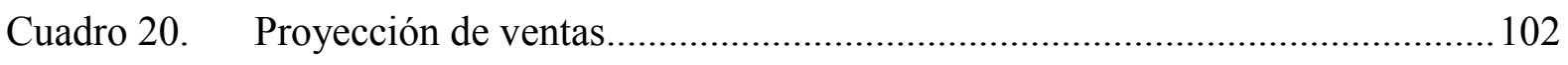

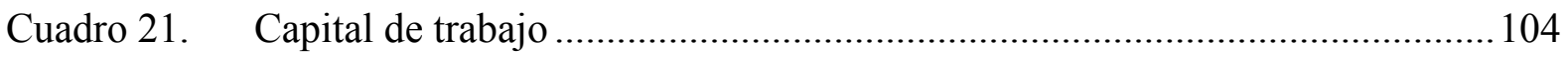

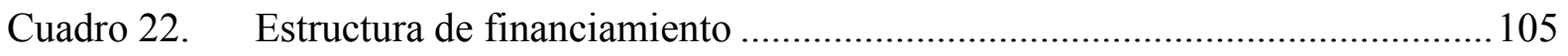

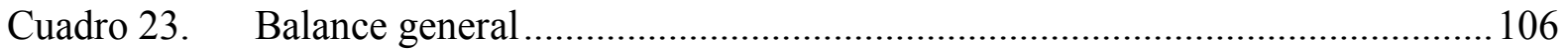

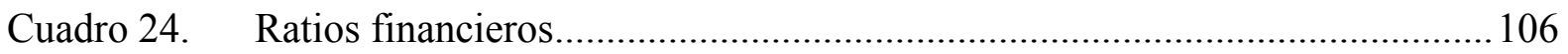

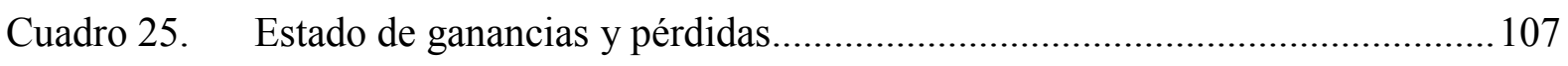

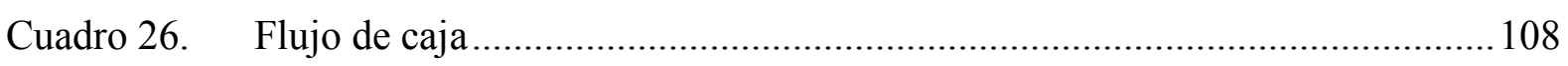

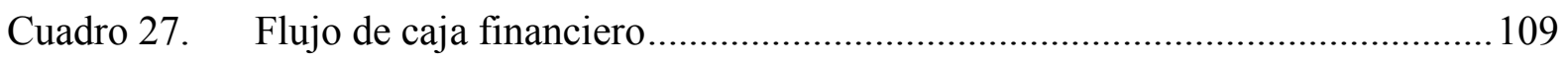

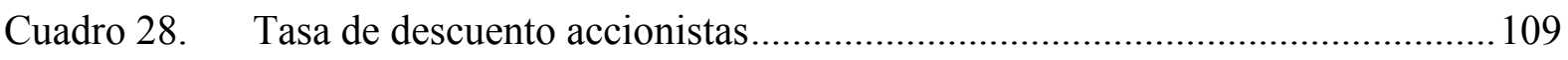




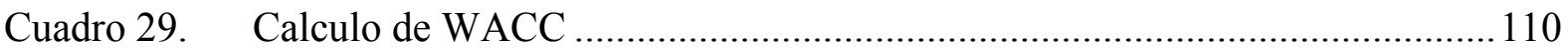

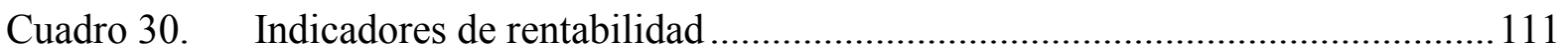

Cuadro 31. Análisis de sensibilidad a variación de precio ..............................................112

Cuadro 32. Análisis de sensibilidad multidimensional....................................................113

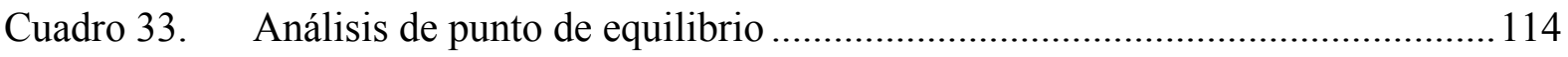




\section{ÍNDICE DE FIGURAS}

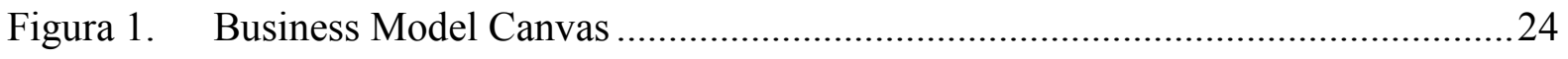

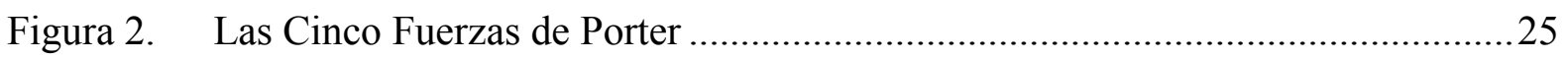

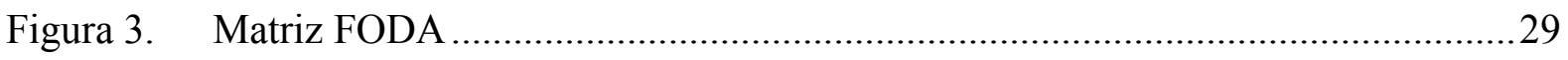

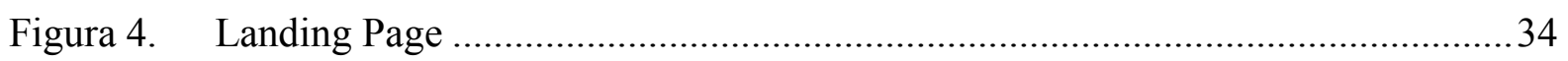

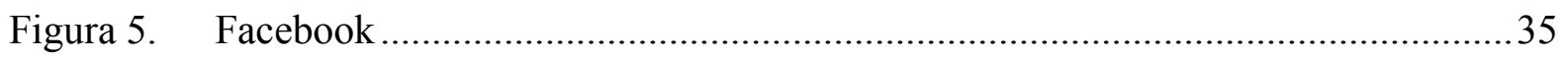

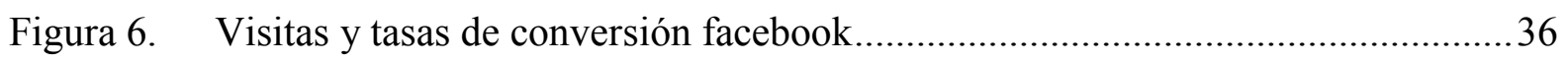

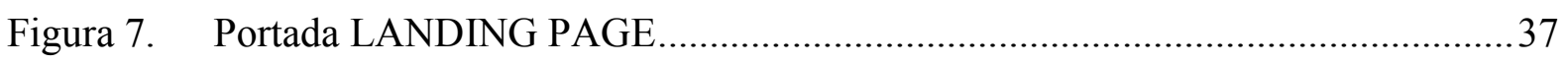

Figura 8. Proyección de la población de San Isidro: 2000-2015 ….................................. 46

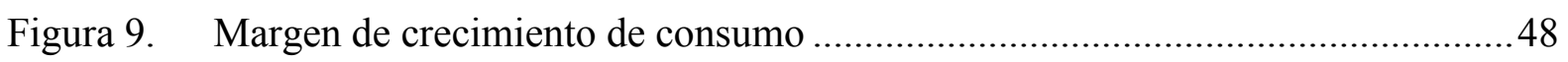

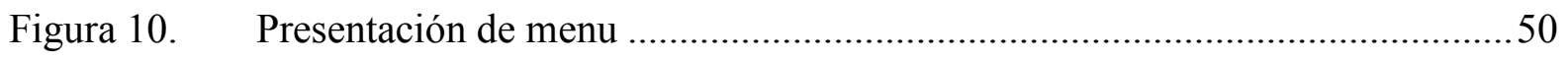

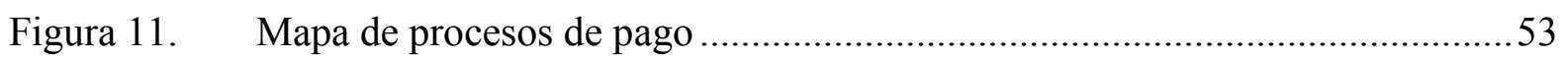

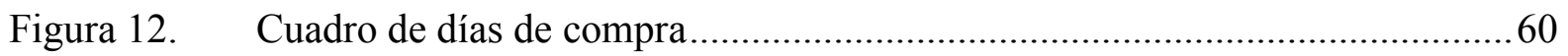

Figura 13. Mapa del Centro de Operaciones de La Tomate:.............................................62

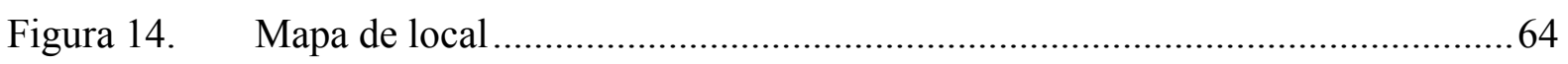

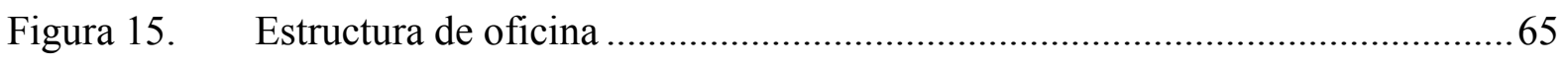

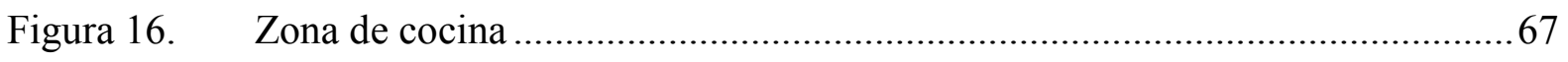

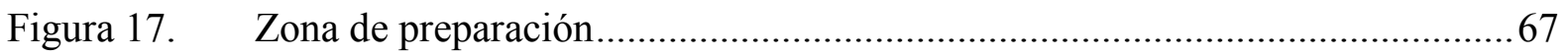

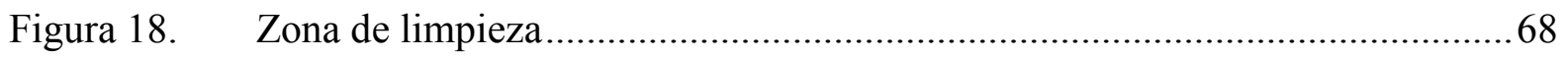

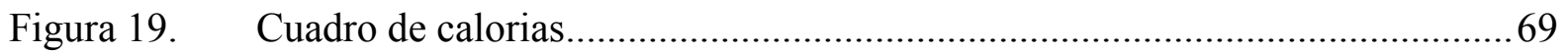

Figura 20. Diagrama - Red Pert (Plato de arroz con pollo) ........................................... 71

Figura 21. Actividades del Pert - plato arroz con pollo ................................................. 72

Figura 22. Planeamiento de Producción - (Plato de arroz con pollo)................................ 74

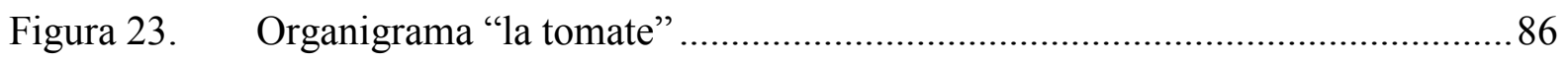




\section{INTRODUCCIÓN}

Gracias a todo lo aprendido en estos años dentro de la Universidad, hemos podido darnos cuenta que conocer y analizar las necesidades de los clientes es parte fundamental y sustancial en el desarrollo y evolución de las nuevas ideas de negocios con el fin de satisfacer las necesidades de los clientes.

El mercado actual es cada vez más imponente y exigente. Esto traducido en la industria de la alimentación, representa un gran reto para generar proyectos que satisfagan la necesidad de buscar nuevas alternativas.

La alimentación es una necesidad representa una de las necesidades básicas primarias que debe ser satisfecha teniendo en cuenta las distintas necesidades de los consumidores. Asimismo, el comer bien y sano, se ha convertido cada vez más en una tendencia más poderosa y a la vez más difícil de alcanzar debido a la falta de tiempo para sentarse y disfrutar de un buen plato casero.

Teniendo en cuenta que volver a lo tradicional y buscar comer mejor, se ha vuelto una fuerte tendencia a día de hoy, nace la idea de desarrollar una empresa que pueda satisfacer este tipo de necesidades. Es cierto que no es un producto nuevo, pero con el valor agregado de llevarte esta comida hasta tu sitio de trabajo, es que nace la innovación en este negocio.

El analizar e identificar este tipo de necesidades es fundamental para poder aprovechar estas oportunidades que se presentan en el entorno y transformarlas en proyectos de alto valor, que generen rentabilidad a los inversionistas y ofrezcan valor a los clientes.

Todo lo descrito anteriormente, nos ha ofrecido el punto de partido para el desarrollo y el salto a realizar el modelo de negocio que procederemos a explicar a continuación. 


\section{ASPECTOS GENERALES DEL NEGOCIO}

La idea principal que desarrolla esta propuesta de preparación y distribución de comida saludable surge de un análisis de las necesidades no satisfechas dentro del mercado de personas con estilo de alimentación casero y principalmente saludable. Buscando satisfacer sus necesidades básicas, como lo es la comida casera y donde vemos una oportunidad de negocio y a su vez que éste nos genere valor y rentabilidad en corto plazo.

Asimismo, vemos la exigencia creciente de los comensales en conservar una vida saludable en base al consumo de alimentos sin condimentos con ingredientes industriales y no tóxicos para su salud.

Por ello, nos estamos enfocando en este nicho de mercado, que inicialmente serán un distrito (San Isidro) para cumplir con todas sus expectativas para luego abarcar a otros distritos de Lima Metropolitana.

Muy aparte de ello, venimos desarrollando un estudio de mercado donde nos podría mostrar los vacíos existentes en este rubro, analizando quienes son nuestra posible competencia fuerte y que ventaja competitiva tenemos respecto a ellos.

\subsection{Idea / Nombre Del Negocio}

La idea del negocio es "Servicio Delivery de comida casera y saludable" se obtuvo al identificar el problema que existe a la hora de querer almorzar en una oficina. Muchas personas carecen del tiempo para preparar sus alimentos en casa, sea cual sea el motivo, solucionan su problema adquiriendo sus alimentos en restaurantes al paso, comida chatarra o un snack, entre otros.

El problema más importante que ellos encuentran en estos lugares es que la comida que se ingiere, no necesariamente será saludable y tampoco llega en el tiempo que ellos la soliciten.

Por ello, con el fin de brindar una solución a este grupo de personas, surge nuestra idea de solución, buscando que nuestros clientes encuentren lo que necesitan a la hora indicada, con un precio acorde a su bolsillo y sobre todo nutritiva y con el sabor como hecho en casa. 
Nuestro servicio se diferenciará del mercado tradicional por la calidad de atención, nuestros insumos de primera, la presentación del momento (como recién salido de la olla) buscando así, brindar una experiencia de primera que asegurará la satisfacción de los comensales y nos puedan abrir la posibilidad de atender incluso a su familia con este servicio. En una primera etapa, el servicio estará dirigido exclusivamente a las personas que trabajan en empresas ubicadas en el distrito de San Isidro.

El nombre "LA TOMATE" surge para poder generar intriga y curiosidad a los posibles clientes, en conjunto con su logo de un tomate fresco que significa saludable.

\subsection{Descripción del producto/servicio a ofrecer}

Nuestros productos para ofrecer, se diferenciará en primer lugar por el sabor, calidad y presentación que le daremos a todos nuestros clientes, desde la forma de servir la comida hasta la entrega en las manos del cliente. Para asegurar el sabor y la calidad, tendremos proveedores fijos ya evaluados con anterioridad, demostrándonos la procedencia de sus productos y la forma de la cosecha.

Adicional a ello empezaremos con una publicidad en redes sociales donde daremos a conocer los platos que prepararemos día a día, los mismos que se encuentran debidamente balanceados, todo esto lo lograremos con la ayuda de charlas nutricionales que el equipo de "La Tomate" recibirá.

Dentro del servicio a ofrecer será fundamental el factor tiempo acordado con nuestros clientes, a fin de que la comida llegue en buenas condiciones y sobre todo a una temperatura adecuada para el almuerzo. 


\subsection{Equipo de trabajo}

Nuestro equipo de trabajo está conformado por:

\section{JACQUELINE PEÑA MANRIQUE}

Edad 39 años, estudiante de la UPC, en la carrera de Administración de Banca y Finanzas, actualmente curso el 10mo ciclo. Apasionada por el arte culinario, el mismo que he aprendido de forma empírica, por lo que unas de mis principales funciones en La Tomate será ser la responsable de supervisar al equipo de trabajo y asegurar que todos los despachos salgan en óptimas condiciones y en los tiempos establecidos.

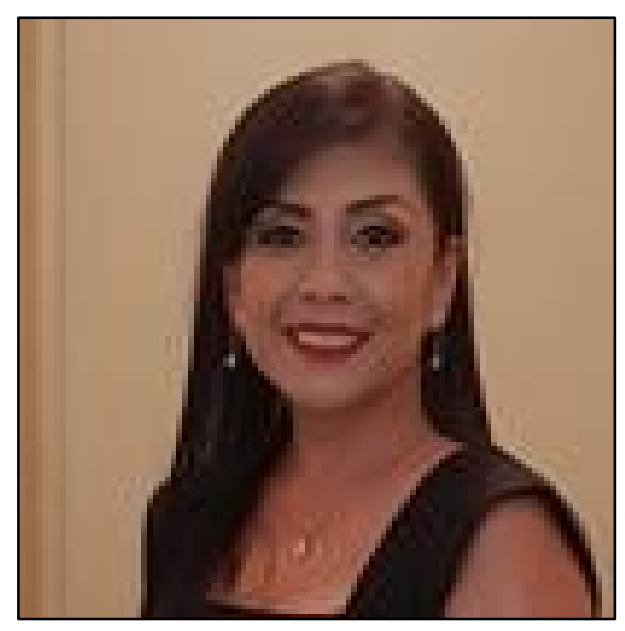

\section{SAMUEL ANGULO CÁRDENAS-GARCÍA}

Edad 29 años, Estudios de informática e ingeniería de redes, actualmente estudiante de Marketing. Emprendedor y entusiasta con 10 años de experiencia en trabajos de tecnología de la información y manejo de equipos, amplia capacidad de organización, desempeño de alto nivel y excelentes habilidades de comunicación y adaptabilidad por lo cual mi principal función será de captación de nuevos clientes mediante nuestras redes sociales y de la

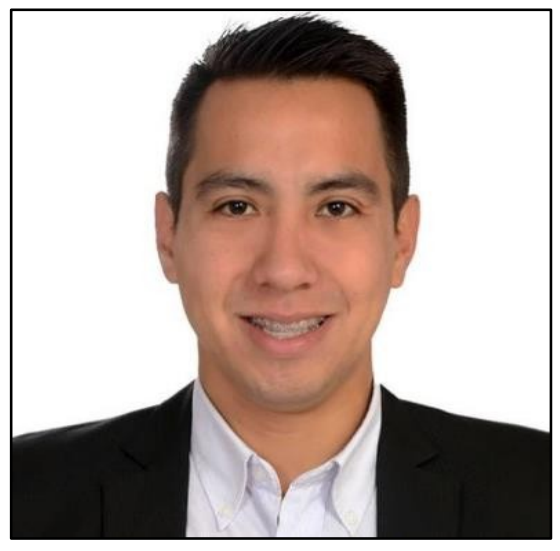
fidelización de los actuales clientes. 


\section{MINELLY ROJAS TACUCHI}

Edad 37 años, estudiante de la UPC en la carrera de Administración de Banca y Finanzas, actualmente cursando el décimo ciclo. Con experiencia sólida en manejo de equipos, administración de empresas, atención al cliente, manejo de quejas y reclamos. Mi principal función será administrar La Tomate, proponiendo políticas y procesos, que ayuden al buen desarrollo del negocio para poder así la máxima rentabilidad y la viabilidad del negocio.

\section{STEWART RIVERA MUÑANTE}

Edad 27 años, estudiantes de la carrera de administración de banca y negocios cursando el $10 \mathrm{mo}$ ciclo. Proactivo y comprometido con experiencia en atención al cliente, manejo de equipos, trabajos bajo presión, logística y abastecimiento. Mi función en La Tomate será de asegurar la calidad de los insumos de cocina, que mantengan un nivel de frescura y de calidad, a su vez manejare al equipo de delivery asignando zonas estratégicas para lograr un reparto oportuno manteniendo nuestro valor agregado.

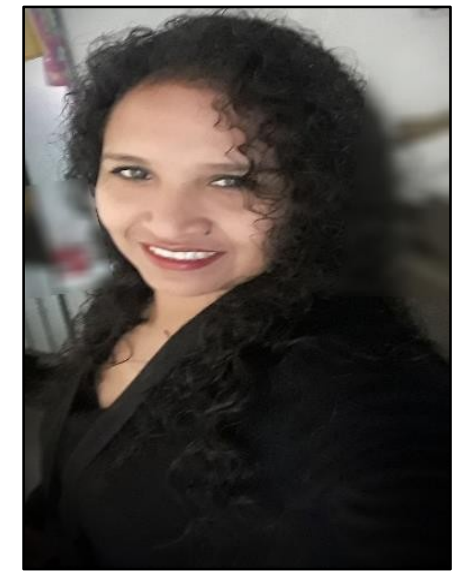

$$
\text { del negocio. }
$$




\section{PLANEAMIENTO ESTRATÉGICO}

Nuestra empresa ha diseñado planes estratégicos para poder lograr nuestros objetivos y metas trazadas en el largo y mediano plazo. Para poder lograr estas metas y objetivos hemos analizado el sector externo e interno del sector, teniendo como resultado lo siguiente:

\subsection{Análisis Externo}

Análisis Externo - Entorno General

El entorno general en el que se encuentra nuestra propuesta nos indica que pertenece a la “industria alimentaria" y al sector "servicios", compitiendo en la industria de servicios de alimentación y de traslado de alimentos.

Identificación del Sector e Industria en la que compite (Modelo Abell)

El sector en el que vamos a operar será el de alimentación y traslado de alimentos pertenecientes a la industria alimentaria y al sector servicios. Ofreceremos el servicio de preparación y traslado de alimentos hechos en condiciones óptimas y adecuadas y en los estándares de salubridad requeridos por la industria.

\subsubsection{Análisis PESTEL}

Se realiza un análisis externo de la empresa "La Tomate" que nos permitirá conocer una valoración de la situación actual. Además, conocer las oportunidades que podríamos obtener en el sector que hemos elegido.

Político - Legal. - Con la reciente situación del país y la renuncia del actual presidente Pedro Pablo Kuczynski las variables macroeconómicas para un desarrollo de la economía nacional son aún estables, ya que al iniciar el año se consideró la posibilidad de una vacancia o renuncia (para que no se vea paralizado el país). Por lo cual no debería haber un ajuste muy significativo al estar preparado para dicho suceso. Por eso a la entrada del nuevo presidente interino Martín 
Vizcarra Cornejo y con promesas del congreso para el apoyo a la nueva presidencia, el sector político y económico deberán de reactivarse y aumentar la inversión privada.

De acuerdo al marco legal, "La Tomate" operará como una empresa de producción y transporte de alimentos debidamente registrada y amparada en LA LEY GENERAL DE TRANSPORTE $\mathrm{N}^{\circ} 27181$ art 4 y en el Decreto Legislativo, donde la primera declara la libre competencia y la siguiente tiene por finalidad establecer el régimen jurídico aplicable para garantizar la inocuidad de los alimentos destinados al consumo humano con el propósito de proteger la vida y la salud de las personas, por lo tanto, vemos que no se presentarán irregularidades ni amenazas en el avance del negocio.

Por la parte legal no existe impedimento para la contratación de personal ni en el tema de licencias y permisos. Ya que en el distrito que nos queremos enfocar el costo de la licencia de funcionamiento oscila entre los 70 a 80 soles para un local menor de $100 \mathrm{~m} 2$

\subsubsection{Social-cultural.}

La gastronomía de Perú es parte de la identidad nacional con sus sabores de cuatro continentes. Sin embargo, es afectada por los cambios que realiza los individuos en la sociedad, entre ellos tenemos las comidas rápidas y la comida gourmet.

Por otro lado, para un mejor crecimiento encontramos apoyo en las ferias gastronómicas como Mistura, la feria gastronómica más importante de nuestro país, que se realiza cada año y como ya es costumbre los restaurantes regionales se presentan en los 19 locales de Tumbes, Ica, Moquegua, Puno, entre otros ofrecerán al público sus mejores potajes.

Un factor que puede afectar es la cultura de la gente siendo determinantes en su vida, por sus hábitos alimenticios La configuración de un establecimiento de comida rápida en una zona donde hay un gran número de personas conscientes de la salud afecta al tipo de comida rápida suministrada. Tienes que considerar si la mayoría de la población es vegetariana o si prefieren carne roja o blanca. Las culturas dictan sus hábitos de alimentación y proporcionan una diversificación de los alimentos. 


\subsubsection{Demográfico.}

En este tipo de análisis se puede estudiar o analizar a través de las poblaciones en cuanto a su extensión, densidad, ubicación, raza, sexo, edad y ocupación. El factor demográfico puede afectar a una empresa, dado que involucra a personas que conforman el mercado objetivo, por lo tanto, en la variable demográfica podemos estudiar varios aspectos de la población, como cambios en la estructura de edad, cambios en la familia, cambios geográficos, o disminución de la población mundial.

\subsubsection{Global-Económico}

Durante los últimos cinco años, el Perú ha lo- grado grandes avances en su desarrollo. Sus logros incluyen: tasas de crecimiento altas, una apertura económica, baja inflación, estabilidad macroeconómica, una política monetaria prudente, reducción de la deuda externa y de la pobreza, y avances importantes en indicadores sociales y de desarrollo.

En lo que se refiere a la actividad productiva nacional, ésta, registró un crecimiento del 3.5\%, tasa que supera a la registrada en el 2017. Sin embargo, en el sector transportes comparado con el año pasado (2.27) sufre una disminución de 2.15 puntos en la variación porcentual productiva. En conclusión, debemos considerar que nuestra economía no está exenta de múltiples riesgos provenientes del frente externo, este dato nos permitirá redoblar esfuerzos para consolidar las expectativas de los agentes económicos.

\subsubsection{Medioambiental}

En cuanto a lo Ecológico podemos reafirmar nuestro compromiso con la sociedad. Es importante mencionar que somos una empresa con alta responsabilidad social y por lo mismo estamos comprometidos no solo con la sociedad en sí, sino con el planeta. Además, en cuanto al tema ecológico, no tenemos amenazas que puedan ir en contra de nuestro modelo de negocio puesto que nuestros productos serán transportados en envases que garantizarán su excelente estado de conservación durante el trayecto y no se verán afectados por el clima del sector. 


\subsubsection{Tecnológico}

Tenemos claro que nuestro modelo de negocio logrará una buena adaptación a las nuevas aplicaciones móviles que cada vez más personas usan en las plataformas Android e IOS. Según Arellano Marketing y su presentación de estilos de vida, nuestro público objetivo son los sofisticados, pues ellos son modernos, innovadores y buscadores de nuevas tendencias con ingresos más altos que el promedio, además de pertenecer al sector socio-económico $\mathrm{B}-\mathrm{B}+$.

En conclusión, adaptamos nuestro modelo de negocio a estas aplicaciones que se presentan como una ventaja tanto para el cliente como para la empresa.

\subsection{Análisis Interno}

\subsubsection{Business Model Canvas: desarrollo de los nueve bloques.}

\subsubsection{Segmentos De Clientes}

Hombres y mujeres entre 25 y 50 años que trabajan en San Isidro que buscan comida de casa, que extrañan un estilo de vida hogareño y al momento de comer están acostumbrados a sentir el sabor de casa demandan de este servicio con la finalidad de encontrar los alimentos nutritivos y saludables para su organismo ofreciéndoles una mejor calidad de vida y a un costo accesible. Asimismo, se preocupan por su salud y buscan comida saludable; disponen de su tiempo y dinero se preocupan por tener una alimentación balanceada con el sabor casero.

\subsubsection{Propuesta de valor}

Ofrecemos un menú de tipo casero con la receta tradicional de mama, insumo natural y de primera calidad a precios accesibles, la entrega será por delivery con ahorro de tiempo en la entrega de cada pedido, solicitado desde la comodidad de su oficina. 


\subsubsection{Canales}

Para la entrega de nuestra propuesta de valor utilizaremos diversos canales de distribución, dándose desde los mismos socios hasta canales indirectos, por ello, enfocamos nuestras actividades en 5 fases para los tres segmentos:

- Evaluación: Usaremos encuestas físicas o vía WhatsApp donde nuestros clientes podrán dar su opinión de nuestros servicios

- Compra: A través de central telefónica, WhatsApp y Facebook.

- Entrega: La entrega de nuestro producto será personalizado y con unos envases acorde a la comida que ha solicita el cliente, donde podrán corroborar la calidad del producto que ofrecemos y vivir la experiencia de consumir una comida saludable.

- Postventa: Postventa: a través de un representante de nuestra central telefónica atenderemos a sus dudas, consultas o sugerencias. Manteniendo la cercanía con nuestros clientes.

- Notoriedad: Utilizaremos diversos medios para hacernos conocer como las redes, publicidad local, referidos, cartas de presentación entre otros.

\subsubsection{Relación con el cliente}

Nuestra relación con los clientes es directa, para el segmento de personas de provincia que trabaja en Lima, utilizaremos la publicidad en su centro de trabajo y a través de la distribución de volantes para llegar a ellos.

Personas con estilo de vida hogareño, nuestra relación con el cliente de este segmento será directa con un representante de servicio con nuestro cliente. Adicionalmente ofreceremos un servicio automatizado en la selección de su producto, es decir que el cliente tenga la opción de elegir la combinación que desee desde nuestro fan page.

Cuanto más cercanos estemos, se sentirá más identificado con nuestra empresa. Esa será nuestra mejor herramienta para generar un compromiso. 


\subsubsection{Fuentes de Ingresos}

Los ingresos vendrán de la venta de nuestros productos (pedidos diarios, pedidos semanales y pedidos especiales). Este pago lo puede realizar al momento de recoger su pedido de comida o a través de la App de "'La Tomate'.

También se piensa obtener un sistema de pago a través de web que esté relacionado al convenio con un socio estratégico (Visanet).

\subsubsection{Recursos Claves}

- Personal capacitado: para la elaboración de las comidas contaremos con un Chef con experiencia, el cual se encargará de abastecernos de los deliciosos platos que ofreceremos. Asimismo, se encargará de capacitar al personal constantemente con la finalidad de que se mantengan a la vanguardia del proceso alimentario y la calidad del servicio se mantenga óptima.

- Infraestructura: contaremos con un local donde se realizará la preparación de los alimentos y desde donde se procederá a despachar los pedidos hacia los distintos puntos.

- Proveedores: quienes nos brindaran los insumos perecibles y no perecibles.

- Aportación de capital: hemos determinado la aportación en dinero y activos quedará cada uno de nosotros pondrá para la puesta en marcha del negocio.

- Página web: tener una página web es indispensable, a través de la plataforma podremos dar a conocer nuestro negocio, captar nuevos clientes y mantenerlos informados de todas las novedades que ofrecemos a todo el público en general.

- APP: contaremos con una app que será el canal más importante de ventas de cara al cliente. Es ahí donde se podrán realizar pedidos y a su vez el cliente estará al tanto del estado del mismo. La App permitirá al cliente realizar pagos y conocer nuestras ofertas.

\subsubsection{Actividades Clave}

Para llevar a cabo nuestro negocio cumpliremos con las siguientes actividades:

- Se realizará el pedido a través de la app de La Tomate. 
- Se procederá a realizar la orden.

- El ayudante de cocina se encargará de empaquetar el pedido para entregarle al motorizado.

- El motorizado se dirigirá a la empresa donde labora la persona que realizo la orden, para entregarle su pedido.

- El mismo motorizado realizará el cobro en efectivo o a través del POS. Asimismo, en caso el pedido ya haya sido cancelado a través de la App, solo lo dejará.

\subsubsection{Socios Clave}

Se detalla a los proveedores necesarios para que nuestro modelo de negocio funcione:

- Proveedores de descartables.

- Proveedores de hortalizas y frutas.

- Proveedores de abarrotes.

- Proveedor de combustible.

- Trabajaremos con POS y se requiere del servicio de un banco.

- Proveedores de tecnología para el correcto funcionamiento de nuestra App.

\subsubsection{Estructura de costos}

Se describe la estructura de costes que incurrimos para poder ejecutar el trabajo.

- Pago de los servicios luz, agua, internet, teléfono

- Pago de los gastos de insumos para la comida

- Pago al personal de cocina y motorizado

- Pago de permiso municipales e impuestos 
Figura 1. Business Model Canvas

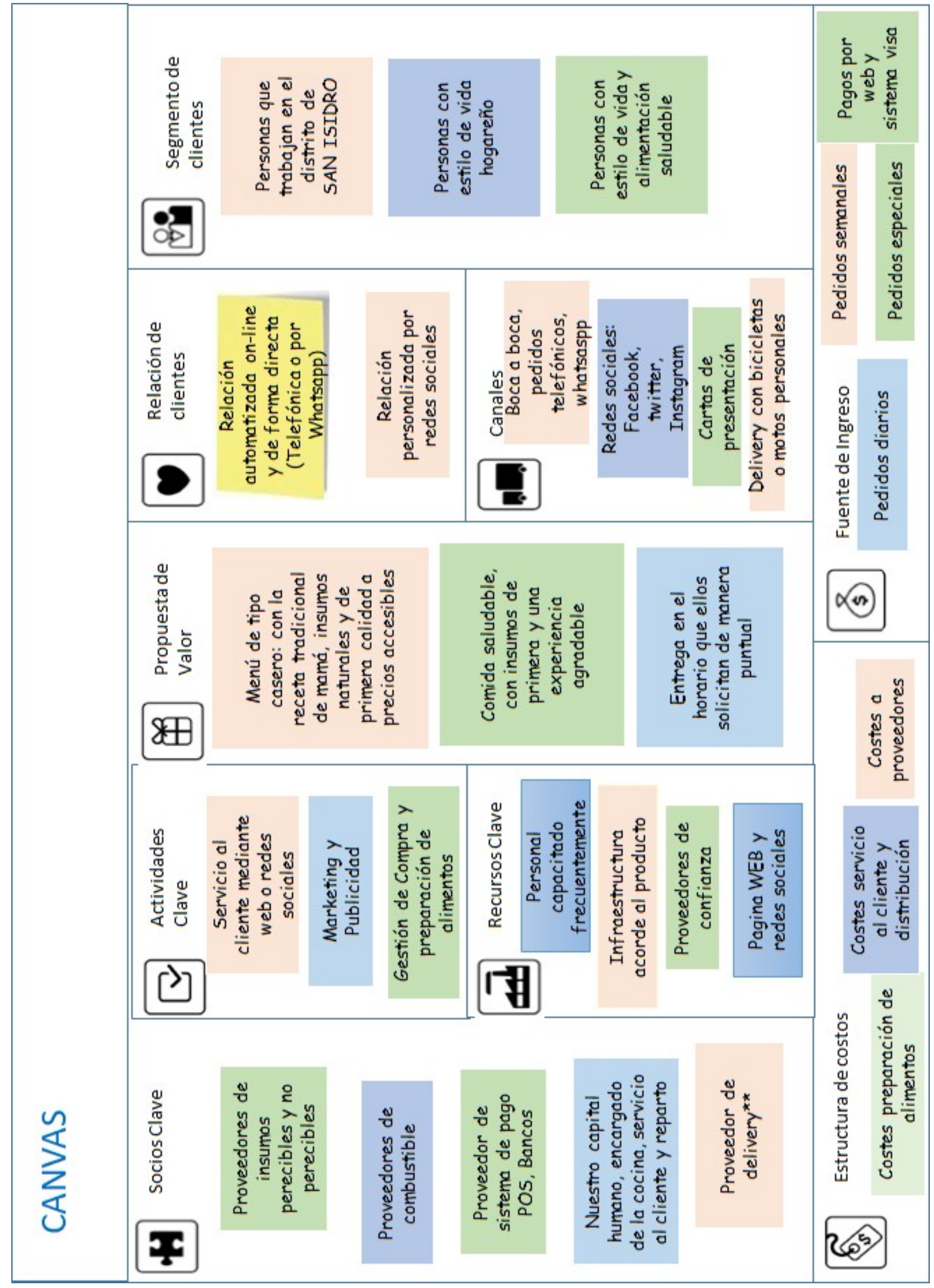

Fuente: Propia 


\subsubsection{Análisis de las 5 fuerzas de Porter}

El modelo de las Cinco Fuerzas de Porter propone un marco de reflexión estratégica sistemática para determinar la rentabilidad de un sector en específico, con el fin de evaluar el valor y la proyección futura del proyecto o unidades de negocio que operan en dicho sector.

Figura 2. Las Cinco Fuerzas de Porter

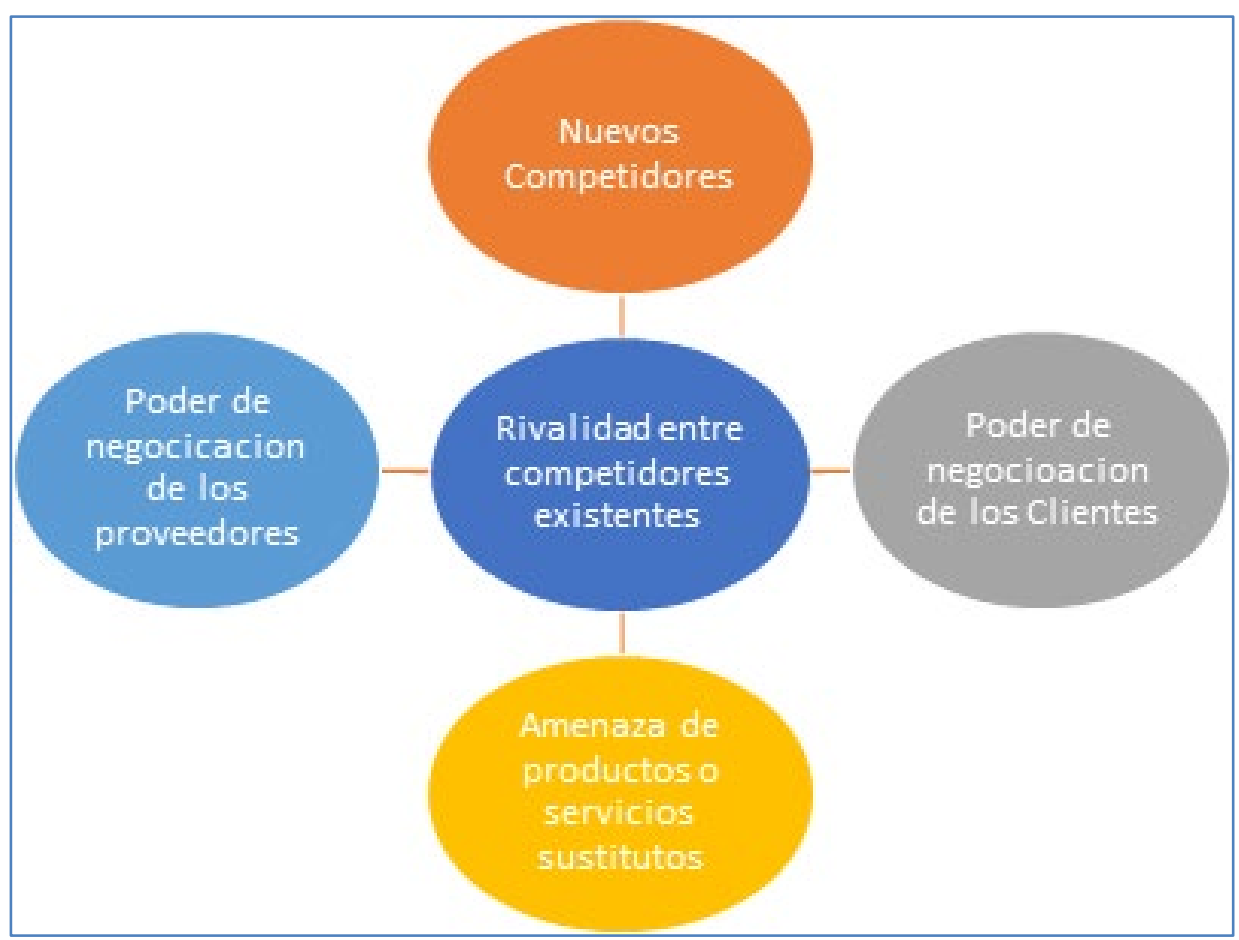

Fuente: Propia

\subsubsection{Fuerza Competitiva "Nuevos Competidores"}

En la actualidad, las compras Online son necesidades para los clientes y el mercado, de tal manera que facilita la vida diaria de ellos, ahorrando tiempo y dinero, según la tendencia actual.

Teniendo en cuenta que la competencia ofrece también servicios de delivery de diversos tipos de almuerzos (Menús) desde frituras hasta platos a la carta. Dichas compras son llevadas al lugar solicitado por el cliente, logrando que no pierda el tiempo en ir a comprar y cargarla.

La ventaja competitiva se diferencia entre las demás, ya que la empresa es la única en el distrito de San Isidro que ofrece los servicios de delivery de almuerzos saludables con sabor a casa, de acuerdo con una ración de ingredientes sanos que aseguran la calidad del producto. A su vez 
aseguramos que el almuerzo llegue a gusto del cliente (temperatura, presentación, calidad de insumos, etc.).

De tal forma aseguramos tener una ventaja competitiva frente a los demás, teniendo un producto de calidad y aun precio asequible. El nivel de entrada de nuevos competidores en "BAJO".

Barreras de Entradas: La empresa tiene un alto nivel de calidad para la adquisición de insumos que asegura la preparación del almuerzo. El sistema eficiente de entregas a tiempo (Delivery). Asimismo, con la buena atención personalizada se logra obtener confianza y fidelización con los clientes para satisfacer los antojos que desea comer en el día. Dichos beneficios podrán evitar el ingreso de nuevos competidores en el mercado, tal como se menciona en el siguiente enunciado.

"Las Barreras de entrada a un mercado son obstáculos de diversos tipos que complican o dificultan el ingreso a un mercado de empresas, marcas o productos nuevos. Pueden existir barreras de carácter económico, legal o incluso relacionadas con ámbitos como la ética o la imagen pública".

Desde un punto de vista económico la industria de los restaurantes tiene una barrera de entrada muy baja, dentro de ellas encontramos las comunes como la falta de capital para inversión (terceros), escepticismo de los consumidores por el sabor, la ubicación del local y el plan de marketing para llegar a hacer conocido el negocio.

Barreras de Salidas: La empresa se encuentra en el ciclo de vida "crecimiento" por lo que no contará aún con barreras de salida.

\subsubsection{Fuerza Competitiva "Poder de Negociación de los Proveedores"}

Los proveedores es uno de los pilares del proyecto, por tal motivo es sumamente importante mantener la relación con ellos para abastecer a nuestros clientes. Por consiguiente, el nivel de Poder de Negociación de los Proveedores es "MEDIO", ya que la demanda es alta y es considerado como cliente fijo de diversos proveedores de diferentes categorías de alimentos, desde carnes hasta frutas, ya sea en los camales hasta en los mercados. 
La empresa posee pocos proveedores que asegura la calidad como para abastecer a toda la demanda de clientes del distrito de San Isidro, ya que básicamente las compras se harán personalmente para asegurar la calidad.

\subsubsection{Fuerza Competitiva "Poder de Negociación con los Clientes"}

La empresa tiene los precios promedio de los restaurantes de la zona, siendo aceptada por los clientes y con productos de alta calidad para preparar los tipos de comidas que deseen. Teniendo los precios promedio los clientes potenciales "la población" no dudarán en realizar sus compras en la empresa, ya que podrá ahorrar tiempo y dinero, Asimismo, la empresa ofrece una cartera de almuerzos de diferentes países del mundo. Por lo consiguiente, el nivel de Poder de Negociación con los Clientes es “BAJO”, ya que los servicios se ofrecen a la población que trabajan y residen principalmente en el distrito de San Isidro.

\subsubsection{Fuerza Competitiva "Rivalidad entre Competidores Existentes"}

Competidores Directos: Existen empresas que realizan sus ventas de diversos tipos de almuerzos Online, como restaurante de comida rápida (KFC, BURGER KING, PIZZA HUT, NORKYS, ROKYS, etc.)"y restaurante de la zona; sin embargo, los tipos de alimentos que los clientes quisieran no los encuentra, ya que no tiene insumos saludables ni se parecen a la comida de casa.

Competidores Indirectos: Los diferentes tipos de comida rápida que existan alrededores de nuestro público objetivo (FoodTruck)

En tal sentido, el nivel de Rivalidad entre Competidores Existentes es "MEDIO" por los Competidores Indirectos que podrían encontrar a bajo precio mediante ofertas o descuentos. Lo cual haremos frente con nuestra ventaja competitiva.

\subsubsection{Fuerza Competitiva "Amenaza de Productos o Servicios Sustitutos"}

Las posibles amenazas de productos o servicios sustitutos son altas, ya que los Restaurantes de alrededor les proporcionan las comidas rápidas y listas para que el cliente pueda consumirlo, 
sin importarles la presentación ni la calidad del producto. En la actualidad, en Lima existen 220 mil restaurantes, que podrían ser una verdadera amenaza para la empresa.

La amenaza de productos sustitutos es "ALTA".

\subsubsection{Matriz FODA - Estratégico}

Presentamos la matriz FODA donde aprovechamos nuestras fortalezas para aprovechar las oportunidades y contrarrestar las amenazas al igual que las debilidades, las cuales se deben mejorar para poder aprovechar todas las oportunidades y contrarrestar sus amenazas. También se presentan las estrategias a desarrollar con cada cruce: 
Figura 3. Matriz FODA

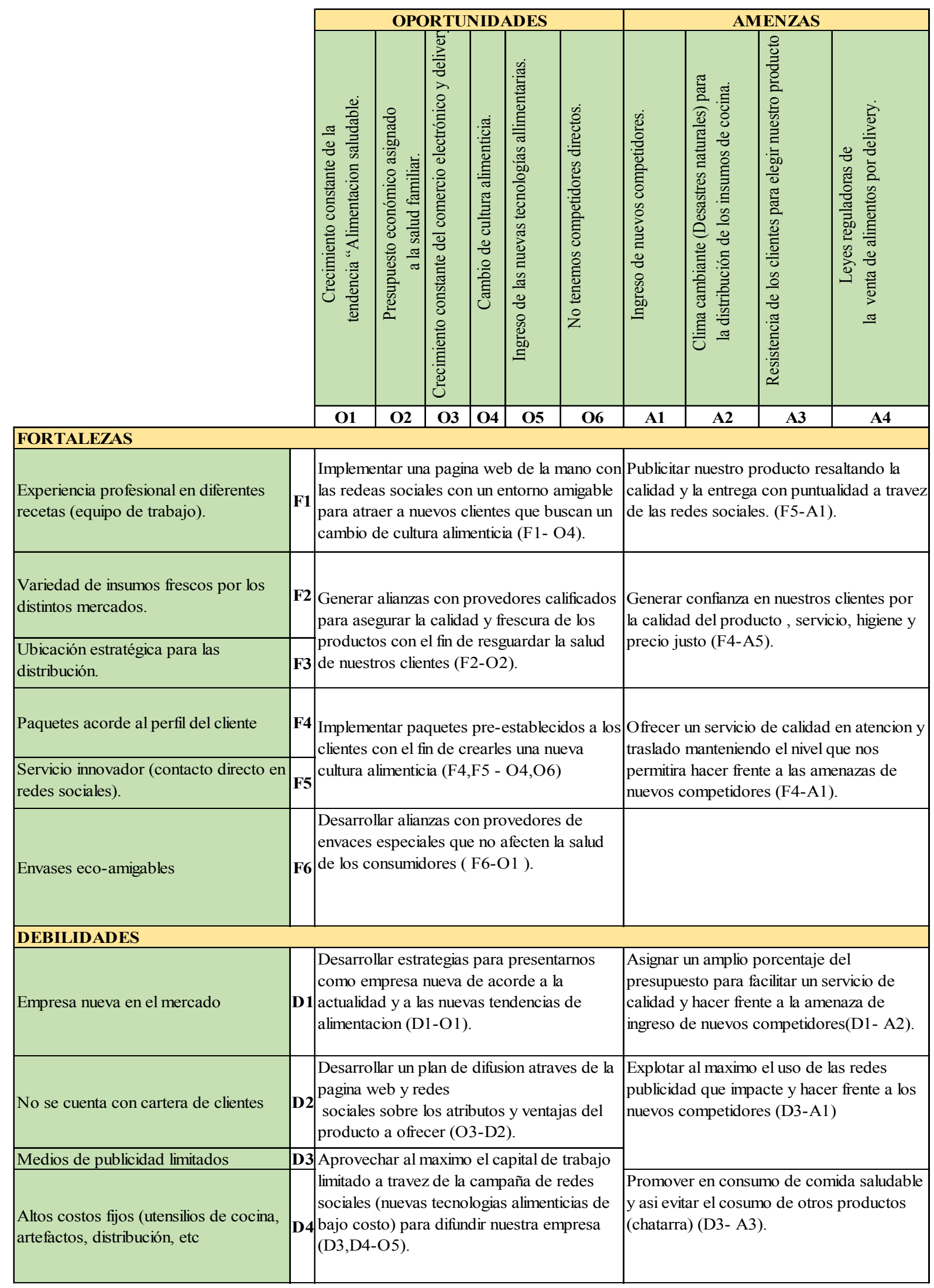

\section{Fuente: Propia}




\subsection{Visión}

"Ser el restaurant delivery líder en comida saludable de la más alta calidad con sabor a casa, con proyección de crecimiento en todo el territorio nacional para el año 2022"

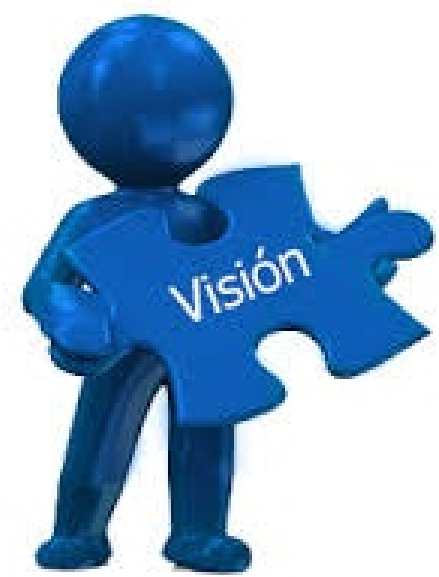

\subsection{Misión}

“Ofrecer un producto saludable de un alto nivel basándonos en insumos de primera calidad con un personal constantemente capacitado, a través de un excelente servicio de delivery con su entrega a tiempo, logrando satisfacer las necesidades de cada cliente."

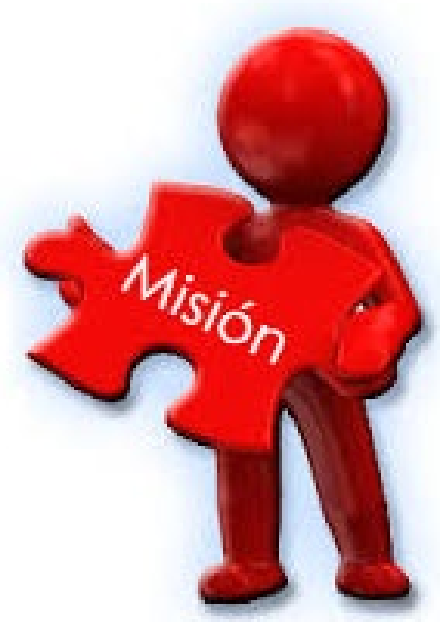




\subsection{Estrategia genérica}

Enfoque con Diferenciación

Nuestro servicio está dirigido al público en general que tiene la necesidad de comer algo saludable y que no tiene tiempo de cocinarse en casa. En tal sentido, nuestra empresa se orientará en la estrategia de la Diferenciación, ya que parte del servicio a ofrecer es que contaremos con el servicio profesional de un cocinero especializado, con el fin de asegurar que los platos que ofreceremos serán óptimos para una vida saludable y mantendrán ese sabor que solo se encuentra en casa. Asimismo, nuestro canal de distribución y de recepción de pedidos permitirá un alcance de personalización del servicio. El servicio se ofrece como reparto de comida casera y saludable, por ello nuestro público objetivo son las personas que trabajan y carecen de tiempo para cocinar en casa.

\subsection{Objetivos Estratégicos}

Los objetivos estratégicos de la organización son imprescindibles para el éxito del negocio, así como para el cumplimiento de todos los objetivos internos.

Todos nuestros Objetivos Estratégicos son SMART, puesto que nos ayudarán a definir con exactitud qué es lo que queremos lograr en cada uno, serán medibles y cuantificables, los podremos alcanzar con sustento sin dejar de ser realistas y sobre todo serán propuestos para ser alcanzados en un determinado tiempo.

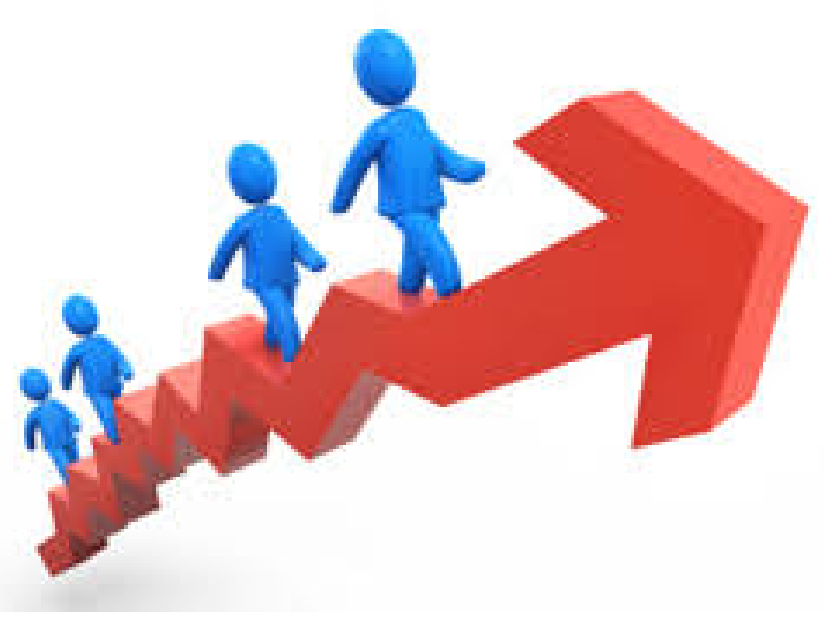


A continuación, se detallan los Objetivos Estratégicos de la empresa:

- Utilizar la administración de las redes sociales al 100\% con el fin de no perder ningún pedido y hacer frente a los posibles competidores que puedan presentarse dentro del primer año de funcionamiento de la empresa.

- Mantener publicidad intensiva en redes sociales para la difusión de la organización, esperando traducir esta difusión en consumos y así alcanzar un $20 \%$ de rentabilidad en el primer año.

- Realizar alianzas estratégicas con los proveedores de insumos renovables cada 12 meses para garantizar y asegurar al 100\% la calidad de los insumos y a la vez mantener el estándar de calidad del producto final.

- Ofrecer la transparencia de nuestros insumos al 100\% para poder generar una cultura de cambio de hábitos para los clientes, generando necesidad y obteniendo, dentro de los primeros 6 meses, el número de clientes necesarios para la rentabilidad esperada en el año.

- Posibilitar el acceso al reconocimiento de la empresa a través de medios masivos tradicionales y digitales para lograr una participación del 5\% en la industria al culminar el segundo año de operación. 


\section{INVESTIGACIÓN / VALIDACIÓN DE MERCADO}

Esta técnica permitirá recoger datos (tendencias, perfiles, gustos de cliente, demanda del producto entre otros) de cualquier aspecto del mercado al cual se va a dirigir el servicio, y cuál es la propuesta de valor (basada en el atributo de valor percibido por los clientes y la ventaja competitiva versus la competencia) es importante validar que la oportunidad de negocio sea viable.

\section{DISEÑO METODOLÓGICO DE LA INVESTIGACIÓN / METODOLOGÍA DE VALIDACIÓN DE HIPÓTESIS}

\section{Problema}

Personas dependientes de 25 a 50 años que por falta de tiempo no se alimentan de la forma saludable ni tampoco se dan el gusto de comer como en casa, sin poder encontrar un producto que ellos esperan comer ni con la presentación que esperan.

\section{Solución}

Proveer a las personas dependientes un producto de calidad, que sea saludable y que tenga el sabor de casa. Para que a su vez puedan cuidar de su salud y poder sentir un sabor claramente casero.

¿Qué se satisface?

Las necesidades de alimentación saludable y de comer como en casa.

¿A quién se satisface?

A personas dependientes de 25 a 50 años que laboran en el distrito de San Isidro.

¿Cómo se satisface? 
Encontrando en un solo lugar lo necesario para cuidar su hábito de alimentación en casa, siendo comida saludable y a su vez entregada a tiempo en la puerta de su oficina con una presentación que atraiga las ganas poder comerlo a gusto y no mezclado.

¿Para qué se satisface?

Para mejorar sus experiencias de compras en almuerzos.

\subsection{Landing Page}

Figura 4. Landing Page

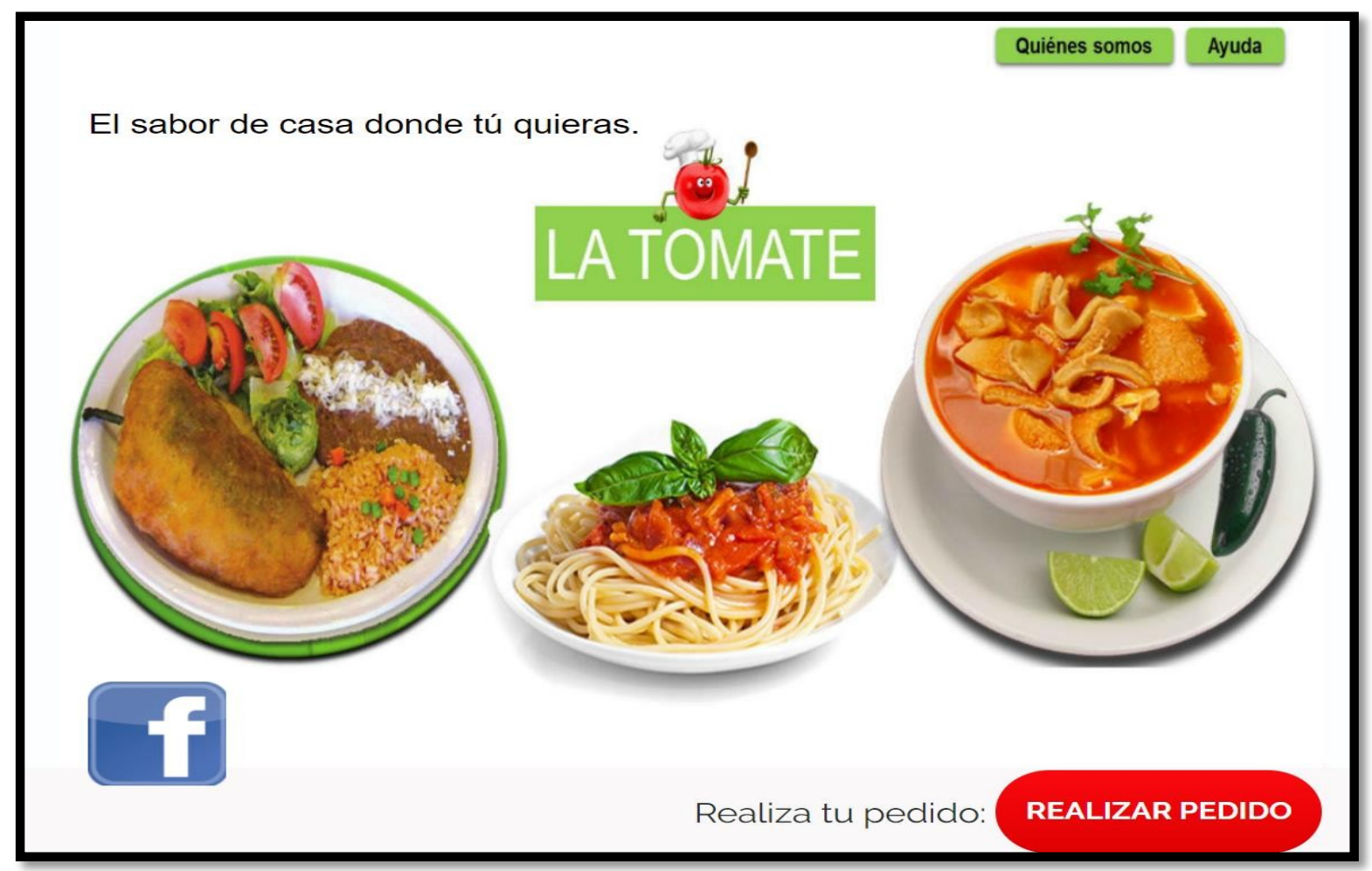

Fuente: Propia 


\subsubsection{Facebook}

Figura 5. Facebook

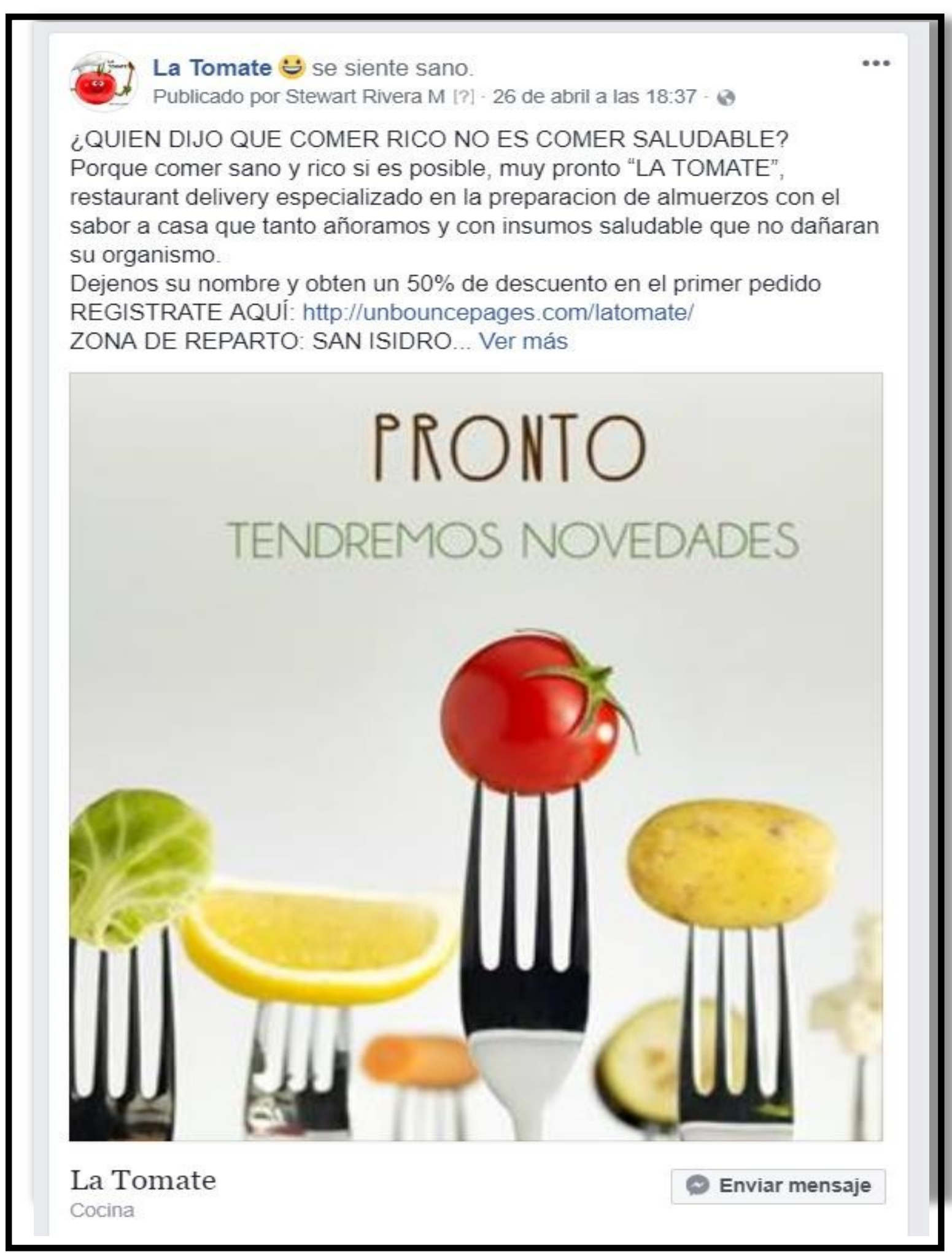

Fuente: Propia 


\subsection{Resultados de la investigación}

\subsubsection{Visitas y Tasas de Conversión FACEBOOK}

Figura 6. Visitas y tasas de conversión facebook

Promociones recientes en La Tomate

La actividad relativa a los anuncios se registra según la zona horaria de tu cuenta publicitaria

+ Crear promoción

if morio

Publicación promocionada

3.328

$\mathrm{S} / 50,00$

¿QUIEN DIJO QUE COMER RICO NO ES CO.

Personas alcanzadas Respuestas a men

Gasto total: $\$ / 50,00$

Promocionada por Stewart Rivera M el 04/26/2

Finalizada

Ver resultados

Resumen de la página Últimos 7 días *

Exportar datos

Resultados del 27 de abril de 2018 al 3 de mayo de 2018

Nota: No se incluyen los datos de hoy. La actividad relativa a las estadísticas se registra según la zona horaria del

Pacifico. La actividad relativa a los anuncios se registra según la zona horaria de tu cuenta publicitaria

Orgánico

Pagado

Acciones en la página

26 de abril - 2 de mayo

5

Acciones totales en la página $\wedge \mathbf{4 0 0} \%$

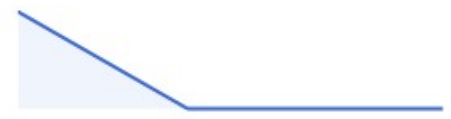

Me gusta de la página

26 de abril - 2 de mayo

23

Me gusta de la página $\triangle 10 \%$

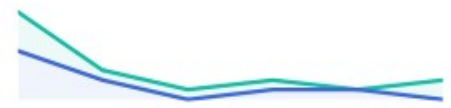

Interacciones con publicaciones

26 de abril - 2 de mayo

174

Interacciones con publicaciones $\boldsymbol{\Delta} 625 \%$

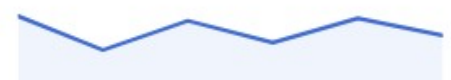

Visitas a la página

26 de abril - 2 de mayo

44

Visitas totales a la página $\mathbf{~} 58 \%$

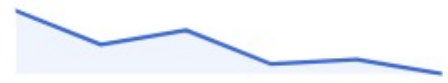

Alcance

26 de abril -2 de mayo

3.117

Personas alcanzadas $\boldsymbol{\Delta} 6.676 \%$

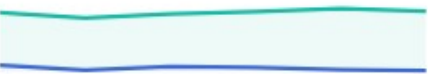

Videos

26 de abril -2 de mayo

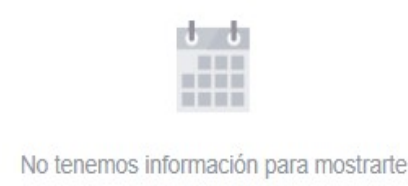
esta semana.
Vistas previas de la página 26 de abril - 2 de mayo

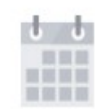

No tenemos información para mostrarte esta semana.

\section{Recomendaciones}

26 de abril - 2 de mayo

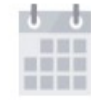

No tenemos información para mostrarte esta semana.

Seguidores de la página 26 de abril - 2 de mayo

24

Seguidores de la página $\mathbf{\wedge} 14 \%$

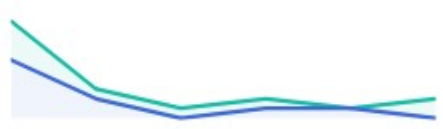

Fuente: Propia 
Con una inversión de S/ 50.00 (Cincuenta con 00/100soles) hemos logrado un alcance de 3,328 personas en un plazo de 7 días calendario. Con dicha inversión se obtuvo una interacción con la Landing page de 44 visitantes.

Dicha publicación fue dirigida a todo Lima metropolitana ya que es de donde asisten a San Isidro a realizar sus labores.

\subsubsection{Métricas de la LANDING PAGE}

Figura 7. Portada LANDING PAGE

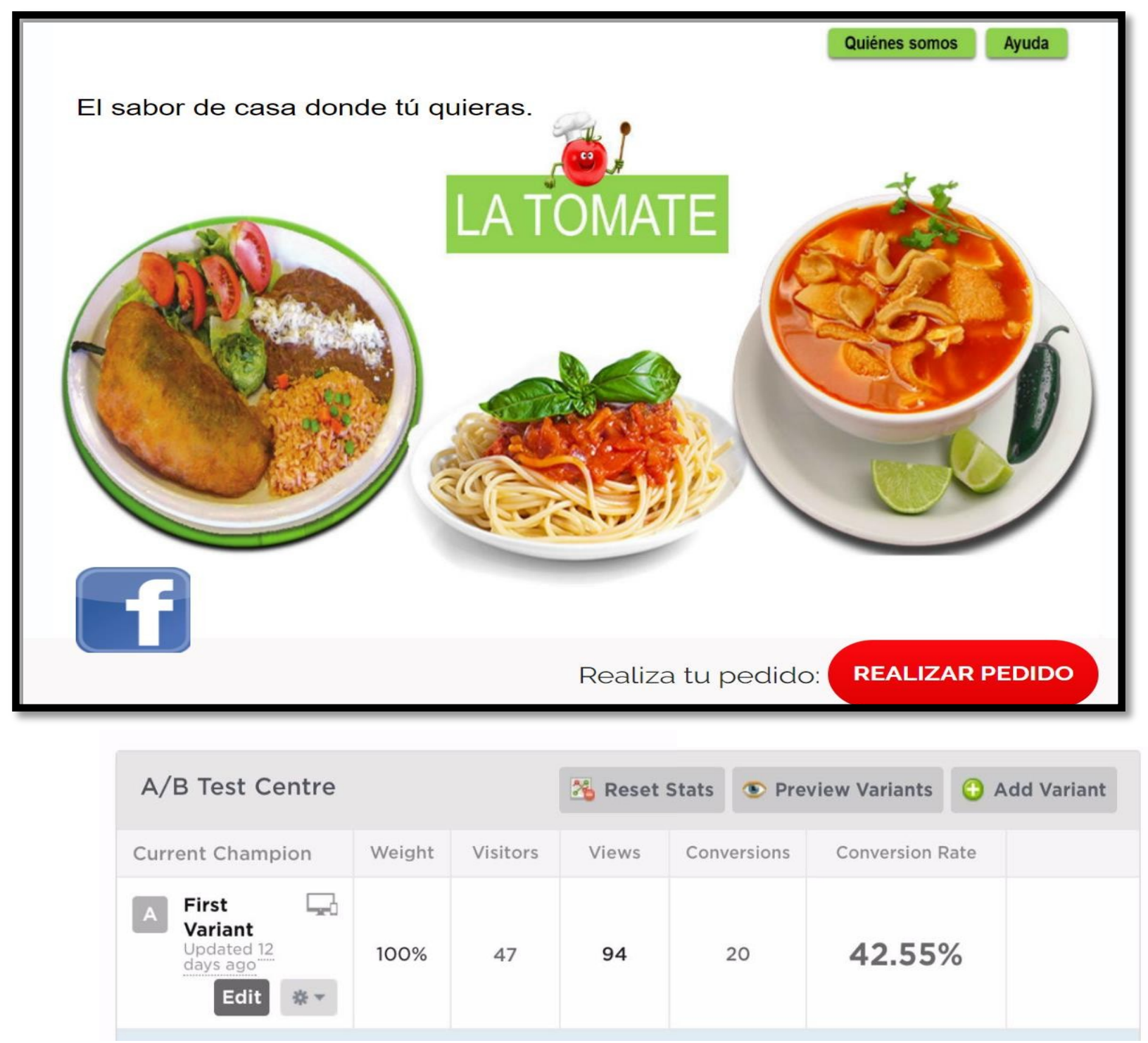

Fuente: Propia 
Nuestra ratio de conversión de visitantes es alta, con un $42.55 \%$ de 47 visitantes nos han dejado sus datos. Evidenciando que tenemos clientes potencialmente interesado en cambiar sus hábitos alimenticios y querer adquirir nuestro producto. Estas visitas están asociadas a la promoción realizada en la FanPage.

Se confirma la existencia de interés y de mercado potencial para nuestra empresa.

\subsubsection{Resultado de la decisión y del aprendizaje de las entrevistas}

Se realizó un resumen general de las 18 entrevistas realizadas, donde las respuestas fueron variadas pero el resultado final era el mismo.

1. ¿Cuál es tu nombre completo?

Nombre del entrevistado

2. ¿Cuál es tu edad?

Rango promedio de edad 25 a 40 años

3. ¿Qué dificultades encuentra para comprar comida con el sabor de casa?

Según el promedio de entrevistados se evidencia que más del 78\% afirma que comprar comida casera y natural en el distrito de SAN ISIDRO es difícil. Por lo general la comida que me venden la tienen como comida criolla, no tiene sabor concentrado que se encuentra en la comida de casa.

4. ¿Cree usted que la comida hecha como en casa, ayudaría a cuidar su salud? ¿Por qué?

Según el promedio de entrevistados se evidencia que el 100\% asegura que la comida preparada en casa es muy saludable, podemos ver cómo la gente que por lo general se cuida trata de prepararla no muy condimentada para que el sabor se agradable y natural.

5. ¿Cuál es el criterio que usa cuando realiza sus compras por internet?

Todos los entrevistado mencionaron que la mejor manera de venta por inter- net es la presentación; todo entra por los ojos; y más en el tema de la comida. Indicaron que muchas veces presentaron inconvenientes con sus cubiertos (rotos, sucios y/o diferentes por el tipo 
de comida) o sus propios tápers (Comida revuelta). También aseguraron que la presentación del producto no es- taba acorde a lo que les llegaba.

6. ¿Qué tipo de comida prefiere usted? ¿Por qué?

- Arroz con pollo (Cocción exacta del pollo y del arroz, la papa a la huancaína con sabor de casa).

- Estofado de pollo/carne (Sabores que resultan de las verduras con la cocción perfecta).

- Tallarines verdes/rojo (Sabor natural de todos los ingredientes).

- Picante de carne

- Pollo al horno

- Ají de gallina

- Puré de papas

7. ¿Es importante para usted adquirir comida casera? ¿Por qué?

Como lo mencionado en la pregunta 4, la comida de casa en mucho más saludable y con mejor sabor, ya que se toma el tiempo necesario para la preparación empleando productos preparados por uno mismo sin emplear persevantes y/o productos industriales (especias embolsadas, aderezos, etc.)

8. ¿En un día familiar prefiere comer en un lugar campestre o cerrado? ¿Por qué?

Prefiero comer en un lugar campestre, al aire libre y juntamente con la familia, donde uno se pueda olvidar un poco del stress diario, sin presiones o tiempos que debas cumplir, por temas de horarios de trabajos o demás.

9. ¿Cuál ha sido su mejor experiencia en la comida?

Las mejores experiencias han sido cuando los productos han estados frescos, la porción de comida servida ha sido generosa y sobre todo cuando te lo has llevado a la boca, sientes ese placer de poder degustar este platillo. 
10. ¿Cuál ha sido su peor experiencia en la comida?

Las malas experiencias representan un número alto obtenido en las entrevistas, sin embargo, una de las malas experiencias en común en más del 50\% de usuarios, refiere a la temperatura de la comida a la hora de empezar a comer. Según los entrevistados, la comida llega fría.

11. ¿Cuáles son sus expectativas cuando va a comer a un restaurant?

La expectativa promedio ( $+50 \%)$, según las entrevistas realizadas se refiere a la percepción de que a los usuarios les sirvan la comida caliente y tenga un sabor agradable bajo en condimentos.

12. ¿Qué espera cuando le ofrecen comida casera?

Según los entrevistados, indican que un factor importante es que la comida se parezca a la comida de casa, es decir, disfrutan de la sensación de cuidado de su salud durante la preparación de la misma.

13. ¿En relación con el precio, ¿cuánto está dispuesto a pagar por comida casera?

Según el promedio de entrevistas realizadas, se evidencia que más del 78\% de entrevistados estaría dispuesto a pagar el predio de s/.12 por la obtención de comida casera.

14. ¿Considera que la temperatura influye en el tipo de comida casera?

El total de entrevistados afirmó que la temperatura representa un factor muy importante hasta la entrega del servicio, sin embargo, un 33\% confirma que este factor no es determinante para el sabor.

15. Considera que la comida casera puede ser: SI o NO ¿Por qué?

- Un $100 \%$ considera que la comida casera es más sana que la que se compra en locales comerciales.

- Un $100 \%$ considera que la comida casera es más nutritiva que la que se compra en locales comerciales. 
- Un 78\% considera que la comida casera es más económica que la que se compra en locales comerciales.

- Un $22 \%$ considera que la comida casera cuenta con más aderezo que la que se compra en locales comerciales.

- Un 78\% considera que la comida casera cuenta con menos aderezo que la que se compra en locales comerciales.

16. ¿Qué experiencias ha tenido utilizando servicios de entrega de comida?

Las experiencias que se ha tenido han sido negativas y desagradables.

Cuando uno pide un almuerzo o algo por delivery se desea que llegue en buenas condiciones, sin embargo pides un arroz con pollo con papa a la huancaína de entrada, en primer lugar el arroz todo revuelto con la cebolla, ocasionando que no la puedas calentar, porque se pierde el sabor y la zarza de cebolla no la puedes poner al microondas, con la entrada sucede algo similar, a veces la crema llega a derramarse y eso te hace que los tapers terminen todos sucios y finalmente termina de ser desagradable almorzar en esas condiciones.

17. ¿Que suele comer entre semanas?

Actualmente por el distrito donde se trabaja; siempre encontramos colas para poder comprar nuestros almuerzos y prefiero comer en los supermercados, pero no es lo mismo recibir la comida servida que no esté expuesta al aire, a la contaminación del ambiente y mientras llego a la mesa ya termino de enfriarse.

Es cierto que en los supermercados la comida es algo agradable, los precios son más o menos altos, pero muy expuestos a la contaminación

\subsection{Informe final: elaboración de tendencias, patrones $y$ conclusiones}

- Luego de realizar la validación del proyecto con la entrevista, Fanpage y Landing page. Hemos detectado que existe un mercado potencial con una aceptación del cliente muy alto por el producto que brindamos. 
- Con el pasar del tiempo con el estudio del proyecto, los potenciales clientes solicitan que se materialice el proyecto para poder cambiar sus hábitos de alimentación en su centro de trabajo.

- Las condiciones del distrito son las mejores, ya que presenta un crecimiento del 3\% en edificios corporativos en lo que va del 2018

- El negocio cuenta con una clara estacionalidad, la cual se deberá tomar muy en cuenta a la hora de ofrecer los tipos de comida y poder mantener al cliente potencial

- Actualmente no existen negocios en lima que brinda el servicio. Todos los existentes son derivados a la idea de negocio presentada. 


\section{PLAN DE MARKETING}

Nuestro plan de marketing consta de una estructura base donde detallamos los esfuerzos a realizar, se realizarán mediante una publicidad para poder tener llegada a nuestros potenciales clientes y fidelizar a los actuales. Analizaremos nuestro entorno, publico objetivo, situación actual y los principales valores del servicio.

El fin de este plan es identificar las estrategias con las que podremos lograr el posicionamiento y conocer a nuestro mercado donde nos desarrollaremos.

\subsection{Planteamiento de Objetivos de Marketing}

\subsubsection{Objetivo General}

El objetivo general es, sin duda, posicionar La Tomate como la primera opción de comida sana y con sabor de casa, para esto debemos ofrecer entregas puntuales con el fin de tener un número de clientes satisfechos y que con- fien en nosotros quienes con el tiempo nos servirán de motor para expandir el negocio a través de sus buenas experiencias.

\subsubsection{Objetivos Específicos}

- Los objetivos específicos, están alineados con el fin de penetrar el mercado del centro financiero de San Isidro como una alternativa nueva en sabor. Nuestra organización debe alentar el uso de nuestro servicio, con el fin de, en un futuro, lograr la creación de una APP que nos permita agilizar los pedidos y reducir costos. Asimismo, dentro de los objetivos específicos, tenemos el mejorar la imagen de la marca a través de una potente estrategia de marketing a través de las redes sociales.

- Generamos una estrategia de promoción para presentar a nuestra empresa y sus respectivas promociones con el fin de captar a más clientes. 


\subsection{Estrategias de Marketing}

\subsubsection{Segmentación}

Los criterios que se utilizarán para tener claro el segmento al que La Tomate atacará fueron, geográficos, demográficos y sociales/económicos.

Una vez realizada la segmentación del mercado total y teniendo claro cuál sería nuestro mercado objetivo, se aplicará una estrategia de delimitación para obtener un nicho de mercado que son las personas que trabajan en el distrito de San Isidro.

Cuadro 1. Criterios de Segmentación

\begin{tabular}{|c|c|}
\hline \multicolumn{2}{|l|}{ Demográficos } \\
\hline Edad & 25-50 años \\
\hline Género & Masculino y Femenino \\
\hline Ciclo de Vida & Joven, Soltero, casado, viudo, divorciado \\
\hline Tipos de Negocio & $\begin{array}{l}\text { Micro, Pequeña, Mediana empresa, gran empresa y } \\
\text { corporaciones }\end{array}$ \\
\hline Geográficos & Perú \\
\hline Región & Lima/San Isidro \\
\hline Socioeconómicos & - \\
\hline Nivel de ingresos & $>1000$ soles \\
\hline Ocupación & Indiferente \\
\hline Grado de instrucción & Indiferente \\
\hline
\end{tabular}

Fuente: Propia

\subsubsection{Posicionamiento}

La Tomate busca ser reconocida como una gran opción gastronómica con el sabor de casa siempre de manera saludable y con un servicio de calidad impecable. Para lograr esto, hay que tener en cuenta que debemos mantener ciertos márgenes que no deben fallar en el proceso como el movimiento activo en redes digitales y la puntualidad de nuestras entregas. 


\subsection{Mercado objetivo}

Este proyecto está dirigido a hombres y mujeres que trabajan en una zona específica de San Isidro. Aquí podemos ofrecer nuestros servicios tanto a las propias empresas como a empleados que buscan todos en común ese sabor casero y sano en una forma fácil de consumir y que llega a la puerta de sus oficinas.

\subsubsection{Tamaño de mercado}

San Isidro es uno de los principales distritos financieros de Lima, donde la población habitante se reduce cada año, pero la población trabajadora aumenta constantemente mediante la creación nuevas oficias y ampliación de las mismas. Este último dato, favorece a nuestro modelo de negocio y significa una gran ven- taja para nuestra expansión. Con esto podemos concluir que nuestra empresa cuenta con un gran mercado potencial listo para ser explotado.

Cuadro 2. Número de Habitantes

\begin{tabular}{|c|c|c|c|}
\hline Descripción & 1981 & 1993 & 2015 \\
\hline Habitantes & 72,132 & 63,004 & 58,056 \\
\hline
\end{tabular}

Fuente: INEI Perú - Censos

Teniendo una variación del $12.65 \%$ cada 10 años aproximadamente, indicando que cada vez crece las empresas y las oficinas de estas. Llegando a tener más potencial de mercado. 
Figura 8. Proyección de la población de San Isidro: 2000-2015

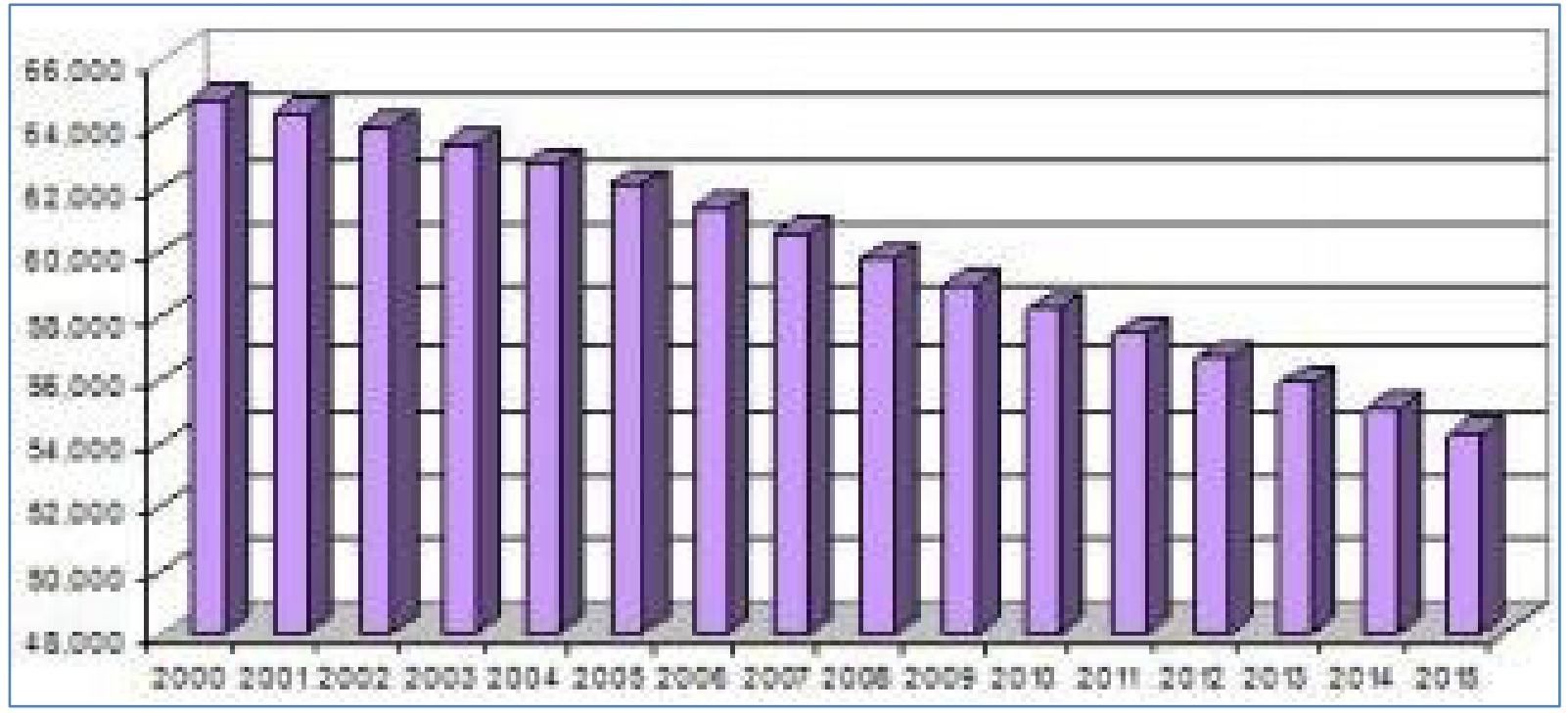

Fuente: Estimaciones y Proyecciones de Población Estimaciones y proyecciones de la Población 2000, 2015INEI

\subsubsection{Tamaño de mercado disponible}

San Isidro es uno de los principales distritos que concentra gran número de población en lo que a empleados se refiere, lo cual claramente nos deja ver que existen varios mercados donde se ofrece menú facilitando un servicio similar al nuestro, sin embargo, se ha comprobado que, en el rubro gastronómico, las personas siempre elegirán una comida rica, sana y variada, en formato casero y mucho mejor si es práctico a la hora de consumir. Lo que nos deja con un mercado en crecimiento y disponible para penetrarlo. 
Cuadro 3. San Isidro: Población económicamente activa estimada de 6 años y más ocupada total, local y flotante según número de empresas o establecimientos. Año: 1993-2008-2012.

\begin{tabular}{|c|c|c|c|c|c|c|c|c|}
\hline \multirow{2}{*}{$\begin{array}{c}\text { CONDICION DE } \\
\text { ACTIVIDAD }\end{array}$} & \multicolumn{2}{|c|}{1.993} & \multicolumn{2}{c|}{2000} & \multicolumn{2}{c|}{2008} & \multicolumn{2}{c|}{2012} \\
\cline { 2 - 9 } & ABSOL. & $\%$ & ABSOL. & $\%$ & ABSOL. & $\%$ & ABSOL. & $\%$ \\
\hline $\begin{array}{r}\text { NUMERO DE } \\
\text { EMPRESAS }\end{array}$ & 3.851 & & 4.037 & & 4303 & & 4442 & \\
$\begin{array}{r}\text { POB. ECONOM. } \\
\text { ACTIVA OCUPADA }\end{array}$ & 97.036 & 100 & 99.826 & 100 & 152.391 & 100 & 188.285 & 100 \\
$\begin{array}{r}\text { PEA OCUPADA } \\
\text { SAN ISIDRO }\end{array}$ & 28.886 & 29.8 & 28.353 & 28,4 & 26.242 & 17.2 & 25.246 & 13.4 \\
$\begin{array}{r}\text { PEA. OCUPADA } \\
\text { FLOTANTE }\end{array}$ & 68.150 & 70.2 & 71.473 & 71.6 & 126.149 & 82.8 & 163.039 & 86.6 \\
\hline
\end{tabular}

Fuente: Resultados Definitivos de los Censos de Población y Vivienda 1981 y 1993/ INEI. Censos Nacionales 2007: XI de Población y VI de Vivienda/INE Censo Económico 1993/INEI IV Censo Nacional Económico 2008 /INEI Elaboración: Proyección del Equipo encargado del Plan Urbano

En conclusión, nuestro tamaño de mercado disponible está en función a la PEA ocupada del distrito de San Isidro, teniendo una minina variación entre años del $-1 \%$, además de mostrar una proyección para el 2018 de 23,840 personas (PEA ocupada)

\subsubsection{Tamaño de mercado operativo (target)}

Cuadro 4. Tamaño de mercado operativo (Target)

\begin{tabular}{|l|c|c|c|c|}
\cline { 2 - 5 } \multicolumn{1}{c|}{} & 1993 & 2000 & 2008 & 2012 \\
\hline Pea FLOTANTE & 68,150 & 71,473 & 126,149 & 163,039 \\
\hline Variación periodo & & $5 \%$ & $76 \%$ & $29 \%$ \\
\hline
\end{tabular}

\begin{tabular}{|l|c|}
\hline Promedio crecimiento anual & $8.44 \%$ \\
\hline Crecimiento al año 2018 (proyec) & 273123 \\
\hline
\end{tabular}

Fuente: Propia

Basándonos en el uso de solamente la PEA ocupada flotante, tenemos un total de 273,123 personas dependiente que trabajan en San Isidro, siendo este nuestro mercado operativo. 


\subsubsection{Potencial de crecimiento del mercado}

En la actualidad, el distrito de San isidro es el mercado empresarial por excelencia y cada vez más gente trabaja en dicho distrito, según reportes demográficos este crecimiento será sostenible y constante durante los próximos años por lo que esto representa un efecto positivo en nuestro negocio con el fin de poder captar más clientes en este mercado existente. Estimando un crecimiento del sector de delivery de comida en un $30 \%$.

Figura 9. Margen de crecimiento de consumo

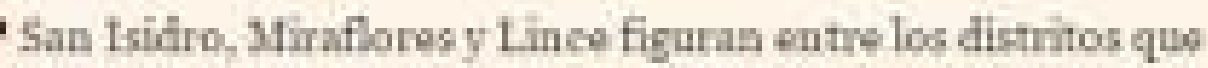
mats erecieros on los podsdos de dolinery do comide salndihle por Internet, segú lecompania I inabelivery:

Lodico que wn agosto ha registrado el myor crecimiento, on

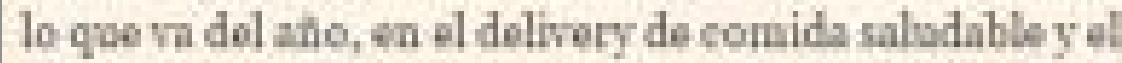

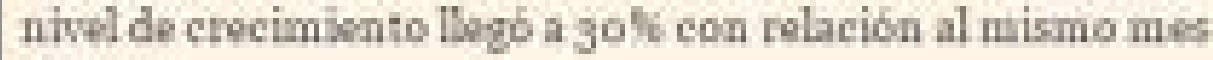
del pos5:

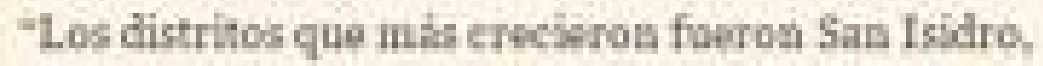
Aliratloren, Lince, La Molinn, Surquillos debido a la movor contidhd de resturantes que se apenturin y qua brindon el sorvicio de delwwry, in dieo santiago Antinez da Mayolo, gurente goneril de LimaDelirory.

Expleo que ha cheoriade comida saludible to estacional

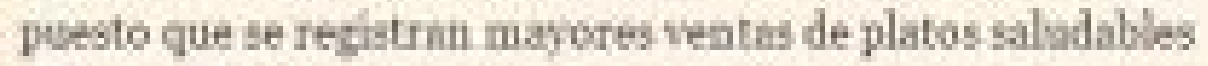
en verano. "Siri embargo, esto se wa equilibraindo al pasar de los mests seiflo

Asimismo, prectso que las ensalindas coo pollo a la planchay Jugos aos lat opcones mits demand das y el theket promedio de esta calegoria alcatiza el valor de $5 f=0$

Fuente: GESTIÓN 


\subsection{Desarrollo y estrategia del marketing mix}

\subsubsection{Estrategia de producto / servicio}

La Tomate se dedicará no solo a la distribución, sino también a la preparación, la venta y la entrega del producto teniendo como radio de distribución la zona de San Isidro.

- Insumos: La empresa contará con proveedores certificados para garantizar que los productos comprados sean frescos y de la mejor calidad.

- Preparación: Tendremos cocineros y ayudantes que serán encargados de la adecuada preparación de las comidas.

- Envase: Para la distribución de los alimentos, contaremos con tapers blancos descartables de tecnopor, cubiertos descartables, botella tapa sellada original para el refresco y servilletas.

- Forma de Pedidos: Los pedidos se realizarán a través de WhatsApp, Facebook, Email y en un futro App La Tomate.

- El cliente podrá contactar con nosotros y solicitar nuestros servicios no solo todos los días, sino también podrán hacer pedidos semanales y mensuales con el fin de satisfacer y ayudar a las personas que no tienen tiempo para realizar esta operación todos los días.

- La comida será entregada todos los días en envases correctamente diseñados para que llegue en buen estado sin mezclarse ni perderse ese orden necesario para la presentación, asimismo, los envases mantendrán la temperatura de los alimentos. Esto tendrá implicancia en los motorizados que se encargarán de distribuir los alimentos a tiempo.

- La Tomate, distribuirá sus pedidos a través de motorizados. La empresa recibirá los pedidos hasta las 10 de la mañana y luego se repartirán por zonas. Esta in- formación será transparente para el personal motorizado con el fin de que también puedan hacer sus rutas y llegar a tiempo a los locales donde se han realiza- do los pedidos.

\subsubsection{Características de la distribución:}

- Los pedidos se reciben hasta las 10:00a.m./ Después de esta hora no se aceptan pedidos

- Personal calificado 
- Horario de entrega de 12:00 à 1:30 pm

- Ruta diseñada para tiempos óptimos de entrega

\subsubsection{Diseño de producto / servicio}

Nuestro producto será almuerzos saludables con sabor a casa, siendo diferentes recetas entre nacionales e internacionales, los cuales serán presentados en presentaciones ordenadas y no combinadas además de ser envases biodegradables. Siendo uno de nuestros valores agregados, ya que la comida primero entra por los ojos.

Figura 10. Presentación de menu

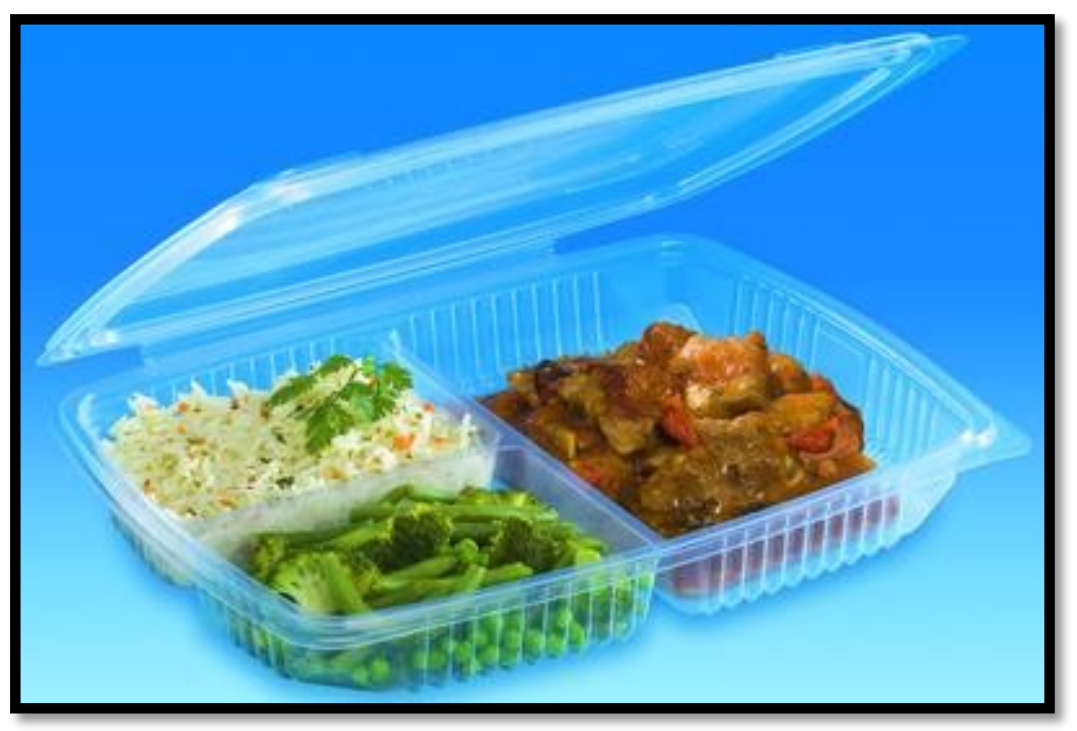

Fuente: Propia

Y el servicio adicional será la distribución en el momento que cada cliente lo solicite, teniendo ubicación temporal estratégica con un auto en una parte central del distrito, siendo el punto de encuentro de cada repartidor para que no estén regresando a la cocina base.

\subsubsection{Estrategia de precios (Análisis de costos, precios de mercado)}

Mantendremos precios estándar con referencia a la competencia puesto que los consumidores ya tienen una idea de estos precios presupuestada en sus mentes y en sus salarios. Para esto, 
tenemos en cuenta que los insumos podremos conseguirlos a menor precio si los compramos al por mayor. Tenemos en cuenta también que los negocios gastronómicos por lo general aportan un $50 \%$ de utilidad y lo hemos tenido en cuenta a la hora de fijar los precios previamente descritos. Es importante mencionar que La Tomate ingresará al mercado con un servicio diferenciado que no solo ofrecerá comida saludable y en la puerta de cada oficina, sino que también se convertirá en una app amigable que ahorrará tiempo a mu- chas personas. La organización tiene en cuenta que el ingreso a un mercado ya existente no es sencillo, es por eso que nos apoyaremos en cuanto al tema de precios, en promociones por introducción para incentivar el uso de nuestros servicios, algunas de las promociones ya las hemos mencionado anteriormente.

Siendo nuestro precio referencial del almuerzo que estaría conformado por, entrada (Sopa o ensalada fresca), plato de fondo, postre y refresco, un costo de $\mathrm{S} / 13$ precio venta al público.

Siguiendo esta misma tendencia de costos, presentamos precios de venta para adicionales al pedido:

- Menú 15.00 Soles

- Dieta 15.00 Soles

- Adicional Arroz 3.50 soles*

- Adicional Sopa 5.00 Soles*

- Adicional Bebida 1.00 Soles*

- Solo Segundo 8.00 Soles*

*Precio mínimo para el pedido $\mathrm{S} / 15$ soles.

\subsubsection{Estrategia Comunicacional}

Utilizaremos los siguientes recursos para intentar que la comunicación llegue donde queremos:

- Fan Page en Facebook

- Perfil en Twitter

- Cuenta en Instagram 
- WhatsApp

- Página Web

Realizaremos publicidad que se dirija no sólo a la zona de san isidro sino a distritos alejados puesto que tenemos en cuenta que, si bien es cierto, nuestro mercado está en San Isidro, la gente que trabaja en San Isidro viene, por lo general, de lejos por lo que nuestra comunicación tiene que llegar a todos

Venta Personal, será una manera de crear relación directa con los clientes, aprovecharemos y mantendremos una buena relación con los clientes para que nos promocionen con potenciales clientes.

Es muy importante mencionar que la lealtad de los clientes es imprescindible para el crecimiento acelerado de nuestro negocio, por lo que realizaremos actividades de seguimiento, post venta para asegurarnos que van a seguir consumiendo nuestro producto.

\subsubsection{Promoción y Publicidad}

La Tomate iniciará con un sistema de calidad que apuntará a la difusión de la organización a través de un boca a boca que refiere a experiencias positivas por parte de los clientes. Contaremos con una amplia estrategia de marketing a través de redes sociales con el fin de promocionar nuestro modelo de negocio y sus características.

En un futuro, se piensa contar con un APP, donde los usuarios podrán registrarse, elegir el menú del día, horarios, etcétera. Es importante tener en cuenta que esta app no tiene costo adicional para ser descargada.

\subsubsection{Estrategia de distribución}

La distribución que vamos a realizar es a través de motorizados propios de la empresa, los clientes van a consumir el producto preparado directamente de sabor de casa y distribuidos por nuestra propia flota de motorizados. Nuestro servicio garantizará la entrega puntual y ordenada de los productos con el fin de con- seguir fidelidad entre los clientes. La toma del pedido se 
realizará hasta las 10:00 am, para asegurar que el servicio llegue en el rango de hora establecido, las cartas de menú serán siempre actualizadas diariamente

La forma de pago inicialmente será en efectivo contra entrega, posteriormente se evaluará la posibilidad de contar con un P.O.S. inalámbrico para que nuestros clientes puedan usar sus tarjetas.

Figura 11. Mapa de procesos de pago
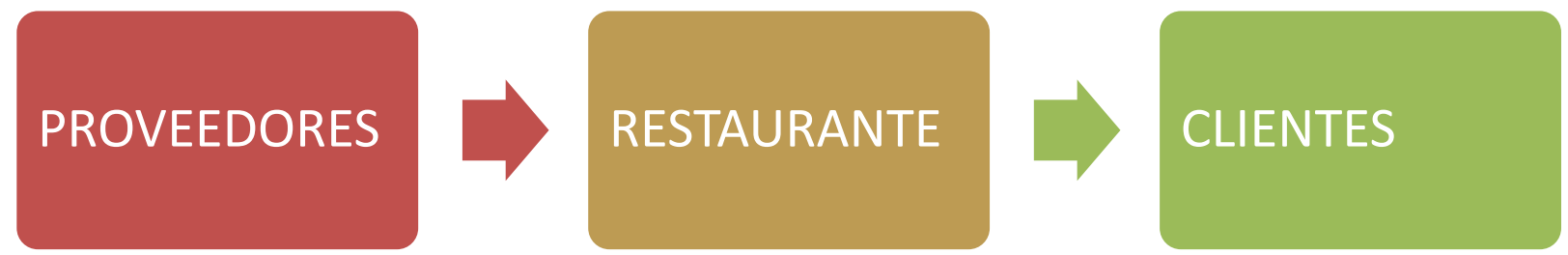

Fuente: Propia

\subsection{Plan de ventas y proyección de la demanda}

El plan de ventas inicial será el ingreso a un mercado existente con un precio acorde al mismo. Según nuestros estudios de investigación, podemos ver que en la zona se encuentran lugares que ofrecen comida desde $\mathrm{S} / 10.00$ hasta los $\mathrm{S} / 40.00$ por lo que creemos que nuestros precios son realmente competitivos (S/. 15 el menú) y atractivos para la venta. Para el primer año tenemos planeado crecer en un $20 \%$ en lo que a ventas se refiere.

La empresa se ha proyectado para realizar la venta aproximada de 900 platos semanales, el monto de la venta semanal es $\mathrm{S} / 13,500.00$ y al mes tenemos el monto de S/ 54,000.00 como venta total.

**Es importante mencionar que en el mes de diciembre las ventas pueden bajar porque la mayoría de las empresas realizan sus reuniones y fiestas en locales y el consumo de refrigerio en las oficinas baja su porcentaje. 


\subsection{Presupuesto de Marketing}

La Tomate es una empresa innovadora y nueva en el mercado que a través de una inversión espera atraer crecimiento y posicionamiento en el lapso de 365 días.

Los recursos que nos ayudarán a lograr esta meta serán:

- Contacto telefónico y digital. Herramientas obligatorias para la realización de nuestro proyecto. El pago de estas herramientas es mensual.

- Facebook. Se considera invertir S/ 200.00 al año en publicidad en Facebook. Con esta acción más personas interactuarán y conocerán de nuestra empresa. Es cierto que un like no es sinónimo de una venta, pero también es cierto que nos acerca al cliente y que el cliente podrá usar estas vías para realizar sus pedidos.

- Encuestas online. Haremos un pago anual en herramientas conocidas para realizar encuestas online con el fin de conocer la satisfacción del cliente. Esto re- presenta un pago anual.

- Merchandising. Lapiceros, Post-it con el logo de la empresa, así como imágenes especiales en fechas determinadas a la hora de entregar los pedidos serán parte del merchandising que utilizaremos para mantenernos en la mente del cliente.

- Volantes/Tarjetas de Presentación. Entregaremos volantes y tarjetas de presentación en cada sitio en que nos encontremos. Tenemos una distribución de impresión de estos materiales para ser realizada dos veces al año.

- Logos en los vehículos. Las motos tendrán nuestro logo por lo que eso también supone un costo adicional aproximado de 500 soles.

- APP (proyección futura). El costo de esta APP es de S/. 800.00 anuales.

Por lo tanto, tenemos que, para el primer año de la empresa, nuestro presupuesto en marketing es de $\mathrm{S} / 6,538.00$. 
Cuadro 5. Presupuesto de marketing

\begin{tabular}{|l|r|r|r|r|r|r|r|r|}
\cline { 2 - 9 } & APP & Facebook & $\begin{array}{c}\text { Volantes + } \\
\text { Tarjetas }\end{array}$ & $\begin{array}{c}\text { Teléfono } \\
\text { Internet }\end{array}$ & $\begin{array}{c}\text { Survey } \\
\text { Monkey }\end{array}$ & Merchand. & Brandeados & Total \\
\hline Enero & & & & 100.00 & & & 120.00 & $\mathbf{2 2 0 . 0 0}$ \\
\hline Febrero & & & & 100.00 & & & & 100.00 \\
\hline Marzo & 800.00 & 50.00 & & 100.00 & 749.00 & & & $\mathbf{1 , 6 9 9 . 0 0}$ \\
\hline Abril & & & 210.00 & 49.00 & & $1,200.00$ & & $1,459.00$ \\
\hline Mayo & & & & 100.00 & & 200.00 & 120.00 & $\mathbf{4 2 0 . 0 0}$ \\
\hline Junio & & 50.00 & & 100.00 & & 200.00 & & $\mathbf{3 5 0 . 0 0}$ \\
\hline Julio & & & & 100.00 & & & & 100.00 \\
\hline Agosto & & & 140.00 & 100.00 & & & & $\mathbf{2 4 0 . 0 0}$ \\
\hline Setiembre & & 50.00 & & 100.00 & & & 120.00 & $\mathbf{2 7 0 . 0 0}$ \\
\hline Octubre & & & & 100.00 & & & & 100.00 \\
\hline Noviembre & & & 210.00 & 100.00 & & $1,000.00$ & & $1,310.00$ \\
\hline Diciembre & & 50.00 & & 100.00 & & & 120.00 & $\mathbf{2 7 0 . 0 0}$ \\
\hline TOTAL & $\mathbf{8 0 0 . 0 0}$ & $\mathbf{2 0 0 . 0 0}$ & $\mathbf{5 6 0 . 0 0}$ & $\mathbf{1 , 1 4 9 . 0 0}$ & $\mathbf{7 4 9 . 0 0}$ & $\mathbf{2 , 6 0 0 . 0 0}$ & $\mathbf{4 8 0 . 0 0}$ & $\mathbf{6 , 5 3 8 . 0 0}$ \\
\hline
\end{tabular}

Fuente: Propia 


\section{PLAN DE OPERACIONES}

\subsection{Políticas Operacionales}

La política de La Tomate se ha desarrollado con la finalidad de alcanzar los objetivos estratégicos.

Manejar un buen nivel de comunicación entre las áreas de tal manera que conozcan toda la información de los clientes sobre todo saber si las entregas fueron hechas en los tiempos establecidos,

Alcanzar la mejor satisfacción de los clientes con la entrega de sus pedidos Menú a la hora solicitada, ya que es para una hora determinada de refrigerio con los empaques correctos que permita una entrega de calidad y buena presentación, para los consumidores.

Alcanzar un margen de ventas, así como un buen control siendo esta el área más importante que nos permite alimentar de información a todas las áreas de la empresa. Asimismo, saber cuánto es el insumo utilizado por los platillos preparados y vendidos. Por otro lado, poder medir en las entregas, la cantidad vendida, el número de reclamos generados de ser el caso, tardanzas, devoluciones.

\subsubsection{Calidad}

Para LA TOMATE el cliente es la primera razón de ser en el servicio que ofrecemos, el cual debe estar orientado a satisfacer sus necesidades y gustos.

No debemos olvidar que la calidad de nuestro servicio es un esquema donde cada parte del proceso y cada uno de nosotros contribuyen a la satisfacción del cliente, obteniendo un recuerdo agradable del sabor y calidad del servicio.

Por lo mencionado, LA TOMATE plantea un sistema de gestión de la calidad adecuado a las normativas vigentes y en ello asentamos los siguientes puntos: 


\section{Calidad de despacho.}

- Satisfacción del cliente: cumplir y satisfacer los requisitos de nuestros clientes, siendo estos el activo fundamental de la empresa.

- No conformidad: tratamiento y seguimiento en este tipo de incidencias para conseguir la mayor satisfacción de nuestros clientes. Se creará

\section{Calidad de insumos.}

- Calidad de materias primas: escoger y seleccionar muy bien los insumos a utilizar.

- Productividad: Capacitación que deben tener nuestros colaboradores, para ofrecer productos de calidad utilizando los recursos que pose La Tomate.

\section{Calidad de procesos.}

- Compra: En el caso de las carnes se realizará compras cada dos a tres días de acuerdo a la rotación, de este modo se mantendrá en las temperaturas necesarias para la conservación.

- Prevención de la contaminación: Gestionan correctamente el uso de utensilio e ingredientes para evitar contaminación.

- Integridad personal, como expresión de disciplina, orden, respeto, honestidad y compañerismo.

- Mejora continua, buscar en todos nuestros procesos que los equipos de trabajo y el capital humano, tengan una producción flexible y capaz de adecuarse a todos los requerimientos solicitados.

Estas estrategias proporcionarán un marco de referencia para el establecimiento de los objetivos que sean necesarios para asegurar la gestión de la calidad en LA TOMATE, y la mejora continua del sistema y sus procesos.

\subsubsection{Procesos}

Entre los procesos más importantes podemos encontrar los siguientes:

\section{Proceso operativo}

- Solicitar su pedido en el aplicativo Facebook, se ingresara los menús semanales para que los clientes puedan solicitar sus pedidos. 
- Carga Facebook para solicitar su pedido deberá revisar la carta de la semana y solicitar su pedido por interno el mismo día hora 10:00 am.

- Conformidad: una vez solicitado su pedido se le enviara un mensaje o correo de conformidad.

\section{Proceso de apoyo}

- Soporte técnico ante inconvenientes que se puedan presentar con el aplicativo.

- Indicadores que nos presentaran la cantidad de pedidos solicitados y la variedad solicitada.

- Con el menú ya preparado se pasa al tapert con el requerimiento del cliente.

- Serán enviados por los motorizados los mismos que ya tienen su mapa de ruta

\section{Proceso de Preparación}

- Asegurarse que el preparado de cada platillo tenga los ingredientes adecuados y la cocción correcta.

- Proceso de despacho. El presente final (como llegan los alimentos al cliente) y la reducción de tiempos de proceso de despacho y delivery, nos permite, permitiendo fidelizar a nuestros clientes.

\section{Proceso de proveedores}

- Se realizará una selección basada en Calidad, Solvencia financiera, Plazos, Precios, Certificación entre otros.

- Logística Externa. Ofrecer un buen servicio al cliente cumpliendo con la entrega de sus platillos solicitados y en el tiempo ofrecido.

\section{Marketing y Ventas}

- Se desarrollará en el proceso de captación del cliente al momento que el cliente ingresa a la página a solicitar su pedido.

- Servicio al cliente: Es un punto clave para superar la brecha de crecimiento y posicionamiento en la mente de nuestros clientes y futuros clientes. Área de distribución y ventas: Nos permite brindar a nuestros clientes calidad en los platillos desde que se les toma el pedido hasta la misma entrega en los tiempos acordados.

\section{Identificación:}


- Desarrollamos lineamientos necesarios de relación de pertenecía entre los colaboradores y La Tomate, haciendo posible que desarrollemos un servicio de alta calidad.

\section{Evaluación de aplicación:}

- Aplicación debe ser muy intuitiva, y fácil en su uso.

- Eficiencia en la evaluación post venta.

\section{Evaluación en el servicio}

- Tiempo de entrega

- Calidad atención al cliente

- Recomendaría nuestro servicio a sus amistades.

\subsubsection{Planificación}

La planificación es el punto más importante para el éxito de La Tomate, ya que permite organizar cada uno de los procesos como:

- Se realizará una planificación de 3 meses en el desarrollo y puesta en marcha del proyecto, la cual inicia con la investigación de mercado, creación de fan page, ingreso a las redes sociales para promocionar y tener un primer alcance en la segmentación de supuestos clientes.

- La búsqueda de proveedores, el personal de reparto con movilidad propia (motorizados), que permitan remodelar su unidad a la necesidad de la empresa.

- Planificamos las entregas de los pedidos medido por indicadores, tanto de entrega como entregas a tiempo, que nos permita la mejora continua.

- Compra de insumos requeridos para el preparado de cada platillo, es decir la compra entre perecibles y no perecibles, son diferenciados ya que cada uno de ellos tiene un tiempo de duración diferente, por lo que para presentar el sabor de casa y fresco debe estar pauteado por fechas de acuerdo con los primeros pedidos. Posteriormente se debe comprar de acuerdo con el stock obtenido. 
Figura 12. Cuadro de días de compra

\begin{tabular}{|c|c|c|c|c|c|c|c|c|c|c|c|c|c|c|c|c|c|c|c|c|c|c|c|c|c|c|c|c|c|c|}
\hline \multirow{2}{*}{ Detalle } & \multicolumn{30}{|c|}{ Dias de compra } \\
\hline & 1 & 2 & 3 & 4 & 5 & 6 & 7 & 8 & 9 & 10 & 11 & 12 & 13 & 14 & 15 & \begin{tabular}{l|l}
16 \\
\end{tabular} & 17 & 18 & 19 & 20 & 21 & 22 & 23 & 24 & 25 & \begin{tabular}{l|l}
26 & 2 \\
\end{tabular} & 27 & 28 & 293 & 30 \\
\hline Carnes & & & & & & & & & & & & & & & & & & & & & & & & & & & 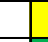 & & & \\
\hline Menestras & & & & & & & & & & & & & & & & & & & & & & & & & & & & & & \\
\hline Arroz & & & & & & & & & & & & & & & & & & & & & & & & & & & & & & \\
\hline Verduras & & & & & & & & & & & & & & & & & & & & & & & & & & & & & & \\
\hline Otros no perecibles & & & & & & & & & & & & & & & & & & & & & & & & & & & & & & \\
\hline
\end{tabular}

Fuente: Propia

\subsubsection{Inventarios}

La política de inventario que manejará La Tomate será en base a los productos perecibles y no perecibles por lo que seleccionamos una rotación constante.

Los productos perecibles con el paso del tiempo son más fáciles de degradarse, van perdiendo sus propiedades nutricionales, ya que se descomponen por agentes como la temperatura por lo que hemos creamos políticas de refrigerado $5^{\circ} \mathrm{C}$ o menos para alimentos congelados como la carne, el pollo, el pescado entre otros los cuales se deben refrigerar con una temperatura diferente $\left(18^{\circ} \mathrm{C}\right)$ con este procedimiento podemos mantener frescos para su preparación y presentación.

Los no perecibles en el tiempo de conservación son poco probables su deterioro se trabajará con la fecha de vencimiento, así como la rotación constante de abastecimiento, por lo menos cada 4 meses se dará su rotación para mantener una frescura muy cercana y la calidad. Asimismo, la conservación será en lugar seco que permita su conservación en buen estado.

\subsection{Diseño de Instalaciones}

Contaremos con una oficina que servirá como registro legal de dirección y que será nuestro centro de operaciones, puesto que ahí tendremos los siguientes espacios correctamente distribuidos:

- Sala para atención de clientes y proveedores

- Cocina

- SS.HH. 
El centro de operaciones se encontrará en Lince, distrito que se encuentra perfectamente posicionado para el mercado sobre el que nos vamos a posicionar, San Isidro.

\subsubsection{Localización de las instalaciones}

La Tomate cuenta con un centro de operaciones alquilado, el cual se encuentra ubicado en el distrito de Lince, límite con San Isidro, en la Calle Tomás Guido 39 en las afueras del mercado Lobatón.

Entre los distritos estudiados, se escogió Lince debido a la cercanía contra el distrito en el que vamos a operar, la zona comercial en la que se encuentra que facilitará la compra de insumos en caso de emergencia y asimismo por que el costo de alquiler se encuentra por debajo, con respecto a los distritos que colindan con San Isidro y que serían aplicables para nuestros negocios.

El costo de alquiler mensual será de S/.1800.

Los criterios utilizados para la elección de la localización son los siguientes:

Cuadro 6. Análisis para la localización

\begin{tabular}{|c|c|c|c|c|c|c|c|}
\hline \multirow{3}{*}{ Criterios } & \multirow{3}{*}{ PESO \% } & \multicolumn{6}{|c|}{ Distritos } \\
\hline & & \multicolumn{2}{|c|}{ Lince } & \multicolumn{2}{|c|}{ Jesus María } & \multicolumn{2}{|c|}{ La Victoria } \\
\hline & & Puntuación & Ponderado & Puntuación & Ponderado & Puntuación & Ponderado \\
\hline Costo de alquiler & $40 \%$ & 7 & 2.8 & 7 & 2.8 & 7 & 2.8 \\
\hline Cercanía a Proveedores & $10 \%$ & 7 & 0.7 & 7 & 0.7 & 8 & 0.8 \\
\hline Cercanía a Clientes & $30 \%$ & 8 & 2.4 & 6 & 1.8 & 6 & 1.8 \\
\hline Seguridad & $10 \%$ & 7 & 0.7 & 8 & 0.8 & 6 & 0.6 \\
\hline Tráfico & $10 \%$ & 8 & 0.8 & 6 & 0.6 & 7 & 0.7 \\
\hline & & & 7.4 & & 6.7 & & 6.7 \\
\hline
\end{tabular}

Fuente: Propia 
Figura 13. Mapa del Centro de Operaciones de La Tomate:

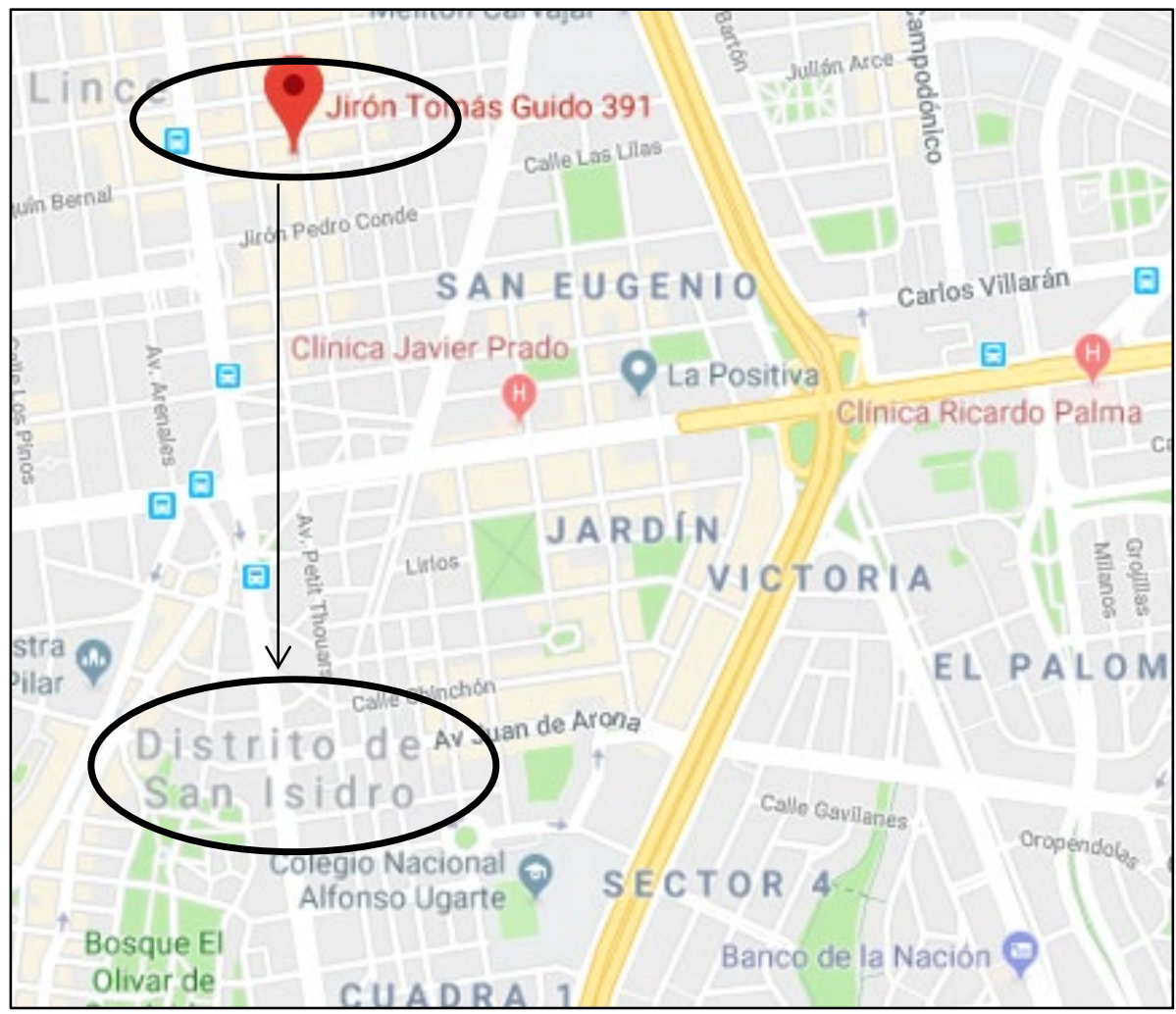

Fuente: Google maps

\subsubsection{Capacidad de las instalaciones}

Las instalaciones de La Tomate serán el centro de operaciones con capacidad de albergar a 6 empleados de manera cómoda quienes cumplirán funciones administrativas y de operaciones. Entre las actividades a realizar por el personal se pueden mencionar.

- Actividades administrativas

- Reuniones con el equipo

- Producción de los alimentos

- Preparación para el reparto

El personal motorizado no está contemplado dentro de la capacidad de las instalaciones puesto que estos almacenarán sus motos fuera de las instalaciones de la empresa y solo entrarán para el momento en el que se dispongan a realizar el reparto. 
La capacidad instalada de La Tomate se mide en base a la cantidad de servicios que podemos atender diariamente vs el tiempo que tenemos para la producción de los platos que vamos a ofrecer.

El local cuenta con $60 \mathrm{~m}^{2}$ correctamente distribuidos con el fin de que sean aprovechados estratégicamente para tener la mayor posibilidad y espacio posible dentro de las instalaciones y que se permita realizar la producción y distribución del producto sin problemas.

Para graficar la capacidad instalada hemos considerado lo siguiente:

- Horario de atención para la producción: 6-12 am: 360 minutos

- Tipo de platos que se cocinen al día: 3 menú +1 dieta (opcional)

- Promedio de número de pedidos diarios: 114

- Cada cocinero puede realizar un plato en 90 minutos.

- Tiempo promedio total requerido para la producción: 270 minutos

Proyectamos que cada personal puede realizar la preparación de un plato en 90 minutos, por lo que requerimos de 3 personas para realizar dicha acción en 270 minutos, quedando 90 minutos para realizar el armado y sacar a reparto los productos.

Según la proyección de la demanda, inicialmente contaremos con 568 pedidos a la semana, pero esto puede ir aumentando, de todos modos, se tendrán en cuenta los números previamente descritos en caso de que sean necesarios contratar más personas para el área de operaciones.

Asimismo, para calcular la capacidad correcta de los equipos, como, por ejemplo, las cámaras frías o refrigeradoras, se utilizó una fórmula basada en comensales de un restaurante.

Cuadro 7. Capacidad instalada del local

\begin{tabular}{|l|c|c|c|}
\hline Cámaras de materias primas & $\begin{array}{c}\text { Hasta } 100 \\
\text { comensales }\end{array}$ & $\begin{array}{c}\text { Entre } 100 \mathrm{y} 300 \\
\text { comensales }\end{array}$ & $\begin{array}{c}\text { Más de } 300 \\
\text { comensales }\end{array}$ \\
\hline Por cada 10 comensales & $0,8 \mathrm{~m}^{2}$ & $0,7 \mathrm{~m}^{2}$ & $0,6 \mathrm{~m}^{2}$ \\
\hline
\end{tabular}

Fuente: Propia 
En nuestro caso, hemos trabajado, basándonos en la proyección de la demanda con una media de 100 platos diarios, podemos usar el factor de $0,8 \mathrm{~m} 2$ por cada 10 comensales. Aplicando ello a 100 comensales, estimamos el área de las cámaras en frío, como sigue: $0,8 \mathrm{~m} 2 \times 10=8$ m2. A la hora de elegir el equipamiento de conservación frigorífica en estos pequeños restaurantes, podemos optar por cámaras o armarios frigoríficos.

Los $60 \mathrm{~m}^{2}$ con los que cuenta nuestro centro de operaciones, garantizarán que todos los equipos se encuentren correctamente ubicados y en correspondencia con el personal para que se pueda trabajar de manera rápida y eficiente sin perder los estándares de calidad. Adicionalmente este espacio nos permitirá hacerle frente a un posible aumento en la proyección de la demanda hacia distritos aledaños.

\subsubsection{Distribución de las instalaciones}

El local de La Tomate tiene $60 \mathrm{~m}^{2}$ distribuidos en:

- Sala para atención de clientes y/o procesos logísticos (proveedores)

- Cocina

- SS.HH

- Sala para atención de clientes y/o procesos logísticos proveedores): En esta sala se llevará a cabo el control de los pedidos diarios y se tomará nota de la contabilidad del negocio.

Figura 14. Mapa de local

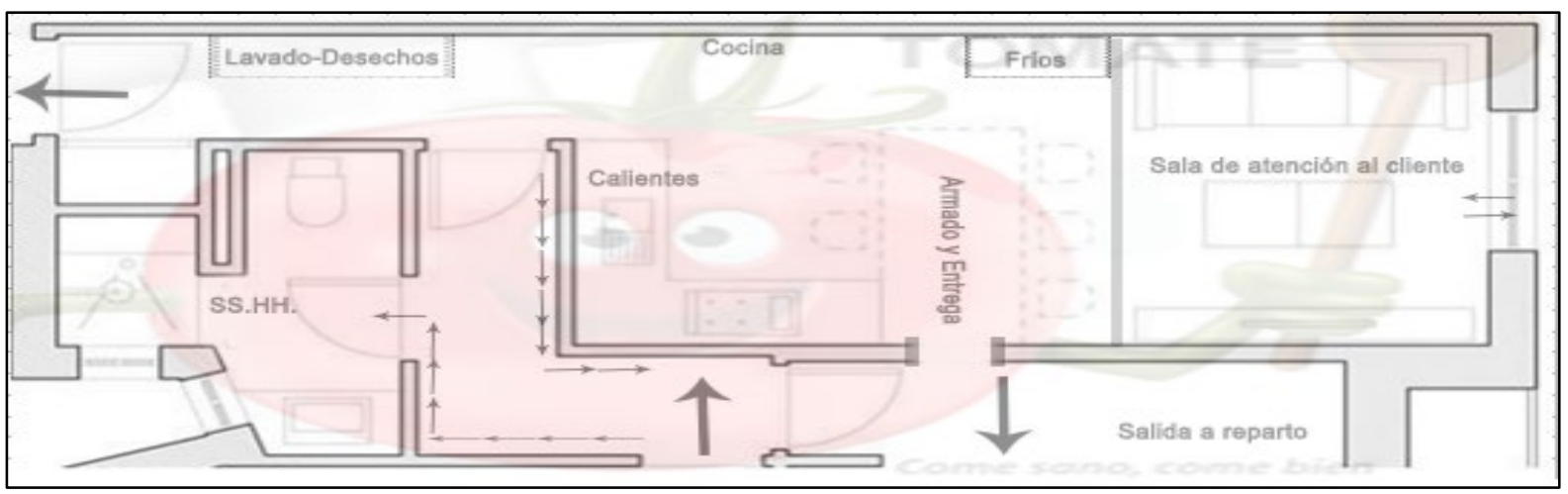

Fuente: Propia 
Este despacho está equipado con:

- 1 computadora de escritorio

- 1 teléfono móvil

- 1 impresora,

- 3 mesas pequeñas

- 1 mesa rectangular (Escritorio)

- 2 sillas

En esta área se encontrará la directiva a cargo quien tendrá a su disposición la laptop y el Administrador del local quien usará la computadora de escritorio.

Figura 15. Estructura de oficina

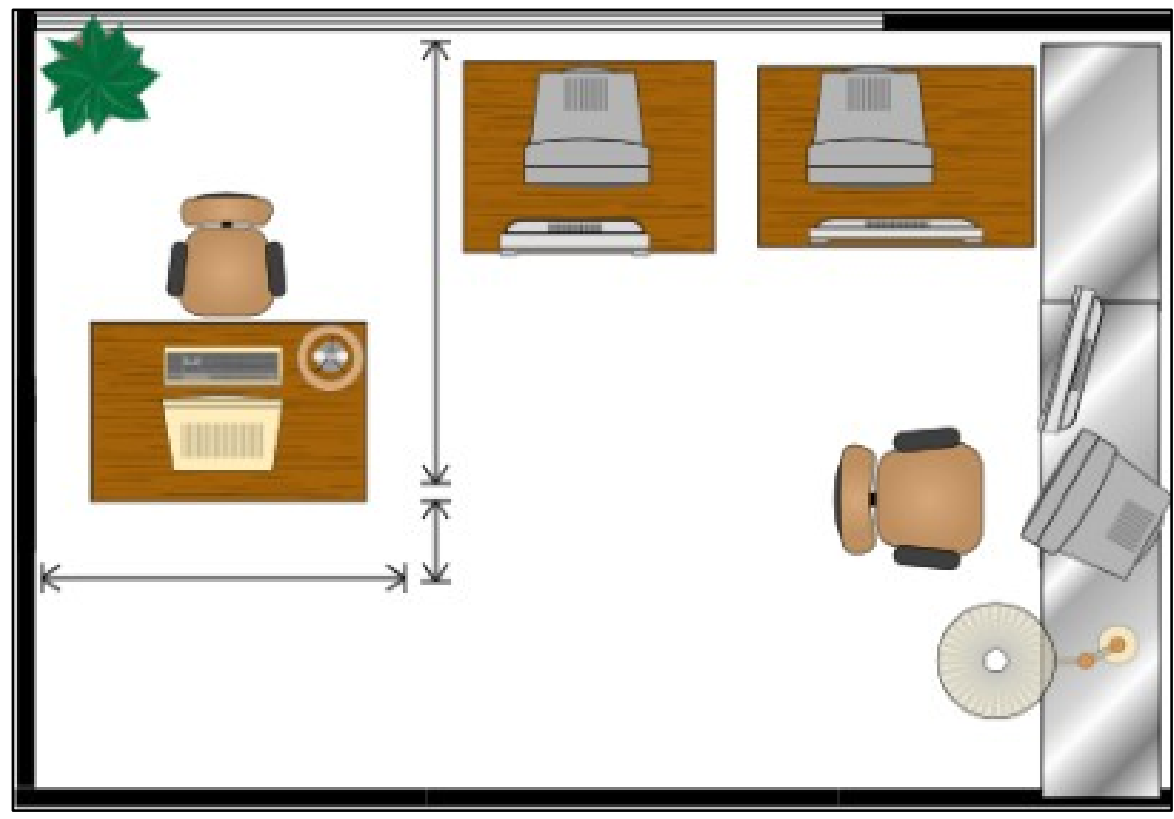

Fuente: Propia

- Cocina: La cocina es el centro de operaciones de La Tomate y por lo tanto es el área principal del negocio. Esta cocina estará equipada con:

Zona de preparación de fríos: Se preparan los insumos que no pasan por una zona de cocción o que utilizarán ingredientes previamente trabajados y que formarán parte del os platos fríos. 
Se contará con un sistema de ida y vuelta con una distancia entre mesas de aproximadamente 1,2 con el fin de permitir el trabajo de dos a tres personas que serán las que estarán directamente en dicho espacio.

Esta área contará con:

- Mesas frías

- Estantes

- Elementos para corte y troceado

- Cubetas refrigeradas para el almacenamiento

- Lavamanos

- Refrigeradora

Zona de preparaciones previas: Se efectuará la preparación y troceo de los ingredientes que serán posteriormente cocinados. Esta zona estará equipada con:

- Mesas de trabajo abiertas y cerradas

- Estantes y fregaderos

- Tablas para realizar cortes

- Equipo de soporte con cortadoras y elementos de corte tradicionales.

Zona de cocción: El área de cocción contiene una máquina de absorción de gases, también llamado extractora y un horno mixto. En la parte inferior de los hornos se almacenarán las ollas y sartenes. En nuestro caso, el área de cocción estará conformada por:

- Equipo de cocina con cuatro quemadores

- Mediana plancha de asado

- Cocedor de pastas

- Cubículo para las frituras, freidora

- Zona de baño maría

- Equipo horno mixto que servirá como almacén de las ollas y sartenes 
Figura 16. Zona de cocina

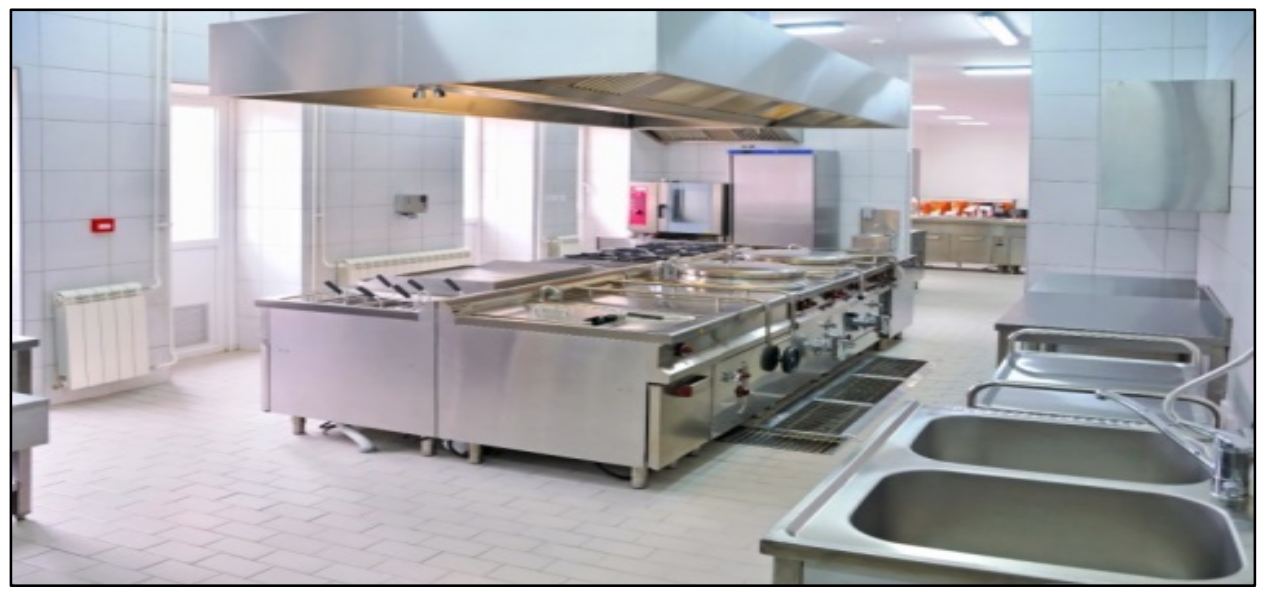

Fuente: Propia

Zona de armado y entrega: En esta zona se realizará el armado de los productos listos para ser entregados. Esta zona de lado de la puerta de ingreso de personal de reparto para facilitar la salida de los productos. Esta zona estará equipada con:

- Microondas

- Una mesa central para ubicar los platos, armarlos y que sean recogidos por el personal de reparto.

Figura 17. Zona de preparación

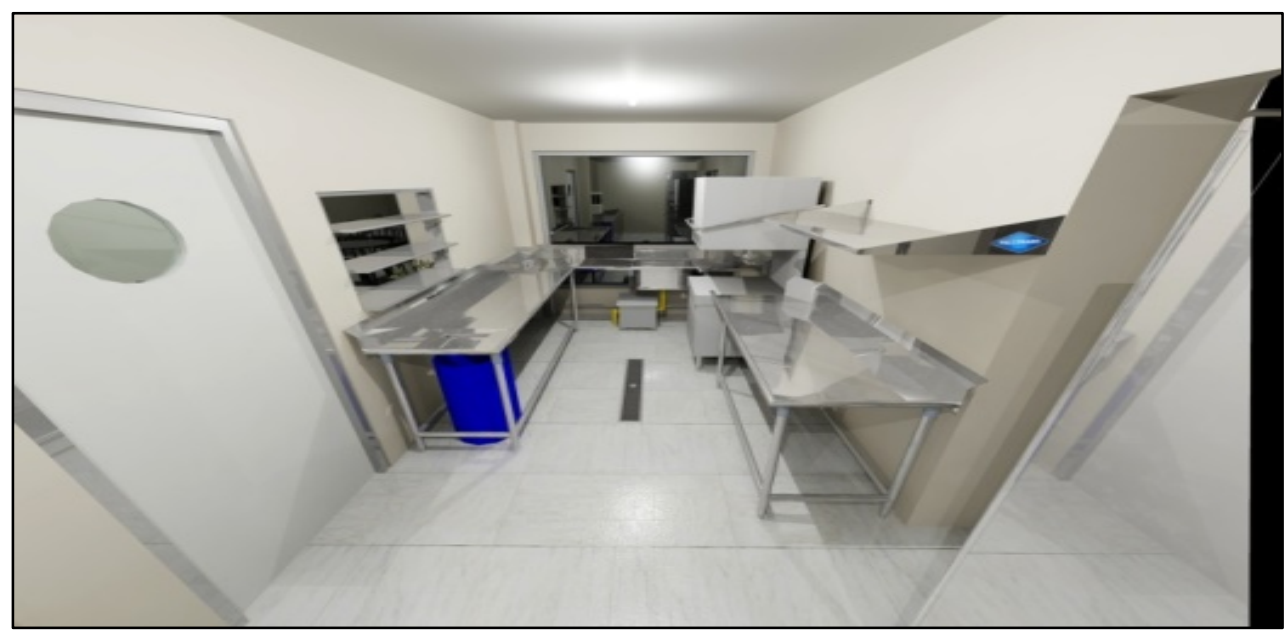

Fuente: Propia 
Zona de limpieza: En esta zona se recibe la vajilla sucia, se almacenan los restos de comida en un tacho de basura, se realiza el lavado en un fregadero amplio que nos permitirá lavar las ollas, utensilios de cocina, etcétera. El equipamiento de esta zona estará conformado por:

- Estantes para ubicar la vajilla sucia

- Fregadero para el lavado de las ollas

- Tacho de basura

- SS.HH: Para damas y caballeros. Será de uso exclusivo del personal interno de la organización y personal de delivery. No incluye por el momento público en general.

Los SS.HH. contarán con:

- 1 lavadero

- 1 inodoro

Y estará correctamente implementado con todos lo necesario para que se mantenga limpio y en correcto estado de funcionamiento para garantizar que el personal se encuentre cómodo y correctamente limpio.

Figura 18. Zona de limpieza

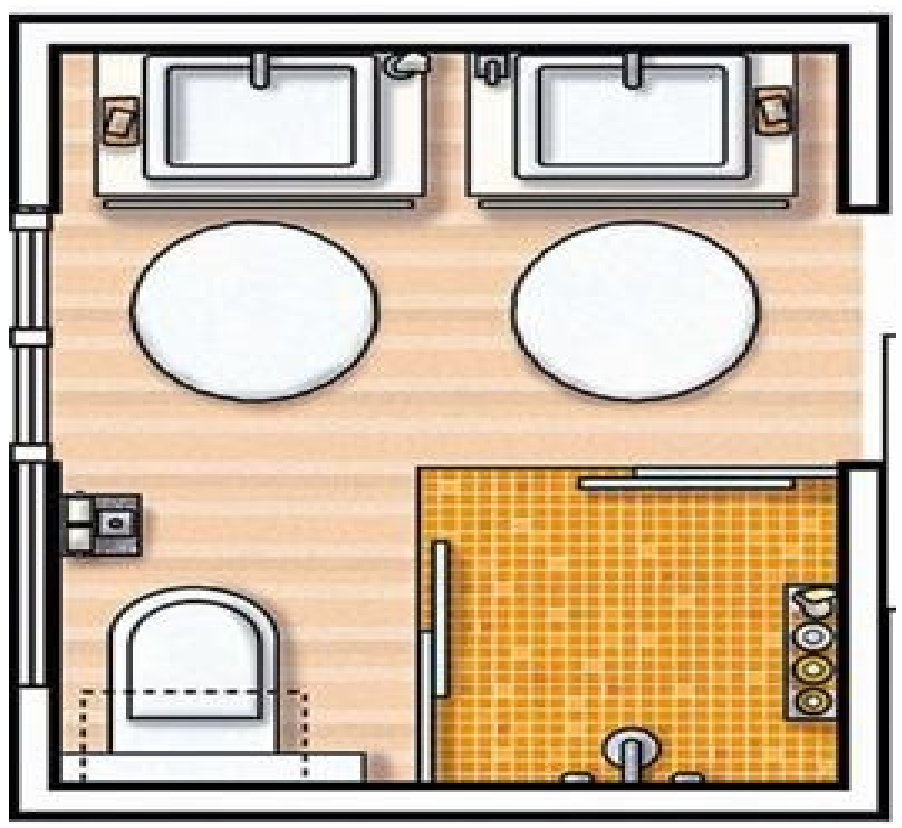

Fuente: Propia 


\subsection{Especificaciones Técnicas del Producto / Servicio}

La especificación técnica de los productos es básicamente un registro interno que contiene información básica, en esta ficha se recoge los datos claves para la prepa- ración de los almuerzos.

A continuación, detallamos un ejemplo:

Figura 19. Cuadro de calorias
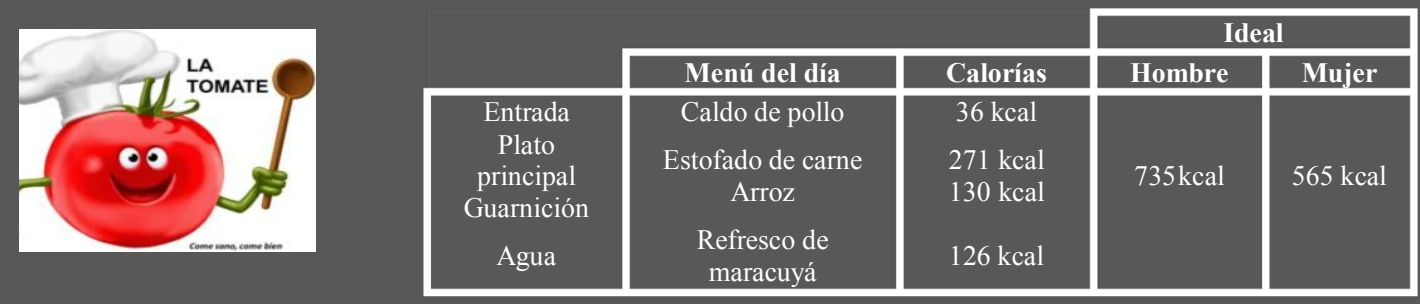

Fuente: Propia

Y se adjunta la ficha técnica del menú

Cuadro 8. Ficha técnica

\begin{tabular}{|c|c|}
\hline Nombre del producto & Sopa de pollo \\
\hline Descripción del producto & Caldo de pollo, con fideos, verduras y pollo \\
\hline Ingredientes & Agua, sal, verduras, pollo, condimentos (orégano, kion) \\
\hline Características sensoriales & $\begin{array}{ll}\text { Color } & \text { : Amarillo } \\
\text { Olor } & : \text { Agradable } \\
\text { Sabor } & : \text { Bueno / Rico } \\
\text { Textura } & \text { : Liquido }\end{array}$ \\
\hline Preparación & $\begin{array}{l}\text { Limpiar el pollo y dejarlo sin piel, cortarlo en trozos pequeños. } \\
\text { Lavar, pelar y cortar los vegetales. } \\
\text { En una olla hervir agua, luego verter las verduras previamente } \\
\text { cortadas, junto con el kion y sal al gusto, cuando este a medio } \\
\text { cocinar se echara los trozos de pollo y la papas cortadas en }\end{array}$ \\
\hline
\end{tabular}




\begin{tabular}{|c|c|}
\hline & $\begin{array}{l}\text { cuadrados pequeños, una vez que este cocinados tos los } \\
\text { ingredientes mencionados, se pondrán los fideos y el orégano., }\end{array}$ \\
\hline Nombre del producto & Estofado de carne \\
\hline Descripción del producto & Guiso de carne, con verduras y papas \\
\hline Ingredientes & $\begin{array}{l}\text { Carne, papas, hongos y laurel, tomate, zanahoria, arverjitas, } \\
\text { cebolla, ajos, sal y pimienta al gusto }\end{array}$ \\
\hline Características sensoriales & $\begin{array}{ll}\text { Color } & \text { : Rojizo / Anaranjado } \\
\text { Olor } & : \text { Agradable } \\
\text { Sabor } & : \text { Bueno / Rico } \\
\text { Textura } & \text { : Especial }\end{array}$ \\
\hline Preparación & $\begin{array}{l}\text { Limpiar la carne y cortarlo en trozos grandes. Lavar, pelar y } \\
\text { cortar los vegetales, la cebolla será cortada en cuadraditos } \\
\text { pequeños para el aderezo. } \\
\text { En una olla poner aceite a calentar, luego poner ajos y la } \\
\text { cebolla, dorar los mismos y pones unas hojitas de laurel y } \\
\text { agregar hongos, luego de mezclar pondremos las alverjitas y } \\
\text { zanahorias, después se incorporará el tomate picado en cuadros } \\
\text { pequeños, se mezclara todo y se pondrá la carne trozada, a tres } \\
\text { cuartos de cocinar la carne se pondrá las papas picadas, por } \\
\text { ultimo al bajar la cocción se echara dos cucharadas de vino tinto } \\
\text { y se roseará azúcar rubia. }\end{array}$ \\
\hline Nombre del producto & Arroz / guarnición \\
\hline Descripción del producto & Arroz blanco cocido \\
\hline Características sensoriales & $\begin{array}{ll}\text { Color } & : \text { Blanco } \\
\text { Olor } & : \text { Agradable } \\
\text { Sabor } & : \text { Bueno / Rico } \\
\text { Textura } & : \text { Graneado / Entero }\end{array}$ \\
\hline Ingredientes & Arroz, agua, sal, aceite y ajos \\
\hline Preparación & $\begin{array}{l}\text { Lavar el arroz, poner en la olla arrocera la misma medida de } \\
\text { agua y arroz, sal, ajos y aceite al gusto. }\end{array}$ \\
\hline Vida útil del producto & Solo para ser consumido en el día \\
\hline
\end{tabular}

Fuente: Propia 


\subsection{Mapa de Procesos y PERT}

Figura 20. Diagrama - Red Pert (Plato de arroz con pollo)

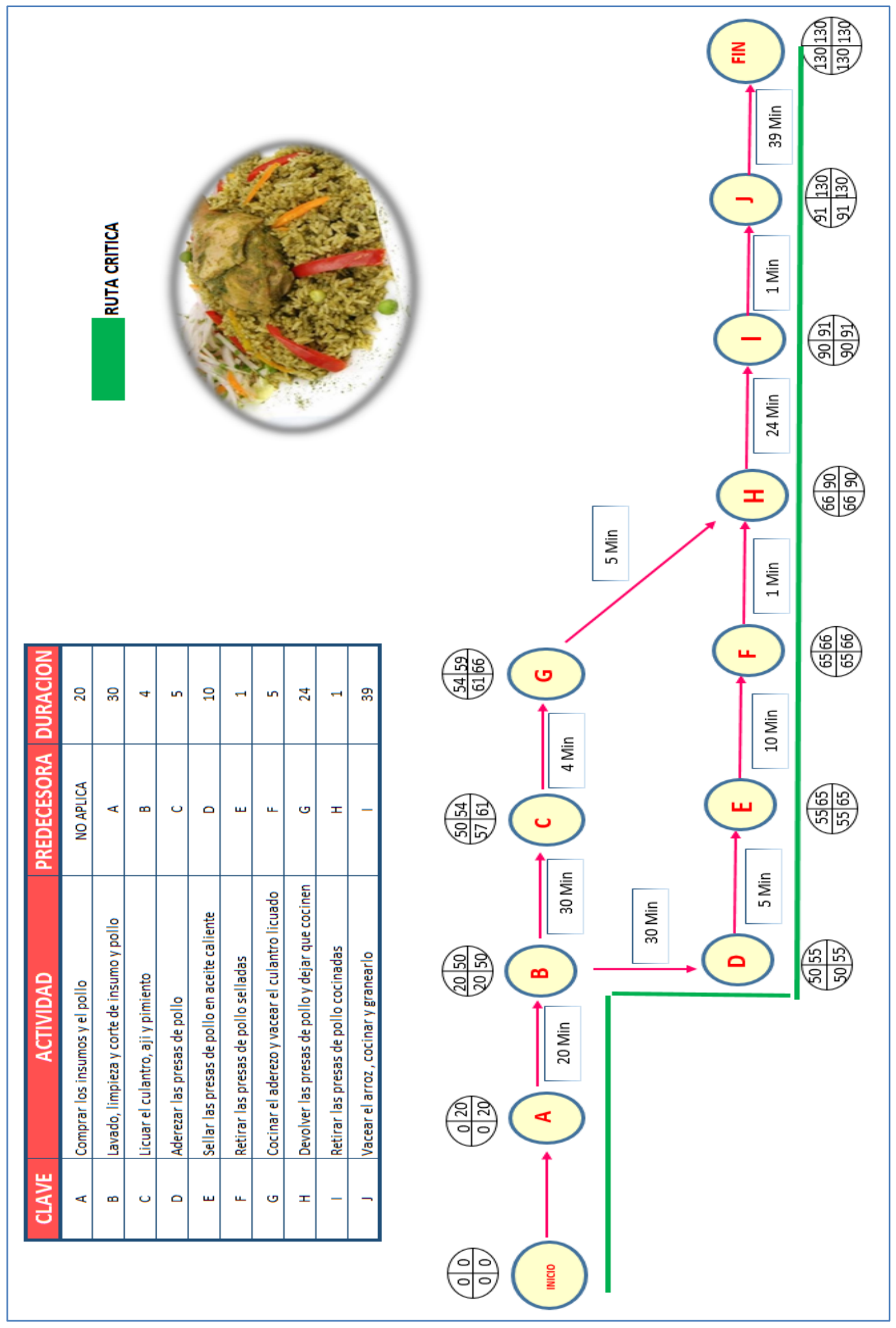

Fuente: Propia 
Figura 21. Actividades del Pert - plato arroz con pollo

Actividad (E)

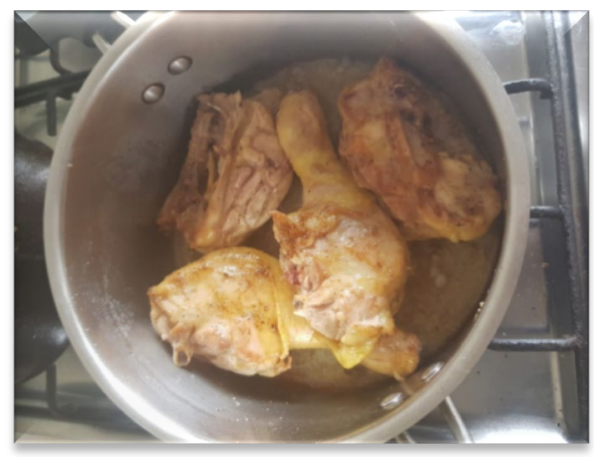

Actividad (A)

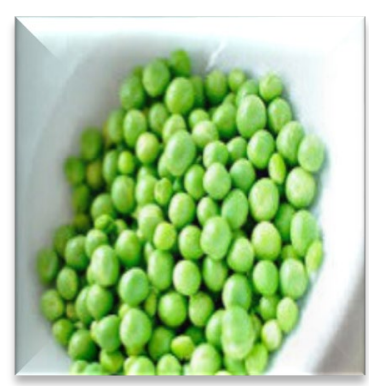

Actividad (B)

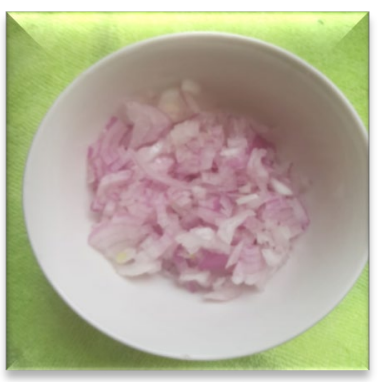

Actividad (G)

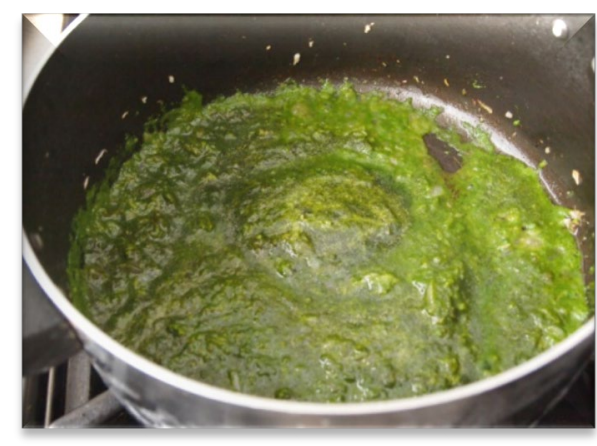

Actividad (J)

Este análisis nos permitirá conocer al detalle los tiempos que se necesitará para la preparación de nuestros platos, además para toda comida hay muchos pasos que se repiten, como el lavado y corte de insumos, por citar un ejemplo.

A su vez con esta herramienta identificaremos los tiempos y momentos que vamos a necesitar para llegar a tiempo en el reparto de los menús, tomando en cuenta que nuestra ventana horaria es aproximadamente de dos horas y la puntualidad será uno de los puntos determinantes para el éxito de LA TOMATE.

Por último, con esta información y la capacidad instalada podremos obtener los números de platos a producir. 


\subsection{Planeamiento de la Producción}

La Tomate, logrará el objetivo de satisfacer la demanda de sus clientes, en cantidad, calidad y precio, pero sobre todo optimizando los recursos de la materia prima, los insumos, materiales, factor humano, equipos e instalaciones, procurando así el crecimiento de la actividad de la empresa a través de la organización de su producción.

La planificación de una compañía empieza por el FORCAST de ventas, será imprescindible tener un volumen de ventas que cumplir, para obtener una rentabilidad esperada.

Paralelamente es indispensable tener la proyección de ventas (anual y mensual), el mismo que se tiene que aterrizar en un PDC, este plan de demanda consensuado se basará en programar reuniones donde se da a conocer los números y proyecciones del área de ventas, con el fin de saber si se puede llegar a producir la cantidad de menús que se espera, y/o saber que necesidades debemos cubrir para poder llegar a ese número objetivo.

El área de planeamiento y producción, conocido también como PCP es el corazón del área de producción, para esto el personal a cargo debe tener en cuenta lo siguiente:

- Registrar diariamente el consumo de productos, al menos de los 06 primeros meses.

- Se deberá omitir el mayor y menor consumo que haya existido, con el fin de evitar que afecte el cálculo promedio.

- El promedio obtenido se multiplicará por el \% de stock de seguridad, con el fin de asegurar la producción ligeramente mayor.

- El área de ventas tendrá la responsabilidad de presentar su proyección mensual de ventas.

- Se concretará las reuniones de demanda para determinar el PDC.

- También se deberá prever y minimizar las mermas, ya que esto afecta los costos, generando sobrecostos.

- Será fundamental tener las políticas y procedimientos adecuados de compras, rotación y acomodo de cocina y almacén, para evitar en lo posible las mermas.

Finalmente, La Tomate, sabe que planear la producción ayuda entre otras cosas, a disminuir los sobrantes de cada día y en consecuencia con la disminución de los costos. 
Figura 22. Planeamiento de Producción - (Plato de arroz con pollo)

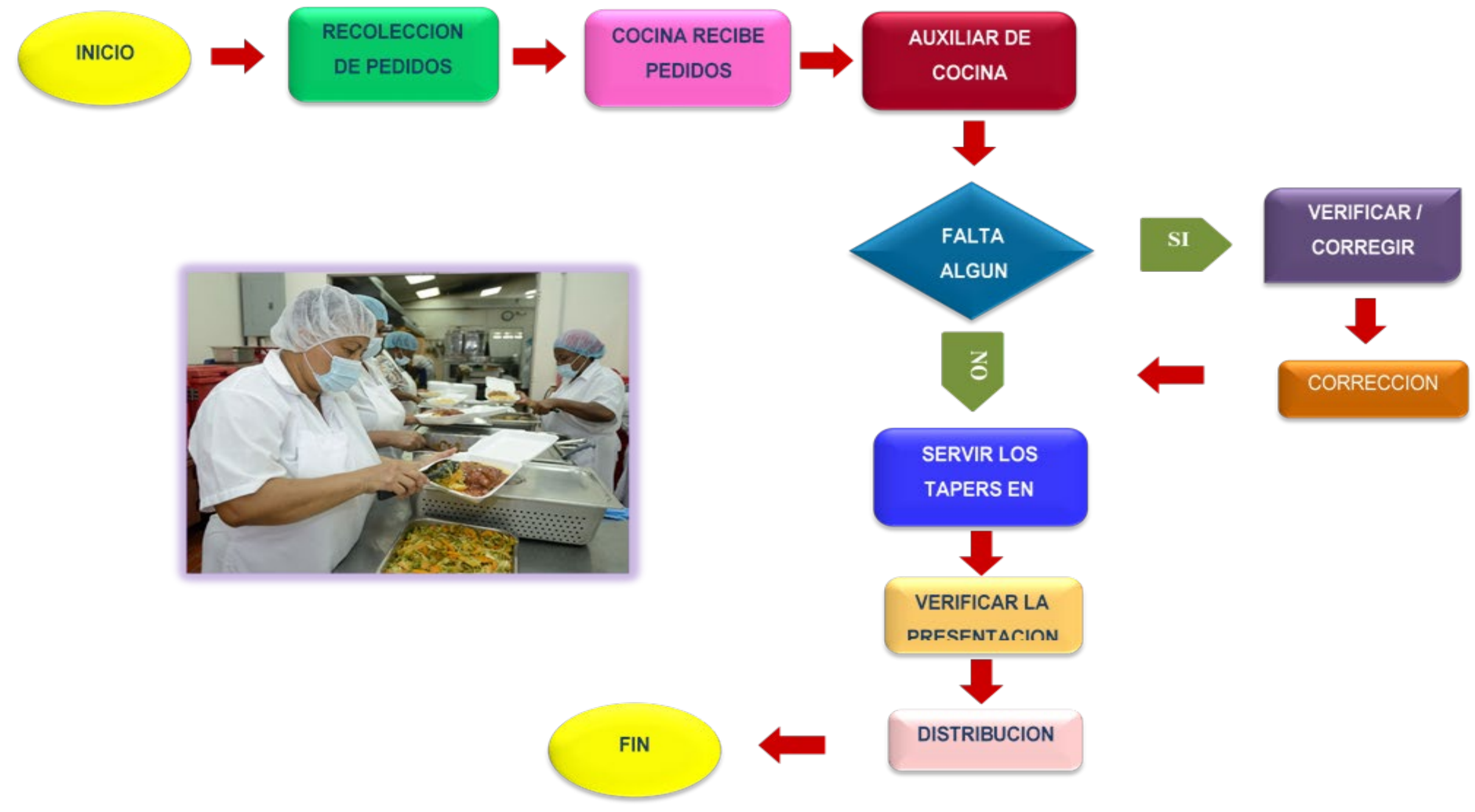

Fuente: Propia 


\subsubsection{Gestión de compras y stock}

- Recepción de inventarios. Esta es la etapa inicial, los inventarios se reciben y se verifica la calidad de los productos, para comprobar la especificación técnica de todas las materias primas que entran a la cocina y depósito; este control es básico, ya que aquí radica el sabor y la presentación de los platos.

- Ingreso a la cocina. Una vez evaluada la calidad y las especificaciones técnicas de los productos, se procede a almacenarlos según corresponda su naturaleza: perecederos y no perecederos, los que necesitan refrigeración y los que pueden estar a temperatura ambiente.

- Preparación. La preparación de las comidas, estarán definidas semana tras semana, para lo cual se deberá tener preparado y las medidas exactas para las recetas. Todos nuestros insumos estarán listos para la preparación de los menús; el cálculo de las cantidades puede variar según la demanda; de esta manera se garantiza la frescura del producto. Una vez realizado el total de pedidos, se procederá a la preparación definitiva del producto, y se pondrán en los envases y bolsas, para la distribución.

- Distribución Una vez está preparado el producto, el ayudante colocara los pedidos en el cooler del motorizado, teniendo el debido cuidado del llenado.

\subsubsection{Gestión de la calidad}

La calidad de los productos ofrecidos será un factor diferenciador en la puesta en marcha de nuestro negocio, respecto a la competencia; consideremos además que nuestro principal objetivo está orientado a manejar un nivel alto de calidad en la forma de operar.

Para esto debemos considerar los siguientes factores:

- Homologación de proveedores. Deberemos contar con un buen número de proveedores, que se encuentren debidamente homologados y estos serán clasificados de acuerdo a la calificación previamente obtenida, esto nos garantizara tener un excelente nivel de abastecimiento de nuestros insumos, para lo cual deberemos tener en cuenta lo siguiente:

- Calificación obtenida de la homologación.

- Evaluar el mejoramiento continuo de manera periódica. 
- Clasificar a los proveedores según su actividad comercial, para que estos sean registrados en la base de datos que se manejará.

- Recepción de la materia prima. Una vez que se haya efectuado la compra de la materia prima, previa homologación de nuestros proveedores y el pase de nuestra área de laboratorio; esta se procederá a almacenar de acuerdos a categorías de perecibles y no perecibles.

En caso de que la materia prima o insumo no sea aprobada por nuestra área de calidad, se etiquetará como RECHAZADO, para tomar las medidas correctivas con el proveedor.

- Elaboración del producto (menú). Una vez que tengamos los pedidos de los clientes y el área de cocina haya comprobado que los insumos a utilizar hayan sido aprobados por el área de calidad, se procederá a la producción de los alimentos de acuerdo a la programación establecida.

- Capacitación del sistema de calidad a los trabajadores. La divulgación del sistema de gestión de calidad entre los trabajadores de LA TOMATE, es uno de los puntos más importantes, porque en ello se buscará el compromiso de cada trabajador para lograr procesos óptimos.

- Control de calidad. Los controles que realiza el área de calidad se realizarán mediante autocontroles e inspección final del producto. Para esto también se realizarán auditorías internas, para validar y mejorar los procesos.

- Distribución del menú. Tener correctamente definidas las pautas de distribución de nuestros menús es un tema importante, ya que esto permite que el producto se encuentre en el lugar y momento adecuado. El producto final antes de llegar al consumidor pasa por tres etapas importantes:

- Almacenamiento.

- Distribución física.

- Cobro del producto.

- Higiene y Seguridad. Las instalaciones de LA TOMATE, deberán estar en orden y manteniendo una limpieza total y de forma continua. 
El personal de cocina tiene la obligación de proteger su cuerpo con trajes aislantes, gorros y guantes para proteger los alimentos, estos mismos artículos serán renovados de manera periódica.

\subsubsection{Gestión de los proveedores}

Contar con buenos proveedores no solo significa tener insumos de calidad sino también precios bajos y/o competitivos. No se puede pensar en tener los mejores insumos a un precio elevado que encarezcan el producto final o, en el otro extremo, tener productos a precios bajos con una calidad que deje mucho que desear. En el mercado actual el departamento de compras busca tener un equilibrio entre calidad y precio por parte del proveedor.

- Búsqueda de proveedores. Es el primer paso y quizás el que tome más tiempo de evaluación. Esto se debe a toda la búsqueda y recolección de la información acerca del proveedor (años de experiencia, clientes actuales y anteriores, certificaciones, entre otros). Para ello podemos considerar las siguientes pautas:

- Recomendaciones: colegas que refieran a proveedores con los cuales hayan trabajado siendo la experiencia positiva o no. De esa forma también se pueden ir descantando posibilidades.

- Competencia: investigar cuáles son los proveedores de nuestra competencia.

- Internet: este medio es importante para encontrar nuevos proveedores o nuevas empresas. Asimismo, brinda la posibilidad de tener referencias por parte de sus clientes.

- Ferias o exposiciones especializadas: es importante asistir a las ferias donde se presentan nuevos proveedores o los ya conocidos exponen sus novedades.

- Criterios de selección. En la selección del proveedor indicado una empresa debe tener claros sus criterios de búsqueda, para que de esta forma será más fácil la elección. Algunas consideraciones más comunes son: precio, calidad, garantías, plazo de entregas, formas de pago, prestigio de empresa. Reiteramos que estos criterios dependerán de cada empresa.

- Evaluación de proveedores Este sería el filtro final para la selección del o los proveedores. Es útil realizar un cuadro comparativo en el cual se detallen las ventajas o desventajas de 
trabajar con cada uno de ellos, por ejemplo. Esto dependerá de los criterios que tenga su empresa.

Otra forma para la evaluación de proveedores es a través de una reunión (pueden ser varias dependiendo de los acuerdos a los que lleguen) en la cual pueda resolver sus du- das o plantear propuestas al proveedor ante una posible incorporación como parte de su cartera de proveedores.

- Selección de proveedores. Después de todos los pasos mencionados tendrá la capacidad de elegir al proveedor más adecuado para su empresa y cumpliendo con sus criterios de selección.

Es recomendable tener un abanico de proveedores. Si bien es cierto se busca construir una relación sólida y a largo plazo, un buen gerente sabrá tener en cuenta el cambio constante del mercado. La competencia siempre estará presente ofreciendo nuevas opciones y, a veces, a mejores precios.

Cuadro 9. Ficha de evaluación de proveedor

\begin{tabular}{|c|c|c|}
\hline $\begin{array}{l}\text { Razón social } \\
\text { Ruc } \\
\text { Giro }\end{array}$ & $\begin{array}{l}\text { Luis Alberto Gastelo Ríos } \\
10126426340 \\
\text { Venta al por menor y por mayor de carnes blancas }\end{array}$ & \\
\hline Calidad & Cumplir con las normas sanitarias y de digesa & \\
\hline Generalidades & $\begin{array}{l}\text { Piel firme, libre de brotes y sin restos de plumas, sin quemaduras o } \\
\text { golpes. Color rosado pálido o crema, uniforme (sin manchas) } \\
\text { Libre de grasas superficiales }\end{array}$ & \\
\hline $\begin{array}{l}\text { Requisitos } \\
\text { específicos }\end{array}$ & $\begin{array}{l}\text { Olor característico que no evidencie presencia de productos } \\
\text { químicos } \\
\text { Rancidez o descomposición. }\end{array}$ & \\
\hline Empaques & $\begin{array}{l}\text { El pollo debe llegar a temperaturas refrigeradas y embolsado } \\
\text { donde muestre la identificación de la fecha de envasado, } \\
\text { vencimiento y nombre del proveedor. }\end{array}$ & \\
\hline Características & Criterios & Calificación \\
\hline $\begin{array}{l}\text { Cumplimiento de } \\
\text { entrega }\end{array}$ & & \\
\hline $\begin{array}{l}\text { Documentación } \\
\text { y garantía }\end{array}$ & & \\
\hline \multicolumn{3}{|l|}{ Precio } \\
\hline \multicolumn{3}{|l|}{ Soporte técnico } \\
\hline & Puntaje & Resultado \\
\hline $\begin{array}{l}\text { Criterios de } \\
\text { calificación }\end{array}$ & $\begin{array}{l}4.5-5 \\
3,9-4,4 \\
3, O-3,8 \\
0,0-3,8\end{array}$ & $\begin{array}{l}\text { Excelente } \\
\text { Confiable } \\
\text { Poco confiable } \\
\text { No confiable }\end{array}$ \\
\hline
\end{tabular}

Fuente: Propia 


\subsection{Inversión en activos fijos vinculados al proceso productivo.}

Cuadro 10. Activo Fijo Tangible

\begin{tabular}{|c|c|c|c|c|}
\hline MAQUINARIAS Y EQUIPOS & IMAGEN REFERENCIAL & CANTIDAD & $\begin{array}{c}\text { PRECIO } \\
\text { COMPRA }\end{array}$ & $\begin{array}{l}\text { PRECIO } \\
\text { TOTAL }\end{array}$ \\
\hline $\begin{array}{l}\text { Cocina industrial } \\
\text {-De } 6 \text { hornillas } \\
\text {-Material acero inoxidable } \\
\text {-Funcion a gas } \\
\text {-Hornillas } 30 \times 30 \mathrm{~cm} \\
\text {-Horno automatico } \\
\text { *INCLUYE INSTALACION }\end{array}$ & & 1 & $S / 6,000.00$ & $S / 6,000.00$ \\
\hline $\begin{array}{l}\text { Plancha freidora } \\
\text {-Freidora de papas } \\
\text {-Plancha para freir } \\
\text {-Funcion a gas } \\
\text {-Material acero inoxidable } \\
\text { *INCLUYE INSTALACION }\end{array}$ & & 1 & $S / 3,000.00$ & $S / 3,000.00$ \\
\hline $\begin{array}{l}\text { Campana industrial } \\
\text { extractora } \\
\text {-Tamaño de cocina } \\
\text {-Material acero inoxidable } \\
\text {-Con filtro de ventilacion } \\
\text { *INCLUYE INSTALACION }\end{array}$ & & 1 & $S / 16,500.00$ & $S / 16,500.00$ \\
\hline $\begin{array}{l}\text { Mesas de trabajo } \\
\text {-Medida } 1.80 \mathrm{mts} \times 0.8 \mathrm{mts} \\
\text {-Estanteria de } 2 \text { niveles } \\
\text {-Material acero inoxidable } \\
\text { *INCLUYE INSTALACION }\end{array}$ & & 2 & $S / 750.00$ & $S / 1,500.00$ \\
\hline $\begin{array}{l}\text { Mesas de trabajo } \\
\text {-Medida } 1.50 \mathrm{mts} \times 0.8 \mathrm{mts} \\
\text {-Material acero inoxidable } \\
\text { *INCLUYE INSTALACION }\end{array}$ & & 4 & $\mathrm{~S} / 500.00$ & $S / 2,000.00$ \\
\hline $\begin{array}{l}\text { Refrigeradora } \\
\text {-Marca SAMSUNG } \\
\text {-Capacidad } 501 \text { Lts } \\
\text {-Conservadora / congeladora } \\
\text {-Uso de frutas y verduras } \\
\text {-Dispensador de agua y hielo } \\
\text { *INCLUYE INSTALACION }\end{array}$ & & 1 & $S / 3,260.00$ & $S / 3,260.00$ \\
\hline $\begin{array}{l}\text { Congeladora Horizontal } \\
\text {-Marca Miray } \\
\text {-Capacidad 420Lt } \\
\text {-2 compartimientos } \\
\text { *INCLUYE INSTALACION }\end{array}$ & & 1 & $S / 1,450.00$ & $S / 1,450.00$ \\
\hline $\begin{array}{l}\text { Exhibidora de insumos } \\
\text {-Marca Miray } \\
\text {-Capacidad } 800 \text { Lts } \\
\text {-8 parrillas divisorias } \\
\text { *INCLUYE INSTALACION } \\
\end{array}$ & & 1 & $S / 1,150.00$ & $S / 1,150.00$ \\
\hline $\begin{array}{l}\text { Horno Microhondas } \\
\text {-Capacidad } 32 \mathrm{Lt} \\
\text {-Marca Panasonic } \\
\text {-Teclas inteligentes } \\
\text { *INCLUYE INSTALACION }\end{array}$ & men. & 2 & $S / 400.00$ & $\mathrm{~S} / 800.00$ \\
\hline
\end{tabular}




\begin{tabular}{|c|c|c|c|c|}
\hline MUEBLES Y ENSERES & IMAGEN REFERENCIAL & CANTIDAD & $\begin{array}{l}\text { PRECIO } \\
\text { COMPRA }\end{array}$ & $\begin{array}{c}\text { PRECIO } \\
\text { TOTAL }\end{array}$ \\
\hline $\begin{array}{l}\text { Computadoras de escritor } \\
\text {-Marca HP } \\
\text {-Modelo All in One } \\
\text {-1Tb DD } \\
\text {-8Gb RAM } \\
\text { *INCLUYE INSTALACION }\end{array}$ & & 2 & $S / 1,900.00$ & $S / 3,800.00$ \\
\hline $\begin{array}{l}\text { Escritorio de madera } \\
\text {-Medida } 1.5 \mathrm{mts} \times 0.8 \mathrm{mts} \\
\text {-Material madera tornillo } \\
-3 \text { cajones } \\
\text {-incluye } 4 \text { sillas } \\
\text { *INCLUYE INSTALACION }\end{array}$ & & 3 & $S / 650.00$ & $S / 1,950.00$ \\
\hline $\begin{array}{l}\text { Impresora multifuncional } \\
\text {-Marca Canon } \\
\text {-Fotocipiadora, scaner, } \\
\text { impresora } \\
\text { *INCLUYE INSTALACION }\end{array}$ & & 1 & $S / 550.00$ & $S / 550.00$ \\
\hline $\begin{array}{l}\text { Televisor de 50" } \\
\text {-Marca Sansumg } \\
\text {-UHD } \\
\text {-Smart-TV } \\
\text {-4K } \\
\text { *INCLUYE INSTALACION }\end{array}$ & 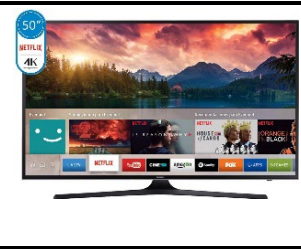 & 1 & $S / 2,000.00$ & $S / 2,000.00$ \\
\hline $\begin{array}{l}\text { Celulares corporativos } \\
\text {-Gamma alta } \\
\text {-Modelo J7 }\end{array}$ & $\theta$ & 5 & $S / 400.00$ & $S / 2,000.00$ \\
\hline $\begin{array}{l}\text { Licuadoras } \\
\text {-Marca Oster } \\
\text {-Modelo profesional }\end{array}$ & $\Rightarrow=$ & 3 & $\mathrm{~S} / 299.00$ & S/897.00 \\
\hline $\begin{array}{l}\text { Procesador de alimentos } \\
\text {-Marca Philips } \\
\text {-Capacidad } 1.3 \mathrm{Lt}\end{array}$ & 2 & 2 & $S / 399.00$ & S/798.00 \\
\hline $\begin{array}{l}\text { Menaje de cocina } \\
\text {-Ollas } \\
\text {-Cucharones } \\
\text {-Platos } \\
\text {-Vasos } \\
\text {-Cucharas/tenedores } \\
\text {-Cuchillos profesionales } \\
\text {-etc }\end{array}$ & 4 & 1 & $S / 2,000.00$ & $S / 2,000.00$ \\
\hline Activo fijo Intangible & Cantidad & $\begin{array}{l}\text { Precio } \\
\text { Compra }\end{array}$ & $\begin{array}{c}\text { PRECIO } \\
\text { TOTAL }\end{array}$ & \\
\hline Constitucion de empresa & 1 & $S / 1,500.00$ & $\mathrm{~S} / 1,500$ & \\
\hline Licencias & 1 & $\mathrm{~S} / 250.00$ & $\mathrm{~S} / 250$ & \\
\hline Costos municipales & 1 & $S / 350.00$ & $\mathrm{~S} / 350$ & \\
\hline Libros contables & 1 & $\mathrm{~S} / 60.00$ & $\mathrm{~S} / 60$ & \\
\hline Comprobantes & 1 & $\mathrm{~S} / 120.00$ & $\mathrm{~S} / 120$ & \\
\hline Creacion de redes sociales & 1 & $\mathrm{~S} / 1,800.00$ & $\mathrm{~S} / 1,800$ & \\
\hline
\end{tabular}

\begin{tabular}{|l|r|}
\hline INVERSION INICIAL EN ACTIVO TANGIBLE & $S / 49,655.00$ \\
\hline INVERSION INICIAL EN ACTIVO INTANGIBLE & $\mathrm{S} / 4,080.00$ \\
\hline
\end{tabular}

INVERSION INICIAL EN ACTIVO FIJO

$\mathrm{S} / 53,735.00$

Fuente: Propia 


\subsection{Estructura de costos de producción y gastos operativos.}

\subsubsection{Costos de producción}

Hemos llegado a un costo por plato de arroz con pollo de S/. 8.86, lo hemos determinado con el método ESCANDALLO, en la primera parte señalamos los insumos de producción por una cantidad de 4 platos, sumando los costos fijos del producción (Entre ellos los directos e indirectos) los cuales fueron calculados con un factor de división de 2273 platos obtenidos del cálculo de la demanda inicial (114 platos x 5 días de trabajo x 4 semanas del mes) obteniendo un costo por plato, luego sumamos los costos variables del producción como son los servicios y gasolina para movilidad.

El presente cuadro es un ejemplo del detalle de análisis a tomar para los diferentes platos a preparar para poder conocer el coste de cada uno

Cuadro 11. Costo fijo

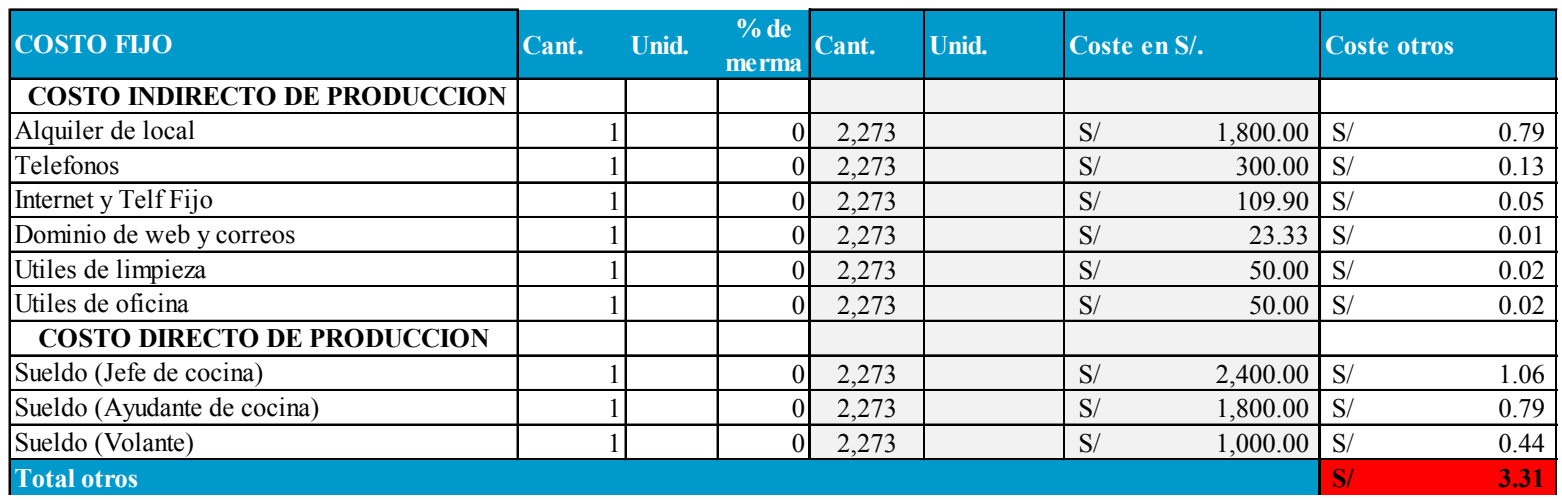

Fuente: Propia

Cuadro 12. Producto / Elaboración

\section{ARROZ CON POLLO}

\begin{tabular}{|c|c|c|c|c|c|c|c|c|c|c|}
\hline Cantidad & 4 & & & & & & & & Fecha & 06-Jun-18 \\
\hline \multirow{2}{*}{\multicolumn{2}{|c|}{ Producto/elaboración }} & & & & \multicolumn{4}{|c|}{ Precio de compra } & & \\
\hline & & Cant. & Unid. & $\begin{array}{c}\% \text { de } \\
\text { merma }\end{array}$ & Cant. & Unid. & \multicolumn{2}{|c|}{ Coste en S. } & Coste mat. prima & $\begin{array}{c}\% \text { coste total mat. } \\
\text { prima }\end{array}$ \\
\hline Pollo & & 1 & $\mathrm{~kg}$ & $25 \%$ & 1 & $\mathrm{~kg}$ & $\mathrm{~S} /$ & 6.80 & 6.82 & 34.13 \\
\hline Arroz & & 0.75 & $\mathrm{~kg}$ & $0 \%$ & 1 & $\mathrm{~kg}$ & $\mathrm{~S} /$ & 3.20 & 2.40 & 12.02 \\
\hline Culantro & & 0.5 & $\mathrm{~kg}$ & $20 \%$ & 1 & $\mathrm{~kg}$ & $\mathrm{~S} /$ & 4.00 & 2.00 & 10.03 \\
\hline pimiento & & 0.11 & $\mathrm{~kg}$ & $10 \%$ & 1 & $\mathrm{~kg}$ & $\mathrm{~S} /$ & 4.40 & 0.48 & 2.43 \\
\hline alverja & & 0.25 & $\mathrm{~kg}$ & $0 \%$ & 1 & $\mathrm{~kg}$ & $\mathrm{~S} /$ & 7.50 & 1.88 & 9.39 \\
\hline Aji verde & & 0.09 & $\mathrm{~kg}$ & $0 \%$ & 1 & $\mathrm{~kg}$ & $\mathrm{~S} /$ & 6.00 & 0.54 & 2.70 \\
\hline Cebolla & & 0.14 & $\mathrm{~kg}$ & $20 \%$ & 1 & $\mathrm{~kg}$ & $\mathrm{~S} /$ & 3.50 & 0.49 & 2.46 \\
\hline \begin{tabular}{|l|} 
zanahoria \\
\end{tabular} & & 0.2 & $\mathrm{~kg}$ & $25 \%$ & 1 & $\mathrm{~kg}$ & $\mathrm{~S} /$ & 3.00 & 0.60 & 3.01 \\
\hline Chica de j & & 0.25 & Lts & $0 \%$ & 1 & Lts & $\mathrm{S} /$ & 8.00 & 2.00 & 10.01 \\
\hline Especias & & 0.2 & $\mathrm{~kg}$ & $0 \%$ & 1 & $\mathrm{~kg}$ & $\mathrm{~S} /$ & 10.00 & 2.00 & 10.01 \\
\hline Envases y & & 0.001 & Mllr & $0 \%$ & 1 & MLLR & $\mathrm{S} /$ & 760.00 & 0.76 & 3.81 \\
\hline Total mat. & & & & & & & & & 19.97 & \\
\hline
\end{tabular}


Fuente: Propia

Cuadro 13. Costo Variable

\begin{tabular}{|c|c|c|c|c|c|c|c|}
\hline COSTO VARIABLE & Cant. & Unid. & $\begin{array}{c}\% \text { de } \\
\text { merma }\end{array}$ & Cant. & Unid. & Coste en S/. & Coste otros \\
\hline \multicolumn{8}{|c|}{ COSTO INDIRECTO DE PRODUCCION } \\
\hline Servicios - LUZ & 1 & & 0 & 2,273 & & 130 & 0.057 \\
\hline Servicios - AGUA & 1 & & 0 & 2,273 & & 292.5 & 0.129 \\
\hline Servicios - GAS & 1 & & 0 & 2,273 & & 227.5 & 0.100 \\
\hline Movilidad - GASOLINA & 1 & & 0 & 2,273 & & 600 & 0.264 \\
\hline Total otros & & & & & & & 0.550 \\
\hline
\end{tabular}

\begin{tabular}{|l|ll|}
\hline Coste mat. prima $x$ ración & S/ & $\mathbf{4 . 9 9}$ \\
\hline COSTOS FIJOS & $\mathrm{S} /$ & $\mathbf{3 . 3 1}$ \\
\hline COSTOS VARIABLES & $\mathrm{S} /$ & $\mathbf{0 . 5 5}$ \\
\hline Total & $\mathrm{S} /$ & $\mathbf{8 . 8 6}$ \\
\hline
\end{tabular}

Fuente: Propia 


\subsubsection{Gastos operativos}

Cuadro 14. Gasto de operación

\begin{tabular}{|l|l|r|r|r|}
\hline \multicolumn{2}{|l|}{ Gasto de operación (Gasto FIJO) } & \multicolumn{1}{c|}{$\begin{array}{c}\text { Costo } \\
\text { Mensual }\end{array}$} & \multicolumn{1}{c|}{ Meses } & \multicolumn{1}{c|}{$\begin{array}{c}\text { TOTAL } \\
\text { ANUAL }\end{array}$} \\
\hline & $\begin{array}{l}\text { Alquiler de local } \\
-2 \text { meses de garantia } \\
-1 \text { mes de adelanto }\end{array}$ & $\mathrm{S} / 1,800.00$ & 12 & $\mathrm{~S} / 21,600.00$ \\
\hline & Servicios basicos (Luz, agua y gas)Anexo 1 & $\mathrm{S} / 650.00$ & 12 & $\mathrm{~S} / 7,800.00$ \\
\hline & $\mathrm{S} / 300.00$ & 12 & $\mathrm{~S} / 3,600.00$ \\
\hline $\begin{array}{l}\text { Delefonos de internet y telefono fijo } \\
\text {-Internet 6Mpbs } \\
\text {-Fijo }\end{array}$ & $\mathrm{S} / 109.90$ & 12 & $\mathrm{~S} / 1,318.80$ \\
\hline & Dominio de web y correos & $\mathrm{S} / 23.33$ & 12 & $\mathrm{~S} / 280.00$ \\
\hline & Combustible & $\mathrm{S} / 600.00$ & 12 & $\mathrm{~S} / 7,200.00$ \\
\hline Utiles de limpieza & $\mathrm{S} / 50.00$ & 12 & $\mathrm{~S} / 600.00$ \\
\hline Utiles de oficina & $\mathrm{S} / 50.00$ & 12 & $\mathrm{~S} / 600.00$ \\
\hline & Presupuesto de MKT & $\mathrm{S} / 450.00$ & 12 & $\mathrm{~S} / 5,400.00$ \\
\hline
\end{tabular}

Gasto de operación anual

$\mathrm{S} / \mathbf{4 8 , 3 9 8 . 8 0}$

\begin{tabular}{|l|r|}
\hline $\begin{array}{c}\text { Servicios } \\
\text { basicos }\end{array}$ & \multicolumn{1}{c|}{$\begin{array}{c}\text { Costo } \\
\text { Mensual }\end{array}$} \\
\hline Agua & $\mathrm{S} / 292.50$ \\
\hline Luz & $\mathrm{S} / 130.00$ \\
\hline Gas & $\mathrm{S} / 227.50$ \\
\hline
\end{tabular}

Fuente: Propia 


\section{ESTRUCTURA ORGANIZACIONAL Y RECURSOS HUMANOS}

\subsection{Objetivos Organizacionales}

Los objetivos organizacionales de La Tomate tienen objetivos organizaciones que siguen la línea de la visión y la misión de la empresa, es decir, se orientan en ofrecer un servicio de calidad y diferenciado para los clientes.

VISIÓN: "Ser el restaurant delivery líder en comida saludable de la más alta calidad con sabor a casa con proyección de crecimiento en todo el territorio nacional para el año 2022"

MISIÓN: "Ofrecer un producto saludable de un alto nivel basándonos en insumos de primera calidad con un personal constantemente capacitado, a través de un excelente servicio de delivery con su entrega a tiempo, logrando satisfacer las necesidades de cada cliente.”

Asimismo, los objetivos organizaciones están alineados con los objetivos estratégicos de la organización:

- Utilizar la administración de las redes sociales al 100\% con el fin de no perder ningún pedido y hacer frente a los posibles competidores que puedan presentarse dentro del primer año de funcionamiento de la empresa.

- Mantener publicidad intensiva en redes sociales para la difusión de la organización, esperando traducir esta difusión en consumos y así alcanzar un $20 \%$ de rentabilidad en el primer año.

- Realizar alianzas estratégicas con los proveedores de insumos renovables cada 12 meses para garantizar y asegurar al 100\% la calidad de los insumos y a la vez mantener el estándar de calidad del producto final.

- Ofrecer la transparencia de nuestros insumos al 100\% para poder generar una cultura de cambio de hábitos para los clientes, generando necesidad y obteniendo, dentro de los primeros 6 meses, el número de clientes necesarios para la rentabilidad esperada en el año. 
- Posibilitar el acceso al reconocimiento de la empresa a través de medios masivos tradicionales y digitales para lograr una participación del 5\% en la industria al culminar el segundo año de operación.

\subsection{Naturaleza de la Organización}

La Tomate se va a constituir como Sociedad Anónima Cerrada (S.A.C) y contará con un directorio representado por los accionistas de la empresa.

El capital social estará repartido en efectivo y en bienes de acuerdo a las aportaciones de los socios accionistas.

Se mantendrá una organización del tipo horizontal con un alto nivel de valores y con una cultura organizacional centrada en la calidad, con el fin de lograr que todas las áreas se encuentren comprometidas con los valores y objetivos de la empresa. 


\subsubsection{Organigrama}

Figura 23. Organigrama "la tomate"

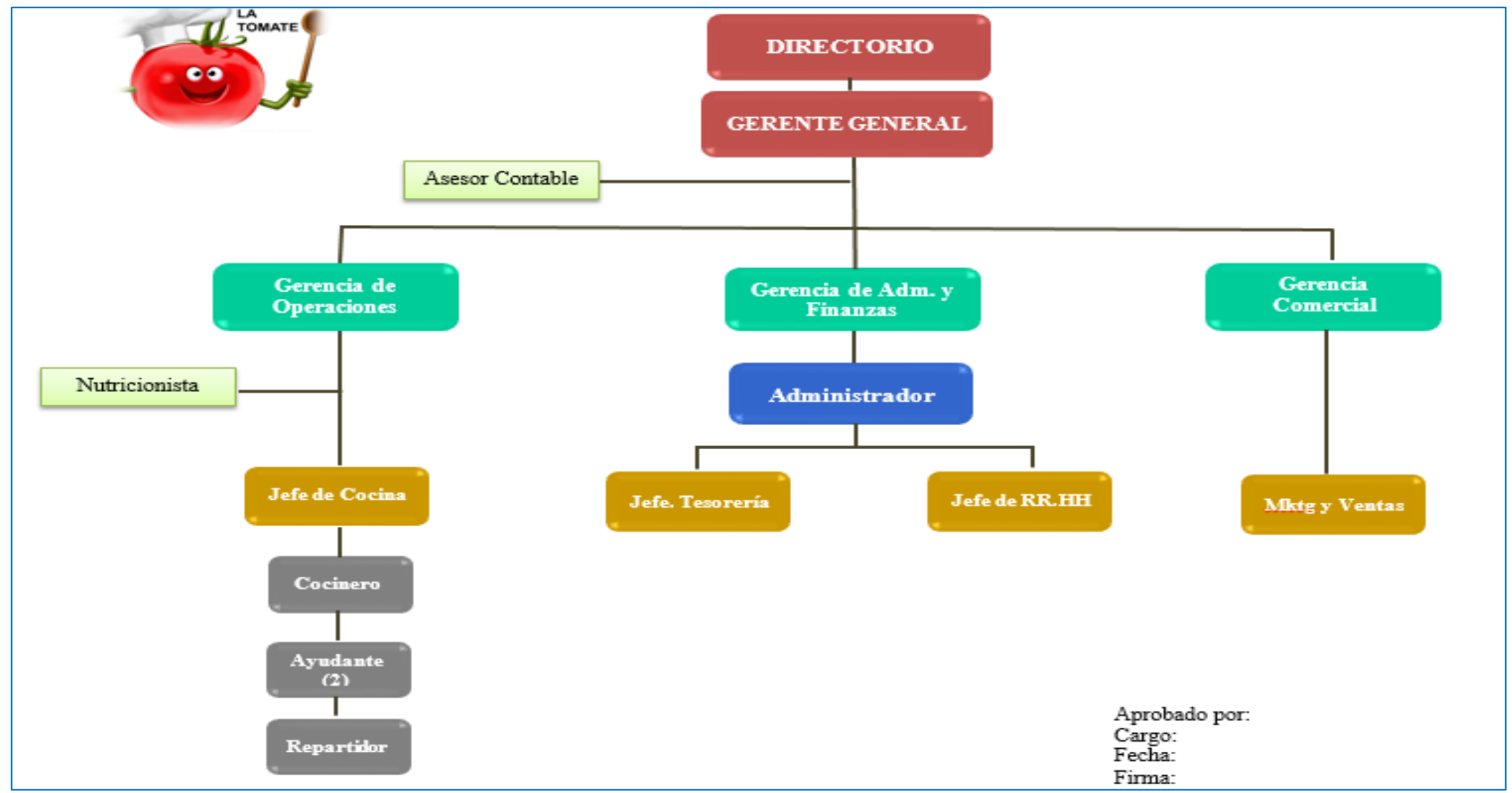

Fuente: Propia 


\subsubsection{Diseño de Puestos y Funciones}

\subsubsection{Directorio}

\begin{tabular}{|l|l|l|}
\hline \multicolumn{2}{|l|}{ Identificación General } \\
\hline$\cdot$ Denominación & $:$ & Director \\
\hline - Área & $:$ & Directorio \\
\hline$\cdot$ Centro de Costos & $:$ & Directorio \\
\hline III. Responsabilidades & Propietarios de la empresa y asociados \\
\hline - Tomar de decisiones en cuanto a inversión y expansión del servicio \\
- Desarrollar planeamientos estratégicos que permitan a la organización mantener los \\
- Gestándares de calidad deseados \\
- Monitorear las finanzas de la organización \\
\hline
\end{tabular}

\subsubsection{Gerencia General}

\begin{tabular}{|c|c|}
\hline I. Identificación $G$ & \\
\hline - Denominación & GERENTE GENERAL \\
\hline - Área & Gerencia General \\
\hline - Centro de Costos & Gerencia General \\
\hline
\end{tabular}

III. Responsabilidades

- Planificar, organizar, dirigir y controlar el funcionamiento general de la Compañía, de acuerdo a los objetivos y lineamientos señalados por el Directorio.

- Desarrollar dentro del giro normal del negocio campañas de marketing, promoción y venta utilizando los apoyos necesarios que competen al diseño de cada campaña en particular, tales como materiales de comunicación, puntos de venta y promoción, Internet y otros que puedan ser utilizados en dichas actividades.

- Formular el presupuesto de la Compañía. Asimismo, es responsable por obtener la aprobación del Directorio y de su cumplimiento.

- Establecer y controlar las políticas y reglamentos de las diferentes áreas de la Compañía. 
- Asesorar permanentemente al Directorio en cuestiones técnicas, administrativas y financieras, proporcionando la información necesaria para facilitar las decisiones del máximo organismo directivo de la Compañía.

- Proponer al Directorio los incrementos en las remuneraciones del personal, promociones y contrataciones de funcionarios, definiendo los poderes que le correspondan a cada cargo, así como la destitución de los mismos.

- Cumplir y hacer cumplir los acuerdos y resoluciones que adopte la Junta General de Accionistas, el Directorio y el Comité de Directorio, así como las disposiciones estatutarias.

- Dirigir y controlar la adecuada administración de los recursos humanos, financieros y materiales de la Compañía.

- Informar periódicamente al Directorio de la marcha de la Compañía y presentarle oportunamente el Balance correspondiente a cada ejercicio anual.

- Representar a la Compañía ante requerimientos efectuados por toda clase de autoridades, entidades y personas, con las facultades que le sean otorgadas, con el poder que para este efecto le confiera el Directorio.

- Velar por el funcionamiento y efectividad de los procesos que permitan la identificación y administración de los riesgos que asume la empresa en el desarrollo de sus operaciones y actividades.

- Representar a la Sociedad en toda clase de actos y contratos.

- Gestionar ante cualquier persona natural y/o jurídica, y ante cualquier autoridad pública, a efectos de comprar los bienes muebles necesarios para el funcionamiento del giro social.

- Aceptar y liberar total o parcialmente hipotecas y/o prendas y/o cualquier clase de garantías

- Celebrar contratos de cuentas corrientes, de depósito y/o crédito.

- Proceder a la inscripción de la matrícula de acciones de la sociedad, los traspasos u transferencias correspondientes, así como suscribir gravámenes y acuerdos entre socios.

- Representar a la sociedad en toda clase de procesos penales, con las facultades específicas de denunciar, constituirse en parte civil, prestar instructiva, preventiva y testimoniales, declaraciones de todo tipo, pudiendo acudir a nombre de la empresa ante las autoridades policiales, judiciales sin restricción y cualquier órgano competente. 


\subsubsection{Gerencia de administración y finanzas}

\begin{tabular}{|l|l|l|}
\hline I. Identificación General & $:$ & Gerente Administrativo \\
\hline$\cdot$ Denominación & $:$ & Operaciones \\
\hline$\cdot$ Área & $:$ & Gerencia General \\
\hline$\cdot$ Centro de Costos & \\
\hline II. Responsabilidades: & \\
\hline - Aceptar las órdenes de compra & \\
- Manejar los inventarios. \\
- Alevar la contabilidad de la empresa
\end{tabular}

\subsubsection{Gerencia de Operaciones}

\begin{tabular}{|l|l|l|}
\hline \multicolumn{2}{|l|}{ Identificación General } \\
\hline$\cdot$ Denominación & $:$ & Gerente de Operaciones \\
\hline$\cdot$ Área & $:$ & Operaciones \\
\hline$\cdot$ Centro de Costos & $:$ & Gerencia General \\
\hline II. Responsabilidades: \\
\hline - Establecer los niveles deseados de eficiencia productiva. \\
- Supervisar al Jefe de Cocina. \\
- Determinar matrices y detalla los riesgos operativos \\
\hline
\end{tabular}

\subsubsection{5. GERENCIA COMERCIAL}

\begin{tabular}{|c|c|c|}
\hline \multicolumn{3}{|c|}{ I. Identificación General } \\
\hline · Denominación & : & Gerente Comercial \\
\hline - Área & : & Operaciones \\
\hline - Centro de Costos & : & Gerencia General \\
\hline \multicolumn{3}{|c|}{ II. Responsabilidades: } \\
\hline \multicolumn{3}{|c|}{$\begin{array}{l}\text { - Elaborar estrategias para el incremento de ventas } \\
\text { - Supervisar el presupuesto del área } \\
\text { - Establecer metas }\end{array}$} \\
\hline
\end{tabular}




\subsubsection{Jefe de Tesorería}

\begin{tabular}{|l|l|l|}
\hline \multicolumn{2}{|l|}{ Identificación General } \\
\hline - Denominación & $:$ & Jefe de Tesorería \\
\hline - Área & $:$ & Tesorería \\
\hline - Centro de Costos & $:$ & Gerencia General \\
\hline II. Responsabilidades: & Realiza las funciones encomendadas por el Gerente de Adm. Y Finanzas. \\
\hline - Revisar las órdenes de compras entregadas por el Jefe de Cocina. \\
- Maneja los inventarios. \\
- Monitoriza el stock mínimo de los productos. \\
- Realiza los reportes de compras. \\
manejo del local. \\
\hline
\end{tabular}

\subsubsection{Jefe de RR.HH}

\begin{tabular}{|l|l|l|}
\hline I. Identificación General & $:$ & Jefe de RR.HH \\
\hline$\cdot$ Denominación & $:$ & Recursos Humanos \\
\hline$\cdot$ Área & $:$ & Gerencia General \\
\hline$\cdot$ Centro de Costos & & \\
\hline
\end{tabular}

\section{Responsabilidades}

- Realizar matrices para establecer el perfil deseado de colaboradores para la empresa

- Analizar candidatos a los puestos requeridos

- Velar por el cumplimiento de la norma legal laboral

- Asistir socialmente a los trabajadores en caso sea necesario 


\subsubsection{Administrador}

\begin{tabular}{|l|l|l|}
\hline I. Identificación General & $:$ & Administrador \\
\hline$\cdot$ Denominación & $:$ & Administración \\
\hline$\cdot$ Área & $:$ & Gerencia General. \\
\hline$\cdot$ Centro de Costos & & \\
\hline
\end{tabular}

III. Responsabilidades:

- Dirigir y controlar la adecuada administración de los recursos financieros y materiales de la compañía.

- Negociar con instituciones financieras tipo de cambio y tasas de interés a fin de optimizar los rendimientos, así como también la negociación del otorgamiento, incremento o nuevas líneas de crédito.

- Revisar, analizar y velar por él envió de la información financiera a los bancos.

- Velar por la documentación sustentadora de las operaciones del área.

- Analizar y aprobar la conciliación de las cuentas contables correspondientes a su área.

- Controlar la gestión de la cobranza de la compañía.

- Administrar el proceso de recaudación de caja.

- Controlar la facturación y el flujo de cobranzas, revisión y cuadre de documentos.

- Controlar, hacer seguimiento e informar los procesos.

- Responsable del pago oportuno de los proveedores en general, tanto de manera individual como por medios masivos.

- Revisión y verificación de la emisión de cheques / transferencias y pagos masivos.

- Responsable de la renovación de los seguros empresariales y vehiculares de la empresa.

- Evaluar a nuevos clientes, para el otorgamiento de una línea de crédito.

- Administración y supervisión de servicios tecnológicos de la empresa.

- Velar permanentemente por la optimización de los procesos del área a cargo.

- Responsable del servicio de vigilancia de la empresa.

- Supervisión y control de las labores de recepción y mensajería.

- Realizar otras funciones que le encargue el Gerente General que sean materia de su competencia y otras que sin serlo le sean encomendadas expresamente. 


\subsubsection{Marketing y Ventas}

\begin{tabular}{|c|c|}
\hline I. Identificación G & \\
\hline - Denominación & Jefe de Marketing \\
\hline - Área & Marketing \\
\hline - Centro de Costos & Gerencia General \\
\hline II. Responsabilida & \\
\hline $\begin{array}{ll}\text { - } & \text { Realizar campa } \\
\text { - } & \text { Realizar activid } \\
\text { - } & \text { Monitorear las } \\
\text { - } & \text { Establecer métr }\end{array}$ & resa \\
\hline
\end{tabular}

\subsubsection{Jefe de Cocina}

\begin{tabular}{|l|l|l|}
\hline I. Identificación General & $:$ & Jefe de Cocina \\
\hline$\cdot$ Denominación & $:$ & Operaciones \\
\hline$\cdot$ Área & $:$ & Gerencia General \\
\hline$\cdot$ Centro de Costos & & \\
\hline II. Responsabildades: &
\end{tabular}

II. Responsabilidades:

- Realizar los menús.

- Realizar los requerimientos necesarios para los menús.

- Controlar la calidad de cada menú.

- Soporte al administrador en los horarios del personal.

- Distribuir el trabajo entre los ayudantes de cocina.

- Mantener adecuadamente el estado de las instalaciones de la cocina.

- Controlar el orden y la limpieza del ambiente.

- Llevar el inventario de la cocina.

- Tomar decisiones sobre el alimento que se desecha o se mantiene refrigerado. 


\subsubsection{Ayudante de cocina}

\begin{tabular}{|c|c|c|}
\hline \multicolumn{3}{|l|}{ I. Identificación General } \\
\hline - Denominación & : & Ayudante de Cocina \\
\hline - Área & : & Operaciones \\
\hline - Centro de Costos & : & Gerencia General \\
\hline \multicolumn{3}{|l|}{ II. Responsabilidades: } \\
\hline \multicolumn{3}{|l|}{$\begin{array}{l}\text { - } \text { Cumplir bajo las órdenes } \\
\text { - } \text { Realizar trabajos mecánic } \\
\text { - } \text { Recibir la requisición de } \\
\text { - Procesar la materia prima } \\
\text { - Mantener el área limpia. } \\
\text { - Preparar de salsas. } \\
\text { - } \text { Despachar las órdenes. }\end{array}$} \\
\hline
\end{tabular}

\subsection{Políticas Organizacionales}

LA TOMATE; es una empresa que empieza a incursionar en el rubro de la comida a delivery, la cual trabaja para mantener un excelente nivel, en la calidad del servicio que brinda, sus platos de comida están hechos a base de insumos naturales y de primera calidad, seleccionados con el cuidado especial que este servicio merece.

Para lograr nuestro objetivo, la Gerencia de la empresa asume los siguientes compromisos:

- Buscamos ser una empresa sólida, comprometidos a la búsqueda de buenos talentos profesionales.

- Al ser una de nuestras prioridades el capital humano, fomentamos la participación de nuestros empleados, en el continuo desarrollo de la empresa.

- Brindar capacitación y fomentar la concientización de nuestros colaboradores.

- Tomamos las medidas necesarias para garantizar la inocuidad de los alimentos, evitando al máximo los riesgos que dañen la salud de nuestros comensales.

- Siempre a tiempo para cumplir nuestras obligaciones y responsabilidades, garantizando la tranquilidad que nuestros proveedores internos y externos. 
- Garantizamos sabores y texturas óptimas en cada preparación, acompañado de una constante mejora continúa basada en opiniones de nuestros clientes.

- Contamos con un equipo de nutricionistas enfocado en garantizar que cada alimento entregado cuente con todos los requerimientos nutricionales para la alta productividad y sana alimentación.

\subsection{Gestión Humana}

El área de gestión humana de LA TOMATE, tiene como principal objetivo garantizar los procesos administrativos que guíen el desarrollo de los colaboradores en todas las áreas de la empresa, desde la concepción de los perfiles de las personas, sus lugares de trabajo y sus interacciones, pasando por su desarrollo en conocimientos, habilidades, bienestar y salud hasta su adecuado cese de actividades.

Dentro de sus principales funciones se encuentran:

- Función económica - guarda relación con los salarios, incentivos y prestaciones sociales.

- Reclutamientos, Selección y Contratación de Personal - procesos.

- Desarrollo de programas motivacionales - recreación, deportes y otros.

- Bienestar, Salud y Seguridad en el trabajo - capacitaciones de salud y seguridad.

- Programas de capacitaciones - Capacitación y desarrollo del personal

\subsubsection{Reclutamiento}

El objetivo de este proceso es Tener candidatos potencialmente calificados para ocupar puestos dentro de la organización.

\subsubsection{Selección, contratación e inducción}

Es un conjunto de etapas o pasos que tienen como objetivo seleccionar y contratar al personal más idóneo para la organización

En el siguiente proceso se detallan los puntos 7.4.1 y 7.4.2 


\subsubsection{Objetivo}

Contar con un proceso uniforme de selección y contratación de personal respecto a procedimientos, conceptos, formatos, entre otros que sean aplicables en la organización, estableciendo un adecuado control interno con las áreas involucradas.

\subsubsection{Alcance}

Aplica a todos los procesos de contratación laboral del personal en las planillas de la organización, en coordinación con el área que requiera la posición.

\subsubsection{Responsables}

Recursos Humanos: El área de Recursos Humanos será responsable de monitorear todo el proceso de Selección y Contratación del Personal en la organización a través de sus representantes en coordinación con el área que requiere la posición.

\subsubsection{Formatos}

- FO 001 - Ficha del Trabajador.

- $\quad$ FO 002 - Solicitud de Personal.

\subsubsection{Desarrollo}

\section{Requerimiento de personal}

Para iniciar el proceso de selección y contratación de personal, se deberá tener en cuenta los siguientes aspectos:

- Contrataciones aprobadas en presupuesto: El perfil a solicitar está dentro del presupuesto anual aprobado por la G.G.

- Contrataciones no presupuestadas: en caso de ser una posición nueva no incluida en el presupuesto. 


\section{Pre-Selección de candidatos:}

El área de Recursos Humanos procederá a identificar a los candidatos potenciales a través de las siguientes fuentes de reclutamiento en orden de prioridad:

- Base de datos

- Recepción de currículos de personas sugeridas por otros miembros de la organización.

- Publicación de aviso por páginas Webs / - Bolsa de trabajo de Universidades o Institutos.

\section{Identificación de candidatos:}

- RR.HH procederá a depurar e identificar candidatos cuyos perfiles cumplen con el requerimiento y con probabilidades de cubrir la vacante.

- El área de Recursos Humanos citara a estos candidatos pre-seleccionados para entrevistas.

\section{Pruebas y entrevistas:}

Tanto el área de RR.HH como la jefatura solicitante del puesto a requerir, procederán a entrevistar a los candidatos y realizar las pruebas pertinentes.

- Experiencia laboral / Conocimientos técnicos

- Compatibilidad de horarios / Expectativas salariales

\section{Selección del Candidato:}

- Finalizado el ciclo de entrevistas, el área de Recursos Humanos y el área solicitante evaluarán en forma conjunta los resultados de las entrevistas sostenidas, presentando su recomendación al jefe de Área y/o al Gerente General de ser el caso.

- Se tomará la decisión por uno de los candidatos

\section{Verificación de Antecedentes}

- El área de Recursos Humanos verificara las referencias laborales del candidato., con respecto al tiempo de servicio, cargo, desempeño, remuneración y funciones que realizo en anteriores empresas.

\section{Contratación del personal:}

- Una vez realizada la verificación de antecedentes y pruebas pertinentes, y de ser satisfactorios los resultados, se procederá a informar al candidato respecto a su ingreso a la empresa. 
- Se solicitará al personal los documentos correspondientes, y Recursos Humanos preparará el contrato correspondiente con los acuerdos establecidos entre el empleado y empleador.

\section{Preparación de lugar y requerimientos de trabajo:}

Recursos Humanos preparará el file personal donde se incluirán la Ficha del colaborador, currículo, Copia DNI, copia de recibos de servicios, constancias de estudios y trabajos.

Cabe señalar que en este file se archivaran todos los documentos que en adelante se le entreguen al colaborador.

\section{Presentación e Inducción:}

La inducción consiste en proporcionarles a los nuevos ingresantes, información básica sobre los antecedentes de la empresa, sus políticas, visión y misión.

Luego se cumplirá con el plan de inducción establecido y la entrega del RIT.

\section{Cuadro 15. RIT}

\begin{tabular}{|c|c|}
\hline $\begin{array}{l}\text { Cargo } \\
\text { Fecha de Ingrerso }\end{array}$ & \\
\hline AREA / TEMA & RESPONSABLE \\
\hline $\begin{array}{l}\text { 1. BIENVENIDA } \\
\begin{array}{l}\text { 1.1 Bienvenida a la empresa } \\
\text { 1.2 Recorrido por la empresa / instalacion } \\
\text { 1.3 Dar a conocer las Politicas Organizacionales de la emrpesa } \\
\text { 1.4 Explicacion del proceso de induccion }\end{array}\end{array}$ & Jefe de RR.HH \\
\hline $\begin{array}{l}\text { 2. CONOCIMIENTO DE LAS AREAS Y JEFATURAS } \\
\text { 2.1 Presentacion de todas las jefaturas de la empresa } \\
\text { Conocera cada area y responsable } \\
\text { Se le explicara como se ineteractua entre las areas de la empresa }\end{array}$ & Jefe de RR.HH / Jefes de areas \\
\hline $\begin{array}{l}\text { 3. RELACION LABORAL CON LA EMPRESA } \\
\text { 3.1 Modalidad de contratacion } \\
\text { 3.2 Horario de trabajo } \\
\text { 3.3 Entrega del MOF } \\
\text { 3.4 Relaciones internas y externas } \\
\text { 3.5 Uso de telefono y herramientas informaticas }\end{array}$ & $\begin{array}{l}\text { Jefe de RR.HH } \\
\text { Sistemas }\end{array}$ \\
\hline $\begin{array}{l}\text { 4. CONOCIMIENTO Y RELACION CON TODAS LAS AREAS } \\
\text { 4.1 Con el supervisor o jefe directo } \\
4.2 \text { Con los compañeros de trabajo } \\
4.3 \text { Con los subordinados de ser el caso }\end{array}$ & Jefe de area \\
\hline
\end{tabular}

Fuente: Propia 


\subsubsection{Capacitación, puesto en práctica y evaluación del desempeño.}

Las capacitaciones serán importantes para los colaboradores ya que así podrán cumplir con sus funciones de manera óptima y además logren adquirir conocimiento para brindar un servicio de calidad.

Temas: Capacitaciones serán la atención y servicio al cliente.

Respecto a la evaluación del desempeño del personal, se realizará en dos etapas. En primer lugar, el primer mes la evaluación del personal se realizará a modo de observación por ser el periodo de adaptación. Asimismo, se realizará reuniones semanales donde se podrán aclarar dudas, reforzar fortalezas y trabajar en los puntos críticos. En segundo lugar. A partir del segundo mes el Administrador o Supervisor realizará evaluaciones mensuales para asegurar que el personal califique para el perfil de acuerdo a la exigencia de La Tomate. Cada uno de estos procesos nos ayuda a que lo colaboradores alcancen los resultados deseados.

\subsubsection{Motivación}

La Tomate se enfocará en actividades para mantener una dinámica motivacional, como integración por ser el tema más importante integrar al personal mediante reuniones de confraternidad a fin de mejorar el clima laboral y relación entre cada uno de los colaboradores. Asimismo; estas actividades incluyen desde agasajos de cumpleaños de los colaboradores. Finalmente, podrán tener días libres, domingos y feriados donde podrán ser aprovechados por ellos, para desarrollar algunas actividades de interés personal.

\subsubsection{Sistema de remuneración}

El sistema de remuneración de "LA TOMATE", es por tiempo fijo de trabajo y de manera mensual. El horario de trabajo será de 6:00 a.m. a 03:00 p.m. Los empleados gozarán de todos sus beneficios de ley (Contrato laboral en base al Decreto Legislativo $N^{0} 728$ aprobado por el Decreto Supremo No 003-97-TR.) La administración será la encargada de realizar dicho pago que serán abonados los 30 de cada mes, mediante una cuenta bancaria que será abierta una vez que el colaborador sea contratado.

El sistema de remuneración será mediante el Régimen Laboral General (PYMEX, 2017) 
- Remuneración: S/. 930.00 (Mínimo) S/. 5000.00 (Máximo)

- Jornada-horarios: 8 horas diarias o 48 horas semanales.

- Descanso semanal: 24 horas y pago por sobretiempo.

- Vacaciones: 15 días.

- Despido arbitrario: $1 \frac{1}{2} 2$ remuneraciones por año, tope 12 remuneraciones, fracción en dozavos y treintavos.

- Seguro social: Trabajador es asegurado regular.

- Pensiones: El trabajador decide el sistema pensionario.

Los repartidores (motorizados), serán remunerados por recibo por honorarios, por comisión según cada entrega, con un sueldo básico de 500 soles. Además, se contará con personal externo como el contador y la nutricionista a quienes se les pagará con recibos de honorarios.

\subsection{Estructura de gastos de RR.HH}

Cuadro 16. Gastos de planilla

\begin{tabular}{|c|c|c|c|c|c|c|c|c|c|c|c|}
\hline \multirow[b]{2}{*}{ Gerente general } & \multirow{2}{*}{\begin{tabular}{|r|}
$\begin{array}{r}\text { Cantidad de } \\
\text { empleados }\end{array}$ \\
1 \\
\end{tabular}} & \multicolumn{2}{|c|}{ Sueldo Mensual } & \multirow{2}{*}{\begin{tabular}{|c|}
$\begin{array}{c}\text { \# sueldos } \\
\text { por año }\end{array}$ \\
12.00 \\
\end{tabular}} & \multicolumn{2}{|c|}{$\begin{array}{c}\text { Gratificaciones } \\
2 \text { por año }\end{array}$} & \multirow{2}{*}{\begin{tabular}{|c|} 
CTS \\
1 por año \\
$S / 2,000.00$ \\
\end{tabular}} & \multirow{2}{*}{\begin{tabular}{|l|} 
SUB TOTAL \\
S/30,000.00 \\
\end{tabular}} & \multirow{2}{*}{$\begin{array}{c}\text { ESSALUD } \\
9 \% \\
\mathrm{~S} / 2,700.00\end{array}$} & \multicolumn{2}{|c|}{ TOTAL ANUAL } \\
\hline & & S/ & $2,000.00$ & & $\mathrm{~s} /$ & $4,000.00$ & & & & $\mathrm{~s} /$ & $32,700.00$ \\
\hline Administrador & 1 & $\mathrm{~s} /$ & $1,500.00$ & 12.00 & s/ & $3,000.00$ & $S / 1,500.00$ & $S / 22,500.00$ & $S / 2,025.00$ & s/ & $24,525.00$ \\
\hline Jefe de cocina & 2 & S/ & $2,400.00$ & 12.00 & s/ & $4,800.00$ & $\mathrm{~S} / 2,400.00$ & $\mathrm{~S} / 36,000.00$ & $\mathrm{~S} / 6,480.00$ & s/ & $42,480.00$ \\
\hline Ayudante de cocina & 2 & S/ & $1,800.00$ & 12.00 & S/ & $3,600.00$ & $S / 1,800.00$ & $\mathrm{~S} / 27,000.00$ & $\mathrm{~S} / 4,860.00$ & S/ & $31,860.00$ \\
\hline Volante (Apoyo) & 2 & S/ & $1,000.00$ & 12.00 & S/ & - & S/ - & $\mathrm{S} / 12,000.00$ & S/ $\quad-$ & S/ & $12,000.00$ \\
\hline Asesor contable (apoyo) & 1 & S/ & 500.00 & 12.00 & S/ & - & $\mathrm{s} /$ & $\mathrm{S} / 6,000.00$ & $\mathrm{~s} /$ & $\mathrm{s} /$ & $6,000.00$ \\
\hline Nutricionista (apoyo) & 1 & s/ & 500.00 & 12.00 & $\mathrm{~s} /$ & - & $\mathrm{s} /$ & s/ $6,000.00$ & $\mathrm{~s} /$ & s/ & $6,000.00$ \\
\hline & & & & & & & & $\begin{aligned} \mathrm{TO} \\
\end{aligned}$ & & $\mathrm{s} /$ & $155,565.00$ \\
\hline
\end{tabular}

Fuente: Propia 


\section{PLAN ECONÓMICO FINANCIERO}

\subsection{Supuestos}

La Tomate, ha considerado los siguientes supuestos:

Cuadro 17. Supuestos

\section{SUPUESTOS}

1 Moneda SOLES

2 Se considera el costo de la mano de obra de isntalacion de todos los activos

3 Se incluye el IGV en todos los precios

4 El impuesto a la renta para el periodo actual es del 29.5\% según sunat

5 No se contara con inventarios al tener una rotacion muy rapida de productos perecibles y no perecibles

6 No se trabajara con ventas al credito

7 Se considera como amoritzacion de depreciacion el deterioro flotante de los activos intangibles

8 Horizonte de evaluacion de 5 años

9 Financiamiento $32 \%$ prestamo y $68 \%$ capital propio

10 Se crecera mas del 50\% que el sector, al ser un producto de calidad (16\% anual)

$11 \mathrm{Al}$ finalizar el año 2023 se volvera a invertir en activo fijo, al tener un valor depreciable de 0

Fuente: Propia

\subsection{Inversión en activos (fijos e intangibles) y depreciación}

Para iniciar este proyecto, necesitamos una inversión inicial de $\mathrm{S} / 53,735,00$, de los cuales el $92.41 \%$ está compuesto por activos tangibles y el diferencial de 7,59\% formado por los activos intangibles y la depreciación que se está considerando es de 05 años a través del método lineal. 
Cuadro 18. Depreciación

\begin{tabular}{|r|r|r|r|}
\hline $\begin{array}{c}\text { VIDA UTIL } \\
\text { (AÑNS) }\end{array}$ & $\begin{array}{c}\text { Depreciacion } \\
\text { ANUAL }\end{array}$ & $\begin{array}{c}\text { Depreciacion } \\
\text { acumulada 2023 }\end{array}$ & $\begin{array}{c}\text { VALOR } \\
\text { LIBROS }\end{array}$ \\
\hline 10 & $\mathrm{~S} / 150.00$ & $\mathrm{~S} / 750.00$ & $\mathrm{~S} / 750.00$ \\
\hline 10 & $\mathrm{~S} / 25.00$ & $\mathrm{~S} / 125.00$ & $\mathrm{~S} / 125.00$ \\
\hline 10 & $\mathrm{~S} / 35.00$ & $\mathrm{~S} / 175.00$ & $\mathrm{~S} / 175.00$ \\
\hline 10 & $\mathrm{~S} / 6.00$ & $\mathrm{~S} / 30.00$ & $\mathrm{~S} / 30.00$ \\
\hline 10 & $\mathrm{~S} / 12.00$ & $\mathrm{~S} / 60.00$ & $\mathrm{~S} / 60.00$ \\
\hline 10 & $\mathrm{~S} / 900.00$ & $\mathrm{~S} / 900.00$ \\
\hline
\end{tabular}

Fuente: Propia

Cuadro 19. Activo fijo intangible y tangible

\begin{tabular}{|c|c|c|c|}
\hline Activo fijo Intangible & Cantidad & $\begin{array}{l}\text { Precio } \\
\text { Compra }\end{array}$ & $\begin{array}{l}\text { PRECIO } \\
\text { TOTAL }\end{array}$ \\
\hline Constitucion de empresa & 1 & $S / 1,500.00$ & $S / 1,500.00$ \\
\hline Licencias & 1 & $\mathrm{~S} / 250.00$ & $\mathrm{~S} / 250.00$ \\
\hline Costos municipales & 1 & $\mathrm{~S} / 350.00$ & $\mathrm{~S} / 350.00$ \\
\hline Libros contables & 1 & $\mathrm{~s} / 60.00$ & $\mathrm{~S} / 60.00$ \\
\hline Comprobantes & 1 & $\mathrm{~S} / 120.00$ & $\mathrm{~S} / 120.00$ \\
\hline Creacion de redes sociales & 1 & $\mathrm{~S} / 1,800.00$ & $\mathrm{~S} / 1,800.00$ \\
\hline
\end{tabular}

\begin{tabular}{|c|c|c|c|}
\hline Activo fijo tangible & Cantidad & \begin{tabular}{l|} 
Precio \\
Compra \\
\end{tabular} & $\begin{array}{l}\text { PRECIO } \\
\text { TOTAL }\end{array}$ \\
\hline Cocina Industrial & 1 & $\mathrm{~S} / 6,000.00$ & $\mathrm{~S} / 6,000.00$ \\
\hline Plancha freidora & 1 & $\mathrm{~S} / 3,000.00$ & $\mathrm{~S} / 3,000.00$ \\
\hline Campana industrial extractora & 1 & $\mathrm{~S} / 16,500.00$ & $S / 16,500.00$ \\
\hline Mesas de trabajo $1.80 \times 0.8 \mathrm{mts}$ & 2 & $\mathrm{~S} / 750.00$ & $\mathrm{~S} / 1,500.00$ \\
\hline Mesas de trabajo $1.50 \times 0.8 \mathrm{mts}$ & 4 & $\mathrm{~S} / 500.00$ & $\mathrm{~S} / 2,000.00$ \\
\hline Refrigeradora & 1 & $S / 3,260.00$ & $\mathrm{~S} / 3,260.00$ \\
\hline Congeladora industrial & 1 & $\mathrm{~S} / 1,450.00$ & $\mathrm{~S} / 1,450.00$ \\
\hline Exhibidora de insumos & 1 & $S / 1,150.00$ & $S / 1,150.00$ \\
\hline Horno microndas & 2 & $S / 400.00$ & $\mathrm{~S} / 800.00$ \\
\hline Computadoras de escritorio & 2 & $S / 1,900.00$ & $\mathrm{~S} / 3,800.00$ \\
\hline Escritorio de madera & 3 & $\mathrm{~S} / 650.00$ & $\mathrm{~S} / 1,950.00$ \\
\hline Impresora multifuncional & 1 & $\mathrm{~S} / 550.00$ & $\mathrm{~S} / 550.00$ \\
\hline Televisor de 50" & 1 & $\mathrm{~S} / 2,000.00$ & $\mathrm{~S} / 2,000.00$ \\
\hline Celulares corporativos & 5 & $\mathrm{~S} / 400.00$ & $\mathrm{~S} / 2,000.00$ \\
\hline Licuadoras & 3 & S/299.00 & $\mathrm{S} / 897.00$ \\
\hline Procesadir de alimentos & 2 & $\mathrm{~S} / 399.00$ & $\mathrm{~S} / 798.00$ \\
\hline Menaje de cocina & 1 & $\mathrm{~S} / 2,000.00$ & $\mathrm{~S} / 2,000.00$ \\
\hline
\end{tabular}

INVERSION INICIAL EN ACTIVO TANGIBLE

$\mathrm{S} / 4,080.00$ INVERSION INICIAL EN ACTIVO INTANGIBLE $\mathrm{S} / 49,655.00$

Fuente: Propia 


\subsection{Proyección de ventas}

Ahora presentaremos la proyección de ventas de los próximos 05 años, en la cual se está considerando un crecimiento del $16 \%$ anual, el cual está por encima del sector en $8.95 \%$, este crecimiento estará sostenido en base a la calidad exclusiva de nuestros productos. Debemos tener en cuenta que para lograr proyección de ventas es importante conocer el plan de publicidad o marketing que se ejecutara, si hubiera ventas estacionales, así como también conocer los gastos fijos que se va a tener en el año, y tener un estimado de los variables también.

Cuadro 20. Proyección de ventas

\section{PROYECCION DE VENTAS}

\begin{tabular}{|c|c|c|c|c|c|}
\hline Producto & Participación & Precio de Venta & Costo de Venta & Margen & Rentabilidad \\
\hline Arroz con pollo & $40 \%$ & 15.00 & 8.86 & 6.14 & $41 \%$ \\
\hline Estofado de carne/pollo & $25 \%$ & 15.00 & 8.05 & 6.95 & $46 \%$ \\
\hline Tallarines rojos/verdes & $22 \%$ & 15.00 & 7.50 & 7.50 & $50 \%$ \\
\hline \multirow[t]{2}{*}{ Aji de gallina } & $13 \%$ & 15.00 & 8.20 & 6.80 & $45 \%$ \\
\hline & $100 \%$ & & 8.15 & & \\
\hline
\end{tabular}

\begin{tabular}{|l|c|c|c|c|c|}
\hline \multicolumn{1}{|c|}{ Años } & $\mathbf{2 0 1 9}$ & $\mathbf{2 0 2 0}$ & $\mathbf{2 0 2 1}$ & $\mathbf{2 0 2 2}$ & $\mathbf{2 0 2 3}$ \\
\hline Programa de Ventas Unidades & $\mathbf{2 7 2 7 2}$ & $\mathbf{3 1 6 3 6}$ & $\mathbf{3 6 6 9 8}$ & $\mathbf{4 2 5 6 9}$ & $\mathbf{4 9 3 8 0}$ \\
\hline Arroz con pollo & 10909 & 12654 & 14679 & 17028 & 19752 \\
\hline Estofado de carne/pollo & 6818 & 7909 & 9174 & 10642 & 12345 \\
\hline Tallarines rojos/verdes & 6000 & 6960 & 8073 & 9365 & 10864 \\
\hline Aji de gallina & 3545 & 4113 & 4771 & 5534 & 6419 \\
\hline
\end{tabular}

\begin{tabular}{|c|c|c|c|c|c|c|c|}
\hline Años & 2019 & & 2020 & & 2021 & 2022 & 2023 \\
\hline INGRESOS & S/. 409,085.76 & S $/$ & $474,539.48$ & S/. & $550,465.79$ & S/. 638,540.32 & S/. 740,706.77 \\
\hline Arroz con pollo & S/. $\quad 163,634.30$ & $\mathrm{~S} /$. & $189,815.79$ & $\mathrm{~S} /$. & $220,186.32$ & S/. $255,416.13$ & S/. $296,282.71$ \\
\hline Estofado de carne/pollo & S/. $\quad 102,271.44$ & $\mathrm{~S} /$. & $118,634.87$ & $\mathrm{~S} /$. & $137,616.45$ & S/. $\quad 159,635.08$ & S/. $\quad 185,176.69$ \\
\hline Tallarines rojos/verdes & S/. $\quad 89,998.87$ & $\mathrm{~S} /$. & $104,398.69$ & $\mathrm{~S} /$. & $121,102.47$ & S/. $\quad 140,478.87$ & S/. $\quad 162,955.49$ \\
\hline Aji de gallina & $53,181.15$ & $\mathrm{~S} /$. & $61,690.13$ & $\mathrm{~S} /$. & $71,560.55$ & $83,010.24$ & $96,291.88$ \\
\hline
\end{tabular}

\begin{tabular}{|c|c|c|c|c|c|c|c|}
\hline Años & 2019 & & 2020 & & 2021 & 2022 & 2023 \\
\hline COSTOS & S/. 225,588.02 & $\mathbf{S} /$ & $261,682.10$ & $\mathbf{S} /$. & $303,551.24$ & S/. 352,119.44 & $\mathrm{S} / \mathrm{408,458.55}$ \\
\hline Arroz con pollo & $96,630.55$ & $\mathrm{~S} /$. & $112,091.44$ & $\mathrm{~S} /$. & $130,026.07$ & S/. $\quad 150,830.25$ & S/. $\quad 174,963.08$ \\
\hline Estofado de carne/pollo & S/. $\quad 54,885.67$ & S/ & $63,667.38$ & $\mathrm{~S} /$. & $73,854.16$ & S/. $\quad 85,670.83$ & $99,378.16$ \\
\hline Tallarines rojos/verdes & S/. $\quad 44,999.43$ & $\mathrm{~S} /$ & $52,199.34$ & $\mathrm{~S} /$. & $60,551.24$ & $70,239.44$ & $81,477.75$ \\
\hline Aji de gallina & $29,072.36$ & $\mathrm{~S} /$ & $33,723.94$ & $\mathrm{~S} /$. & $39,119.77$ & $45,378.93$ & $52,639.56$ \\
\hline
\end{tabular}

Fuente: Propia 


\subsection{Calculo del capital de trabajo}

Los recursos de una empresa se dividen en dos partes, primero es en inmuebles, maquinas (activos) y la otra parte es para cubrir y pagar los sueldos, gastos entre otros.

El capital de trabajo es el fondo económico que utilizara la empresa para seguir reinvirtiendo y alcanzar utilidades para mantener la operación. Para establecer el capital de trabajo necesitamos de dos informaciones, que es el activo circulante y el pasivo circulante.

\section{Necesidad de Capital De Trabajo $=$ Activo Circulante - Pasivo Circulante}

Sin embargo para calcular nuestro capital de trabajo, La Tomate va a utilizar el Método de Déficit Acumulado de Caja, que consiste en estimar los flujos de ingresos y egresos mensuales y acumulados, considerando que están todos los gastos y costos indirectos y directos. 
Cuadro 21. Capital de trabajo

\begin{tabular}{|c|c|c|c|c|c|c|c|c|c|c|c|c|}
\hline Año 2018 & Enero & Febrero & Marzo & Abril & Mayo & Junio & Julio & Agosto & Septiembre & Octubre & Noviembre & Diciembre \\
\hline Ingresos & S/ $13,200.00$ & S/ 15,300.00 & S/ 17,745.00 & S/ 20,580.00 & S/ $23,865.00$ & S/ $27,675.00$ & S/ 32,100.00 & S/ 37,230.00 & S/ 43,185.00 & S/ 50,085.00 & S/ 58,095.00 & S/ 67,380.00 \\
\hline Costos & S/ $7,279.07$ & S/ $8,437.10$ & S/ $\quad 9,785.38$ & S/ 11,348.72 & $S / 13,160.22$ & S/ 15,261.22 & S/ 17,701.36 & S/ 20,530.27 & S/ 23,814.12 & S/ 27,619.09 & S/ 32,036.16 & S/ 37,156.32 \\
\hline Gastos Administrativos Mensuales & S/ $2,933.23$ & S/ $2,933.23$ & S/ $2,933.23$ & S/ $2,933.23$ & S/ $2,933.23$ & S/ $2,933.23$ & S/ $2,933.23$ & S/ $2,933.23$ & S/ $2,933.23$ & S/ $2,933.23$ & S/ $2,933.23$ & S/ $\quad 2,933.23$ \\
\hline Gastos de Venta Mensuales & S/ $\quad 450.00$ & S/ $\quad 450.00$ & S/ $\quad 450.00$ & 450.00 & S/ $\quad 450.00$ & 450.00 & S/ $\quad 450.00$ & 450.00 & 450.00 & 450.00 & 450.00 & 450.00 \\
\hline Gastos Operativos Mensuales & 650.00 & 650.00 & SI $\quad 650.00$ & S/ $\quad 650.00$ & 650.00 & 650.00 & 650.00 & 650.00 & 650.00 & 650.00 & 650.00 & 650.00 \\
\hline Planilla & S/ $\quad 9,700.00$ & S/ $\quad 9,700.00$ & S/ $\quad 9,700.00$ & S/ $\quad 9,700.00$ & $\mathrm{~S} / 13,550.00$ & S/ $9,700.00$ & S/ $17,400.00$ & S/ $9,700.00$ & S/ $9,700.00$ & S/ $9,700.00$ & $S / 13,550.00$ & S/ $17,400.00$ \\
\hline
\end{tabular}

\begin{tabular}{|c|c|c|c|c|c|c|c|c|c|c|c|c|}
\hline Acumulado & S/ - $-7,812.30$ & S/ - $-6,870.33$ & S/ $-5,773.61$ & S/ $-4,501.96$ & S/ $-6,878.45$ & S/ $-1,319.46$ & S/ $-7,034.60$ & S/ $2,966.49$ & S/ $\quad 5,637.64$ & S/ $8,732.68$ & S/ $8,475.61$ & S/ $\quad 8,790.45$ \\
\hline Saldo Inicial de caja & S/ & S/ $-7,812.30$ & S/-14,682.63 & S/-20,456.24 & S/-24,958.20 & S/-31,836.65 & S/-33,156.11 & S/-40,190.70 & S/-37,224.21 & S/-31,586.57 & S/-22,853.89 & S/-14,378.28 \\
\hline SALDO FINAL & S/ $-7,812.30$ & S/-14,682.63 & S/-20,456.24 & S/-24,958.20 & S/-31,836.65 & S/-33,156.11 & S/-40,190.70 & S/-37,224.21 & S/-31,586.57 & S/-22,853.89 & S/-14,378.28 & S/ $-5,587.83$ \\
\hline
\end{tabular}

Capital de trabajo S/-40,190.70

Fuente: Propia 


\subsection{Estructura de financiamiento: Tradicional y No tradicional}

Para el desarrollo de nuestro producto, hemos analizado cual sería la inversión, considerando aquellos instrumentos o recursos que necesita La Tomate, para poder iniciar operaciones.

Cuadro 22. Estructura de financiamiento

\begin{tabular}{|c|cc|c|}
\hline Concepto & \multicolumn{2}{|c|}{ Monto } & Peso \\
\hline Inversionistas privado & S/. & $30,000.00$ & $32 \%$ \\
\hline Capital social & S/. & $63,925.70$ & $68 \%$ \\
\hline Total & S/. & $\mathbf{9 3 , 9 2 5 . 7 0}$ & $\mathbf{1 0 0} \%$ \\
\hline
\end{tabular}

Fuente: Propia

\section{Cobertura de Inversión}

El total de la inversión que La Tomate necesita asciende a S/. 93, 925.70, de los cuales el $68 \%$ es de capital propio y el cual será financiado directamente de los socios y el $32 \%$ se obtendrá a través de un inversionista a cambio del $20 \%$ (sujeto a negociación) de las acciones de la empresa.

\subsection{Estados Financieros (Balance General, Estado de GGPP, Flujo de Caja)}

\subsubsection{Balance General}

El balance de la empresa nos va a mostrar la situación actual y futura de La Tomate, donde se puede apreciar el crecimiento de la misma.

Consideremos además que nuestros activos o capex no aumentaran, debido que desde un inicio nuestra empresa se ha implementado correctamente y con la inversión necesaria.

Si observamos los ratios de liquidez y endeudamiento, La Tomate tiene la suficiente capacidad para hacer frente a sus obligaciones. 
Cuadro 23. Balance general

\begin{tabular}{|l|c|c|c|c|c|c|}
\hline \multicolumn{1}{|c|}{ AÑOS } & $\mathbf{2 0 1 8}$ & $\mathbf{2 0 1 9}$ & $\mathbf{2 0 2 0}$ & $\mathbf{2 0 2 1}$ & $\mathbf{2 0 2 2}$ & $\mathbf{2 0 2 3}$ \\
\hline \multicolumn{1}{|c|}{ Activo } & & $\mathrm{S} / \mathbf{1 0 0 , 3 4 7}$ & $\mathrm{S} / . \mathbf{1 2 7 , 1 5 2}$ & $\mathrm{S} / \mathbf{1 7 7 , 6 1 4}$ & $\mathrm{S} / . \mathbf{2 6 7 , 5 7 4}$ & $\mathrm{S} / . \mathbf{3 8 9 , 8 4 3}$ \\
\hline Efectivo & & $\mathrm{S} / .16,760.04$ & $\mathrm{~S} / .53,903.91$ & $\mathrm{~S} / .114,705.60$ & $\mathrm{~S} / .215,004.77$ & $\mathrm{~S} / .347,612.22$ \\
\hline Capital de Trabajo & & $\mathrm{S} / .40,190.70$ & $\mathrm{~S} / .40,190.70$ & $\mathrm{~S} / .40,190.70$ & $\mathrm{~S} / .40,190.70$ & $\mathrm{~S} / .40,190.70$ \\
\hline Activo Fijo & & $\mathrm{S} / .53,735.00$ & $\mathrm{~S} / .53,735.00$ & $\mathrm{~S} / .53,735.00$ & $\mathrm{~S} / .53,735.00$ & $\mathrm{~S} / .53,735.00$ \\
\hline Depreciación & & $-\mathrm{S} / .10,339.00$ & $-\mathrm{S} / .20,678.00$ & $-\mathrm{S} / .31,017.00$ & $-\mathrm{S} / .41,356.00$ & $-\mathrm{S} / .51,695.00$ \\
\hline
\end{tabular}

\begin{tabular}{|l|l|c|c|c|c|c|}
\hline \multicolumn{1}{|c|}{ Pasivo y Patrimonio } & & $\mathrm{S} / . \mathbf{1 0 0 , 3 4 7}$ & $\mathrm{S} / . \mathbf{1 2 7 , 1 5 2}$ & $\mathrm{S} / .177,614$ & $\mathrm{~S} / . \mathbf{2 6 7 , 5 7 4}$ & $\mathrm{S} / . \mathbf{3 8 9 , 8 4 3}$ \\
\hline \multicolumn{1}{|c|}{ Pasivo } & & $\mathrm{S} / . \mathbf{2 1 , 1 0 9 . 5 3}$ & $\mathrm{S} / .11,152.20$ & $\mathrm{~S} / .0 .00$ & $\mathrm{~S} / . \mathbf{0 . 0 0}$ & $\mathrm{S} / . \mathbf{0 . 0 0}$ \\
\hline Préstamo & & $\mathrm{S} / .30,000.00$ & $\mathrm{~S} / .30,000.00$ & $\mathrm{~S} / .30,000.00$ & & \\
\hline Amortización & & $-\mathrm{S} / .8,890.47$ & $-\mathrm{S} / .18,847.80$ & $-\mathrm{S} / .30,000.00$ & & \\
\hline \multicolumn{1}{|c|}{ Patrimonio } & & $\mathrm{S} / .79,237.22$ & $\mathrm{~S} / .115,999.41$ & $\mathrm{~S} / .177,614.30$ & $\mathrm{~S} / .267,574.47$ & $\mathrm{~S} / .389,842.92$ \\
\hline Patrimonio & & $\mathrm{S} / .63,925.70$ & $\mathrm{~S} / .63,925.70$ & $\mathrm{~S} / .63,925.70$ & $\mathrm{~S} / .63,925.70$ & $\mathrm{~S} / .63,925.70$ \\
\hline resultado del ejercicio & & $\mathrm{S} / .15,311.51$ & $\mathrm{~S} / .36,762.19$ & $\mathrm{~S} / .61,614.89$ & $\mathrm{~S} / .89,960.17$ & $\mathrm{~S} / .122,268.45$ \\
\hline Resultado Acumulado & & $\mathrm{S} / .52,073.70$ & $\mathrm{~S} / .113,688.60$ & $\mathrm{~S} / .203,648.77$ & $\mathrm{~S} / .325,917.22$ \\
\hline
\end{tabular}

Fuente: Propia

Cuadro 24. Ratios financieros

\begin{tabular}{r|r|r} 
Ratio de Liquidez & S/. 1,062,530.06 & S/. 32.93
\end{tabular}

Por cada sol de deuda, existe un respaldo de S/. 32.93 soles mas

\begin{tabular}{|c|r|c|}
\hline Ende udamie nto & $\mathrm{S} / .32,261.74$ & $\mathrm{~S} / .3 .04$ \\
\cline { 1 - 2 } & $\mathrm{S} / .1,062,530.06$ & \\
\hline $\begin{array}{c}\text { Se puede mostrar que existe autonomia financiera y } \\
\text { respaldo exonomico, frente a contingencias }\end{array}$ \\
\hline
\end{tabular}

\subsubsection{Estado Ganancias y Perdidas}

Con el estado de ganancias y pérdidas, mediremos la actividad de La Tomate a lo largo de los periodos presentados, a fin de conocer si da o no rentabilidad. 
Los números que se muestran a continuación, dan como resultado un crecimiento años tras año, lo que también se puede interpretar que hay un buen control y medición de costos y gastos.

Esta herramienta es de suma importancia, para saber en qué momento debemos reaccionar o cambiar de estrategia, ante una posible contingencia o riesgos que se puedan presentar.

Cuadro 25. Estado de ganancias y pérdidas

\begin{tabular}{|l|r|r|r|r|r|r|}
\hline \multicolumn{1}{|c|}{ AÑOS } & \multicolumn{1}{c|}{$\mathbf{2 0 1 9}$} & \multicolumn{1}{c|}{$\mathbf{2 0 2 0}$} & \multicolumn{1}{c|}{$\mathbf{2 0 2 1}$} & \multicolumn{1}{c|}{$\mathbf{2 0 2 2}$} & \multicolumn{1}{c|}{$\mathbf{2 0 2 3}$} \\
\hline Incremento Procentual & & & $\mathbf{0 . 1 6}$ & $\mathbf{0 . 1 6}$ & $\mathbf{0 . 1 6}$ & $\mathbf{0 . 1 6}$ \\
\hline Ingresos & & $409,085.76$ & $474,539.48$ & $550,465.79$ & $638,540.32$ & $740,706.77$ \\
\hline Costo de Ventas & & $225,588.02$ & $261,682.10$ & $303,551.24$ & $352,119.44$ & $408,458.55$ \\
\hline Utilidad Bruta & & $\mathbf{1 8 3 , 4 9 7 . 7 4}$ & $\mathbf{2 1 2 , 8 5 7 . 3 7}$ & $\mathbf{2 4 6 , 9 1 4 . 5 5}$ & $\mathbf{2 8 6 , 4 2 0 . 8 8}$ & $\mathbf{3 3 2 , 2 4 8 . 2 2}$ \\
\hline Gastos Adm & & $75,603.76$ & $75,603.76$ & $75,603.76$ & $75,603.76$ & $75,603.76$ \\
\hline Gastos Venta & & $65,075.04$ & $65,075.04$ & $65,075.04$ & $65,075.04$ & $65,075.04$ \\
\hline Gastos Operativos & $7,800.00$ & $7,800.00$ & $7,800.00$ & $7,800.00$ & $7,800.00$ \\
\hline Depreciación & & $9,931.00$ & $9,931.00$ & $9,931.00$ & $9,931.00$ & $9,931.00$ \\
\hline Amortización & & 408.00 & 408.00 & 408.00 & 408.00 & 408.00 \\
\hline Utilidad Operativa & & $\mathbf{2 4 , 6 7 9 . 9 4}$ & $\mathbf{5 4 , 0 3 9 . 5 7}$ & $\mathbf{8 8 , 0 9 6 . 7 5}$ & $\mathbf{1 2 7 , 6 0 3 . 0 8}$ & $\mathbf{1 7 3 , 4 3 0 . 4 2}$ \\
\hline Gastos Financieros & & $2,961.48$ & $1,894.62$ & 699.74 & & - \\
\hline Utilidad Antes de Imp & & $\mathbf{2 1 , 7 1 8 . 4 6}$ & $\mathbf{5 2 , 1 4 4 . 9 5}$ & $\mathbf{8 7 , 3 9 7 . 0 1}$ & $\mathbf{1 2 7 , 6 0 3 . 0 8}$ & $\mathbf{1 7 3 , 4 3 0 . 4 2}$ \\
\hline Imp a la Renta & & $-6,406.95$ & $-15,382.76$ & $-25,782.12$ & $-37,642.91$ & $-51,161.97$ \\
\hline Utilidad neta & & $\mathbf{1 5 , 3 1 1 . 5 1}$ & $\mathbf{3 6 , 7 6 2 . 1 9}$ & $\mathbf{6 1 , 6 1 4 . 8 9}$ & $\mathbf{8 9 , 9 6 0 . 1 7}$ & $\mathbf{1 2 2 , 2 6 8 . 4 5}$ \\
\hline
\end{tabular}

\section{Rentabilidad}

Fuente: Propia

\subsubsection{Flujo de Caja}

En el flujo de caja económico, nos va a permitir conocer la rentabilidad y viabilidad de nuestro proyecto. Acá estamos proyectando los ingresos y egresos de dinero, en un determinado periodo.

Con los números mostrados, evidenciamos que el proyecto de La Tomate es rentable y se puede sostener en el tiempo.

La inversión inicial es de S/. 93, 925.70 y entre finales del tercer año e inicios del cuarto año, recuperamos la inversión. 
Nuestro estimado en el crecimiento de ventas, está basado a la buena salud de la empresa, asi como también en la demanda que vamos a cubrir y la expansión a la que pretendemos llegar.

Cuadro 26. Flujo de caja

FLUJO DE CAJA - LA TOMATE

\begin{tabular}{|l|r|r|r|r|r|r|}
\hline \multicolumn{1}{|c|}{ AÑ̃S } & \multicolumn{1}{c|}{$\mathbf{2 0 1 8}$} & \multicolumn{1}{c|}{$\mathbf{2 0 1 9}$} & \multicolumn{1}{c|}{$\mathbf{2 0 2 0}$} & \multicolumn{1}{c|}{$\mathbf{2 0 2 1}$} & \multicolumn{1}{c|}{$\mathbf{2 0 2 2}$} & \multicolumn{1}{c|}{$\mathbf{2 0 2 3}$} \\
\hline Ingresos & & $409,085.76$ & $474,539.48$ & $550,465.79$ & $638,540.32$ & $740,706.77$ \\
\hline Costo de Ventas & & $225,588.02$ & $261,682.10$ & $303,551.24$ & $352,119.44$ & $408,458.55$ \\
\hline Utilidad Bruta & & $183,497.74$ & $212,857.37$ & $246,914.55$ & $286,420.88$ & $332,248.22$ \\
\hline Gastos Adm & & $75,603.76$ & $75,603.76$ & $75,603.76$ & $75,603.76$ & $75,603.76$ \\
\hline Gastos Venta & & $65,075.04$ & $65,075.04$ & $65,075.04$ & $65,075.04$ & $65,075.04$ \\
\hline Gastos Operativos & & $7,800.00$ & $7,800.00$ & $7,800.00$ & $7,800.00$ & $7,800.00$ \\
\hline Depreciación & & $9,931.00$ & $9,931.00$ & $9,931.00$ & $9,931.00$ & $9,931.00$ \\
\hline Amortización & & 408.00 & 408.00 & 408.00 & 408.00 & 408.00 \\
\hline EBIT & & $24,679.94$ & $54,039.57$ & $88,096.75$ & $127,603.08$ & $173,430.42$ \\
\hline Impuesto a la Renta & & $7,280.58$ & $15,941.67$ & $25,988.54$ & $37,642.91$ & $51,161.97$ \\
\hline Depre ciación & $9,931.00$ & $9,931.00$ & $9,931.00$ & $9,931.00$ & $9,931.00$ \\
\hline Amortización & 408.00 & 408.00 & 408.00 & 408.00 & 408.00 \\
\hline FEO & & $27,738.36$ & $48,436.90$ & $72,447.21$ & $100,299.17$ & $132,607.45$ \\
\hline Activos Fijos Tangibles & $-49,655.00$ & & & & & \\
\hline Activo Fijos Intangible & $-4,080.00$ & & & & & \\
\hline Capital de Trabajo & $-40,190.70$ & & & & & \\
\hline Flujo de Caja Libre & $-93,925.70$ & $27,738.36$ & $48,436.90$ & $72,447.21$ & $100,299.17$ & $132,607.45$ \\
\hline
\end{tabular}

Fuente: Propia

\subsection{Flujo Financiero}

Según se muestra el flujo de caja financiero, el inversionista podrá recuperar su inversion a principios del tercer año. Incluso con miras a un crecimiento se podría proponer una nueva reinversion a fin de buscar la expansion en el mercado. 
Cuadro 27. Flujo de caja financiero

\section{FLUJO DE CAJA - LA TOMATE}

\begin{tabular}{|c|c|c|c|c|c|c|}
\hline AÑOS & 2018 & 2019 & 2020 & 2021 & 2022 & 2023 \\
\hline Ingresos & & $409,085.76$ & $474,539.48$ & $550,465.79$ & $638,540.32$ & $740,706.77$ \\
\hline Costo de Ventas & & $225,588.02$ & $261,682.10$ & $303,551.24$ & $352,119.44$ & $408,458.55$ \\
\hline Utilidad Bruta & & $183,497.74$ & $212,857.37$ & $246,914.55$ & $286,420.88$ & $332,248.22$ \\
\hline Gastos Adm & & $75,603.76$ & $75,603.76$ & $75,603.76$ & $75,603.76$ & $75,603.76$ \\
\hline Gastos Venta & & $65,075.04$ & $65,075.04$ & $65,075.04$ & $65,075.04$ & $65,075.04$ \\
\hline Gastos Operativos & & $7,800.00$ & $7,800.00$ & $7,800.00$ & $7,800.00$ & $7,800.00$ \\
\hline Depreciación & & $9,931.00$ & $9,931.00$ & $9,931.00$ & $9,931.00$ & $9,931.00$ \\
\hline Amortización & & 408.00 & 408.00 & 408.00 & 408.00 & 408.00 \\
\hline EBIT & & $24,679.94$ & $54,039.57$ & $88,096.75$ & $127,603.08$ & $173,430.42$ \\
\hline Impuesto a la Renta & & $7,280.58$ & $15,941.67$ & $25,988.54$ & $37,642.91$ & $51,161.97$ \\
\hline Depreciación & & $9,931.00$ & $9,931.00$ & $9,931.00$ & $9,931.00$ & $9,931.00$ \\
\hline Amortización & & 408.00 & 408.00 & 408.00 & 408.00 & 408.00 \\
\hline FEO & & $27,738.36$ & $48,436.90$ & $72,447.21$ & $100,299.17$ & $132,607.45$ \\
\hline Activos Fijos Tangibles & $-49,655.00$ & & & & & \\
\hline Activo Fijos Intangible & $-4,080.00$ & & & & & \\
\hline Capital de Trabajo & $-40,190.70$ & & & & & \\
\hline Flujo de Caja Libre & $-93,925.70$ & $27,738.36$ & $48,436.90$ & $72,447.21$ & $100,299.17$ & $132,607.45$ \\
\hline Prestamo & $30,000.00$ & & & & & \\
\hline Cuota & & $11,851.95$ & $11,851.95$ & $11,851.95$ & & \\
\hline Escudo Fis cal & & 873.64 & 558.91 & 206.42 & & \\
\hline Flujo de Caja del Inversionista & $-63,925.70$ & $16,760.04$ & $37,143.87$ & $60,801.69$ & $100,299.17$ & $132,607.45$ \\
\hline
\end{tabular}

Fuente: Propia

\subsection{Tasa de descuento accionistas y wacc}

Cuadro 28. Tasa de descuento accionistas

\begin{tabular}{|c|c|c|}
\hline Concepto & Base & Dato \\
\hline Rendimiento del Mercado & Rendimiento USA (S\&P 500) - Damodaran & $11.6 \%$ \\
\hline Tasa Libre de Riesgo & Tasa USA (T-Bonds) - Damodaran & $7.0 \%$ \\
\hline Beta & Diversified & $56.0 \%$ \\
\hline \% Capital Propio & Estructura de financiamiento del proyecto & $100.0 \%$ \\
\hline$\%$ Financiamiento & Estructura de financiamiento del proyecto & $0.0 \%$ \\
\hline Tasa Impuesto a la Renta & Leagislación Vigente & $29.5 \%$ \\
\hline Beta Desapalancada & $\mathrm{BD}=\mathrm{B} /\left\{[1+(\mathrm{D} / \mathrm{E})]^{*}(1-\mathrm{I})\right\}$ & $79.4 \%$ \\
\hline Riesgo País & $\mathrm{BCR}$ & $1.4 \%$ \\
\hline Beta Apalancado & $\mathrm{BA}=\mathrm{BD} *\left\{[1+(\mathrm{D} / \mathrm{E})]^{*}(1-\mathrm{I})\right\}$ & $56.0 \%$ \\
\hline Costo Capital Propio al/ & $\mathrm{KP}=\mathrm{TLR}+[\mathrm{BA} *(\mathrm{RM}-\mathrm{TLR})]+\mathrm{RP}$ & $11.0 \%$ \\
\hline Riesgo Tamaño del Negocio & 80\%: $\quad \mathrm{RTN}=\mathrm{KP} * 0.80$ & $8.8 \%$ \\
\hline Riesgo Know How & $\mathrm{RN}=\mathrm{KP} * 0.50$ & $5.5 \%$ \\
\hline Costo Capital Propio Ajustado $\underline{\mathrm{b}} /$ & $K P_{1}=K P+R T N+R N$ & $25.3 \%$ \\
\hline
\end{tabular}

Fuente: Propia 


\section{Tasa de Descuento Accionistas}

Para hallar costo de oportunidad de los accionistas estamos usando el modelo CAMP, de esta manera damos a conocer al accionista el rendimiento esperado.

Para obtener este cálculo se ha usado información basada en el mercado de capitales de EE.UU, añadiendo el riego país, con el cual se obtuvo un COK de 25.3\%.

\section{WACC}

La utilidad del cálculo del Wacc en el siguiente cuadro permite estimar datos de la empresa desde tres enfoques:

- Desde el activo de la compañía; es la tasa que se debe usar para descontar el flujo de caja esperado.

- Desde el pasivo de la compañía; el costo económico para la compañía de atraer capital del sector.

- Desde el Inversionista de la compañía; el retorno que esperan al invertir su deuda.

Cuadro 29. Calculo de WACC

\begin{tabular}{|c|c|c|}
\hline Concepto & Base & Dato \\
\hline Rendimiento del Mercado & Rendimiento USA (S\&P 500) - Damodaran & $11.6 \%$ \\
\hline Tasa Libre de Riesgo & Tasa USA (T-Bonds) - Damodaran & $7.0 \%$ \\
\hline Beta & Diversified & $56.0 \%$ \\
\hline \% Capital Propio & Estructura de financiamiento del proyecto & $68.1 \%$ \\
\hline$\%$ Financiamiento & Estructura de financiamiento del proyecto & $31.9 \%$ \\
\hline Tasa Impuesto a la Renta & Leagislación Vigente & $29.5 \%$ \\
\hline Beta Desapalancada & $\mathrm{BD}=\mathrm{B} /\left\{[1+(\mathrm{D} / \mathrm{E})]^{\star}(1-\mathrm{I})\right\}$ & $54.1 \%$ \\
\hline Riesgo País & BCR & $1.4 \%$ \\
\hline Beta Apalancado & $B A=B D^{*}\left\{[1+(D / E)]^{*}(1-I)\right\}$ & $56.0 \%$ \\
\hline Costo Capital Propio al/ & $\mathrm{KP}=\mathrm{TLR}+[\mathrm{BA} *(\mathrm{RM}-\mathrm{TLR})]+\mathrm{RP}$ & $11.0 \%$ \\
\hline Riesgo Tamaño del Negocio & $80 \%: \quad$ RTN $=K P * 0.80$ & $9 \%$ \\
\hline Riesgo Know How & $\mathrm{RN}=\mathrm{KP} * 0.50$ & $5.50 \%$ \\
\hline Costo Capital Propio Ajustado b/ & $K P_{1}=K P+R T N+R N$ & $25 \%$ \\
\hline Costo de la Deuda & T.E.A del Préstamo & $12.0 \%$ \\
\hline Costo Efectivo de Deuda & $C E=C D^{*}(1-I)$ & $8.5 \%$ \\
\hline Costo Promedio de Capital $\underline{\mathbf{c l}}$ & $W A C C=\left\{K P_{1}^{*}[E /(E+D)]\right\}+\{C D *(1-I) *[D /(E+D)]\}$ & $20 \%$ \\
\hline
\end{tabular}

Fuente: Propia 


\subsection{Indicadores de rentabilidad}

El proyecto LA TOMATE, está generando una VAN positivo para él, tanto para el flujo económico como para el financiero. Con el flujo financiero representa un valor de S/ 87,725.87 soles, generando una mayor rentabilidad frente a lo esperado ganar que fue de un COK de $25.3 \%$.

Cuadro 30. Indicadores de rentabilidad

\section{INDICADORES DE RENTABILIDAD}

\begin{tabular}{|c|c|c|c|c|c|c|}
\hline \multirow{2}{*}{ CONCEPTO } & \multirow{2}{*}{ Año 0} & \multicolumn{5}{|c|}{ Proyección Anual } \\
\hline & & 2019 & 2020 & 2021 & 2022 & 2023 \\
\hline FLUJO ECONOMICO & $-S / .93,926$ & $S / .27,738$ & $5 / .48,437$ & $5 / .72,447$ & S/.100,299 & S/.132,607 \\
\hline FLUJO FINANCIERO & $-5 / .63,926$ & $\mathrm{~s} / .16,760$ & S/.37,144 & $\mathrm{s} / .60,802$ & $\mathrm{~s} / .100,299$ & S/.132,607 \\
\hline
\end{tabular}

\begin{tabular}{|lr|}
\hline VAN ECONOMICO & $\mathrm{S} / 106,934.07$ \\
VAN FINANCIERO & $\mathrm{S} / 87,725.87$ \\
TIR ECONOMICO & \\
TIR FINANCIERO & $53 \%$ \\
& $63 \%$ \\
TIRM ECONOMICA & \\
TIRM FINANCIERA & $43 \%$ \\
\hline
\end{tabular}

Considerando una tasa del $29.5 \%$ para las Reinversiones

\begin{tabular}{|c|c|c|c|c|c|c|}
\hline CONCEPTO & Año 0 & 2018 & 2019 & 2020 & 2021 & 2022 \\
\hline Flujo Económico Descontado & $(93,926)$ & 27,738 & 48,437 & 72,447 & 100,299 & 132,607 \\
\hline Acumulado & $(63,926)$ & $(36,187)$ & 12,250 & 84,697 & 184,996 & 317,603 \\
\hline Período de Recupero Económico & \multicolumn{2}{|c|}{2 años } & & & & \\
\hline CONCEPTO & Año 0 & 2018 & 2019 & 2020 & 2021 & 2022 \\
\hline Flujo Financiero Descontado & $(63,926)$ & 15,100 & 33,466 & 54,781 & 90,367 & 119,475 \\
\hline Acumulado & $(66,819)$ & $(51,718)$ & $(18,253)$ & 36,528 & 126,894 & 246,370 \\
\hline Período de Recupero Financiero & \multicolumn{2}{|c|}{2 años } & & & & \\
\hline
\end{tabular}

Fuente: Propia

\subsection{Análisis de Riesgos}

Procederemos con la evaluación de los riesgos cuantitativos y cualitativos, esto nos permitirá conocer que tal vulnerables podemos estar y la amenazas a las que nos enfrentamos, conforme vayamos teniendo el conocimiento de estas, podremos tomar el control y las mejores decisiones para contrarrestar estos riesgos. 


\subsubsection{Análisis de sensibilidad}

El análisis de sensibilidad le va a permitir a La Tomate tomar decisiones acertadas, respecto a la inversión, teniendo en cuenta los flujos de caja y el VAN.

En este escenario hemos considerado o supuesto variaciones que puedan castigar el presupuesto de caja y también mostrar la holgura con la que contamos para la realización ante cambios eventuales que puedan presentarse en el mercado.

El análisis de la sensibilidad a la variación del precio con disminución de S/ 1.00 sol, sigue representando un VAN mayor a 0, ya nos genera un ingreso adicional de $\mathrm{S} / 19,829$ soles a la tasa esperada.

Cuadro 31. Análisis de sensibilidad a variación de precio (Importes en Nuevos Soles)

\begin{tabular}{|c|c|c|c|c|c|}
\hline \multicolumn{6}{|c|}{ DATOS DE LA PROYECCIÓN INICIAL } \\
\hline Concepto & Año 1 & Año 2 & Año 3 & Año 4 & Año 5 \\
\hline Precio del menu & 15.00 & 15.00 & 15.00 & 15.00 & 15.00 \\
\hline \multicolumn{5}{|c|}{ VANE } & 106,934 \\
\hline \multicolumn{5}{|c|}{ TIRE } & $52.58 \%$ \\
\hline \multicolumn{5}{|c|}{ PORCENTAJE DE DISMINUCIÓN EN EL PRECIO } & \\
\hline Precio Litro & 14.00 & 14.00 & 14.00 & 14.00 & 14.00 \\
\hline \multicolumn{5}{|c|}{ NUEVO VANE } & 19,829 \\
\hline \multicolumn{5}{|c|}{ NUEVO TIR } & $26.00 \%$ \\
\hline
\end{tabular}

Fuente: Propia

\subsubsection{Análisis por escenarios (por variables)}

- En el escenario pesimista, si al precio del menú le bajamos 1 sol, este proyecto sigue siendo viable. Ya que aún sigue presentando un VAN de S/ 19,829

- En los escenarios normales se genera VAN positivos. Con un valor de S/ 106,934 y una probabilidad de ocurrencia del $50 \%$ a favor de nosotros.

- Si se aumenta el precio a 1 sol por cada menú, nuestro VAN sigue siendo aún positivo. Con una VAN de S/ 196,958 y una probabilidad del 40\% de ocurrencia 
Cuadro 32. Análisis de sensibilidad multidimensional

\section{ANÁLISIS DE SENSIBILIDAD MULTIDIMENSIONAL}

\begin{tabular}{|c|c|c|c|}
\hline & PESIMISTA & NORMAL & OPTIMISTA \\
\hline \multicolumn{4}{|c|}{ VARIABLES ENTRADA } \\
\hline PRECIOS & $-7 \%$ & $0 \%$ & $7 \%$ \\
\hline DEMANDA & $-7 \%$ & $0 \%$ & $7 \%$ \\
\hline COSTOS VARIABLES & $-7 \%$ & $0 \%$ & $7 \%$ \\
\hline \multicolumn{4}{|c|}{ VARIABLES DE SALIDA } \\
\hline VANE & 19,829 & 106,934 & 196,958 \\
\hline TIRE & $28.80 \%$ & $52.58 \%$ & $253.97 \%$ \\
\hline
\end{tabular}

\begin{tabular}{|l|c|c|c|}
\hline ESCENARIOS PROBABILIDADES & $10 \%$ & $50 \%$ & $40 \%$ \\
\hline
\end{tabular}

\begin{tabular}{|l|ll|}
\hline VAN ECONOMICO ESPERADO & S/. $134,233.14$ \\
\hline
\end{tabular}

Fuente: Propia

\subsubsection{Análisis de punto de equilibro}

Lo que se busca con el punto de equilibrio, es confirmar que La Tomate podrá cubrir los costos fijos y variables, al lograr que nuestras ventas incrementen, el punto de equilibrio será mayor y obtendremos un beneficio positivo, en cambio si el escenario se mostrará adverso vamos a generar pérdidas.

De acuerdo al desarrollo se observa que la cantidad en unidades para no perder ni ganar debe ser de 22,445 unidades, llegando así al punto de equilibrio en soles de S/. 336,675.71.

Respetando estas cifras La Tomate no perderá rentabilidad, aunque la idea de todo negocio es ir creciendo de manera proporcional y anual. 
Cuadro 33. Análisis de punto de equilibrio

\section{PUNTO DE EQUILIBRIO}

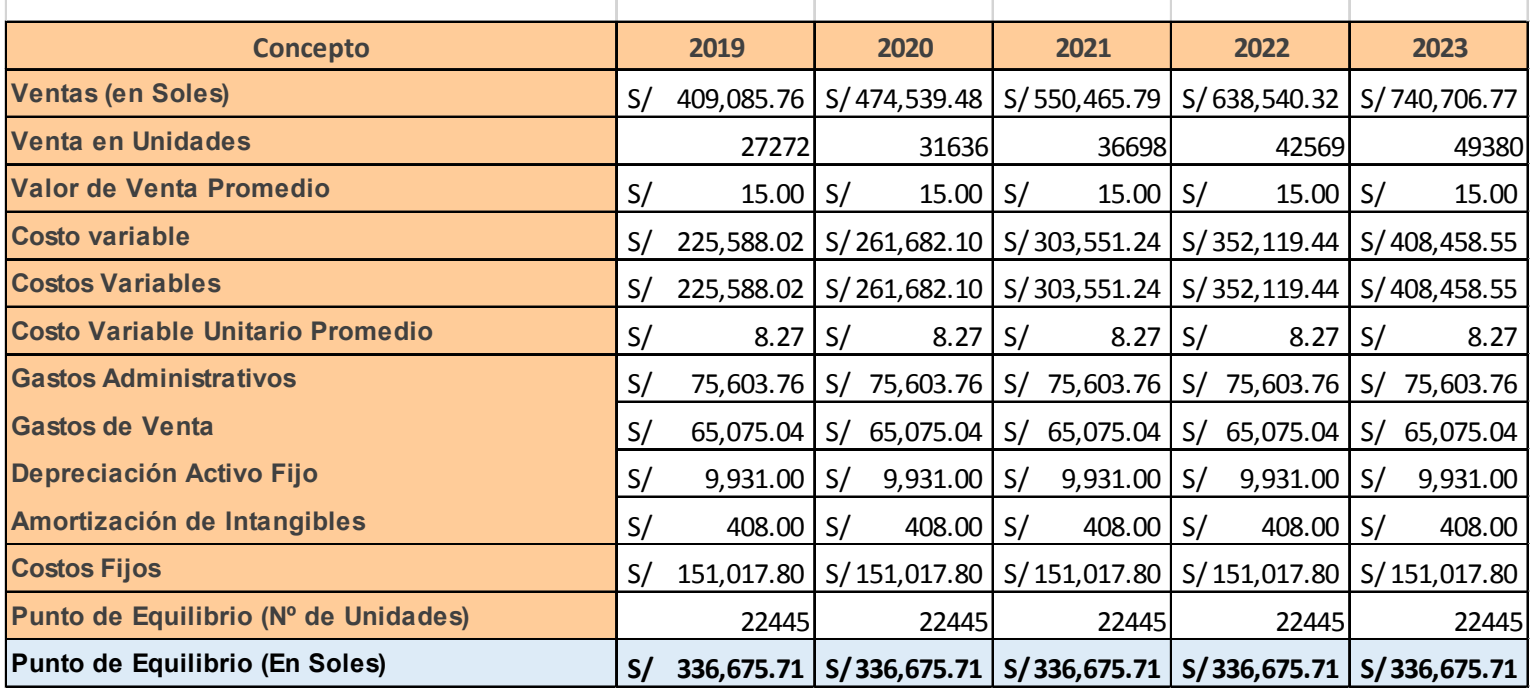

Fuente: Propia

\subsubsection{Principales riesgos del proyecto (cualitativos)}

- Falta de compromiso de nuestros colaboradores, al no tomar con responsabilidad las tareas que se les encomiende.

- No cumplir con nuestros clientes, entregando pedidos que no sean los solicitados.

- Que la cultura organizacional y política sean débiles.

- Mala distribución de funciones.

- Que los proveedores nos ofrezcan insumos de mala calidad, lo cual perjudicaría la imagen y servicio de la empresa.

- No respetar los tiempos ofrecidos con nuestros clientes.

- Permitir que los menús lleguen a la temperatura no adecuada o que los tapers estén sucios de la propia comida. 


\section{CONCLUSIONES}

\subsection{Conclusiones generales}

- La necesidad de comer a diario, es la principal fuente impulsadora para la creación de este modelo de negocio. Gracias a los estudios realizados, se ha podido medir el impacto que el modelo tendrá para afrontar esta necesidad a través del valor que ofrecerá la compañía.

- Los estudios realizados directamente sobre el mercado objetivo de San Isidro nos permiten observar que es un mercado con alto potencial de desarrollo debido al nivel socio económico de los trabajadores que operan en el sector y de la competencia que en primera instancia apunta hacia otro sector. Esto permitirá el éxito y desarrollo del negocio a través del tiempo.

- El modelo de negocio de La Tomate, busca cubrir la necesidad de aquellos comensales que trabajan en la zona de san isidro a fin de tener una alimentación sana, de calidad y con el sabor de casa. Uno de los factores claves para el éxito del negocio, será que se encuentren bien definidos y homologados nuestros proveedores, cumpliendo como mínimo las normas dadas por Digesa.

- La Tomate al ser una empresa nueva y con miras al crecimiento sostenido, deberá cumplir con procedimientos y políticas que estan definidas de acuerdo al modelo de negocio. Para el éxito de esto es importante que las cabezas de la organización sean las primeras en cumplir y hacerlas cumplir, de ser necesario serán modificadas previo consenso.

- La Tomate está construyendo políticas de calidad importantes que nos permita identificar, resaltar y desarrollar los puntos que hay que cubrir y considerar para llevar acabo un manejo exitoso de la empresa. Nos deja muchas cosas importantes que reflexionar, así como para reforzar y ejecutar una buena implementación.

- Se concluye que en San isidro para las personas que laboran es muy importante buscar comida sana en un tiempo tan corto, sobre todo en la hora de su refrigerio debido a que son pocos los lugares que brindan un servicio de calidad rápida y ágil para la alimentación en la zona, por lo que la Tomate apuesta en brindar el mejor servicio en un tiempo oportuno y de calidad para siendo el factor más importante el sabor de casa. 
- La Tomate al será una empresa nueva y con miras al crecimiento sostenido, deberá cumplir con procedimientos y políticas que están definidas de acuerdo al modelo de negocio. Para el éxito de esto es importante que las cabezas de la organización sean las primeras en cumplir y hacerlas cumplir, de ser necesario serán modificadas previo consenso.

- En la evaluación de los escenarios, la disminución del precio en un 7\% solo tiene un $10 \%$ de probabilidad de que ocurra, siendo este un valor disminución de S/. 1.00 sol frente al precio actual de S/ 15.00 soles. El proyecto seguiría siendo rentable al tener VAN positivo de S/. 35,760.00. Evaluando nuestro potenciales de riesgos para que ocurra dicho escenario está el ingreso de nuevos competidores, los cuales aumentaría la oferta en el distrito y harían que los precios disminuyan para no perder a los actuales clientes.

- El proyecto "La Tomate" es viable, al presentar un van económico de 106934.07 soles, representando una ganancia adicional al COK del 23\% y un van financiero de 87725.87 al solicitar un inversionista a cambio de acciones de la empresa.

\subsection{Conclusiones individuales}

- La necesidad implícita de comer a diario, es la principal fuente impulsadora para la creación y desarrollo de este modelo de negocio. Esto, de la mano con los estudios cualitativos y cuantitativos realizados en el punto 5. Plan de Marketing, a través de encuestas y principalmente salidas al campo, donde se plantea el desarrollo del mercado objetivo, nos permitieron encontrar insights diferentes dentro de la mente del consumidor los cuales no representaron solo frases publicitarias, sino el sentir real del consumidor antes de ver cualquier imagen publicitaria. Es de vital importancia tener clara antes de cualquier estrategia la relación producto consumidor. En nuestro caso, dentro de los insights detectados, utilizamos el siguiente: "No importa donde estés, ni el momento... cuando la pruebes siempre estarás en casa" y es bajo este insight, que nacieron estrategias creativas e innovadoras que nos permiten aprovechar las oportunidades que el mercado ofrece.

- La principal idea de encontrar un insight del consumidor es que este sea accionable y nos permita desplegar, a través de este, una propuesta de comunicación o estrategia de 
marketing, por lo que La Tomate, a través de los insights detectados y mencionados anteriormente, es que crea el slogan "Come sano, come bien" el cuál, no solo refleja una relación con el consumidor actual, sino además, se encuentra de la mano con la tendencia explícita de comer bien la cual representa una oportunidad importante para el desarrollo de estrategias ofensivas de penetración del mercado al que nos dirigimos tal como se puede visualizar en el punto 3. Planeamiento estratégico y su desarrollo.

- Finalmente, es importante mencionar que en la actualidad, verse bien es cada vez una tendencia más grande y poderosa, sobre la que las empresas debemos desarrollarnos y optar por estas verdades ocultas o inisghts, para el desarrollo de nuestras estrategias publicitarias en los diferentes canales. En el caso de La Tomate, se desglosa este insight y se transforma en la principal fuente para verse bien, que es comer sano. Es ahí donde surge y se acciona la idea para crear este negocio que después de estudiar el mercado, sus ratios e indicadores financieros (punto 8. Plan económico-financiero), apunta a ser un negocio exitoso, rentable y sostenible a través del tiempo. Partiendo de esto y apoyados en la rentabilidad de la empresa y su capacidad instalada, el éxito de La Tomate, está garantizado.

\section{BIBLIOGRAFIA}

Instituto Nacional de Estadística e Informática. (2014). Una mirada a Lima Metropolitana. Lima. Recuperado de

https://www.inei.gob.pe/media/MenuRecursivo/publicaciones_digitales/Est/Lib1168/libro. pdf

Gestión (2016). Los distritos que piden más comida saludable por Internet. Lima. Diario Gestión. Recuperado de https://gestion.pe/economia/empresas/distritos-lima-pidendelivery-comida-saludable-internet-113984

Betas Damodarn (2017). Betas Damodaran 2007. Lima. Betas Damodaran. Recuperado de http://www.betasdamodaran.com/betas-damodaran-2017/

Fagor Industrial (2014). ¿Cómo equipar la cocina de un restaurante para 40 comensales? Madrid. Fagor Industrial. Recuperado de http://blog.fagorindustrial.com/?cat=678 
Emprende Hoy (2017). ¿Qué son los consumer insight? Lima. Emprende Hoy. Recuperado de http://rpp.pe/campanas/contenido-patrocinado/que-son-los-consumer-insight-noticia1062408

America Retail (2016). Perú: 55 por ciento crecieron las ventas de comida delivery online. Lima. América Retail. Recuperado de http://www.america-retail.com/horeca/peru-55-porciento-crecieron-las-ventas-de-comida-delivery-online/ 